UNIVERSIDADE DE SÃO PAULO

INSTITUTO DE FÍSICA

\title{
Estudo das Propriedades do Biospeckle e suas Aplicações
}

\author{
Emerson Rodrigo da Silva \\ Orientador: Prof. Dr. Mikiya Muramatsu
}

Dissertação apresentada ao Instituto de Física da USP

para obtenção do título de Mestre em Ciências.

Banca Examinadora:

Prof. Dr. Mikiya Muramatsu (IFUSP)

Profa. Dra. Elisabeth Mateus Yoshimura (IFUSP)

Prof. Dr. Inácio Maria Dal Fabro (FEAGRI-UNICAMP)

São Paulo 
FICHA CATALOGRÁFICA

Preparada pelo Serviço de Biblioteca e Informação do Instituto de Física da Universidade de São Paulo

Silva, Emerson Rodrigo da

Estudo das propriedades do biospeckle e suas aplicações - São Paulo 2007.

Dissertação (Mestrado) - Universidade de São Paulo. Departamento de Física Geral

Orientador: Prof. Dr. Mikiya Muramatsu

Área de Concentração: Física

Unitermos: 1. Biospeckle; 2. Atividade Biológica;

3. Diagnóstico por Imagem; 4. Teste não-destrutivo. 


\section{Resumo}

Esta dissertação é dedicada ao estudo de algumas das propriedades e aplicações do speckle dinâmico no monitoramento de atividade em tecidos biológicos. As estatísticas espaço-temporais de primeira e segunda ordem são discutidas em vias gerais. As principais técnicas para obtenção de dados a partir do granulado óptico são apresentadas, com especial destaque para a função de autocorrelação, as matrizes de co-ocorrência, o método de Fujii e a Análise de Contraste do Laser Speckle (LASCA). Uma nova metodologia de análise, baseada no estudo do contraste das correlações sucessivas, é proposta. Diversas simulações numéricas, utilizando diferentes funções densidade de probabilidade para as velocidades dos centros espalhadores, foram realizadas com intuito de testar os métodos de análise e fornecer subsídios para a interpretação de resultados in vivo. Tecidos vegetais e animais foram investigados, realizando-se o monitoramento do processo de senescência e mapas de vascularização em folhas, acompanhamento de frutos contaminados por fungos, mapeamento de atividade em flores e análise de cicatrização em ratos submetidos à cirurgia abdominal. Ensaios explorando o uso do biospeckle em microscopia são implementados. Por fim, é avaliado o potencial da técnica como ferramenta de diagnóstico em um caso de úlcera venosa crônica submetida a tratamento por meio de laserterapia de baixa intensidade. Os resultados encontrados revelaram o grande potencial em aplicações biológicas, através da construção de mapas que permitiram, por exemplo, a visualização detalhada da rede vascular de folhas vegetais. Também foi possível a identificação de áreas atacadas por micro organismos. Os estudos em tecidos animais e humanos apontaram perspectivas bastante promissoras do uso do biospeckle em ambiente clínico. 


\section{Abstract}

This master thesis is devoted to the study of some properties and applications of dynamic speckles on monitoring of activity in biological tissues. The first and second order space-time statistics are dicussed in an overview perspective. The main techniques used to obtain information from grainy pattern are presented, with special prominence to autocorrelation function, co-occurrence matrices, Fujii's method and the Laser Speckle Contrast Analisys (LASCA). A new methodology, based on the study of the contrast of sucessive correlations, is proposed. Several numerical simulations, using different probability density functions to velocities of scatterers, are done in order to test the analysis methods and supply subsidies for interpretation of in vivo results. Vegetable and animal tissues are investigated by monitoring of senescence process and construction of vascularization maps of leaves, accompanying of fungi contamined fruits, mapping of activity in flowers and analysis of healing in rats undergone to abdominal surgery. Experiments using the biospeckle phenomenon in microscopy are carried out. At last, it is evaluated the potentiality of the technique as diagnosis tool in a chronic vein ulcer undergone to treatment through low intensity laser therapy. The found results showed the great potential in biological applications, through the construction of maps that maked possible, for example, the detailed visualization of the vascular net on leaves. It was allowed the identification of areas injured by micro organisms. The studies on animal and human tissues pointed very promising perspectives of the use of biospeckle in clinical environment. 


\section{Sumário}

Sumário $\quad$ iv

Lista de Figuras $\quad$ vii

Lista de Tabelas $\quad$ xi

Introdução $\quad 1$

1 Fundamentos Teóricos $\quad 6$

1.1 Espalhamento de Luz . . . . . . . . . . . . . . . 6

1.1.1 Espalhamentos Rayleigh, Mie e geométrico . . . . . . . . 7

1.2 Origens físicas do Biospeckle . . . . . . . . . . . . . . 10

1.2.1 Geometrias de observação . . . . . . . . . . . . . . 11

1.2.2 Efeito Doppler, turbulência e difusão . . . . . . . . . . . . . . . 12

1.2.3 Tamanho dos Grãos de Speckle . . . . . . . . . . . . . 14

1.3 Características dos tecidos biológicos . . . . . . . . . . . . 15

1.3.1 Dimensões típicas das estruturas histológicas . . . . . . . . . . 16

1.3.2 Velocidades dos movimentos presentes em tecidos . . . . . . . 17

1.3.3 Morfologia do sistema vascular vegetal . . . . . . . . . . . 19

1.3.4 Morfologia do tecido cutâneo . . . . . . . . . . . 20

1.3.5 Propriedades de absorção: a janela terapêutica . . . . . . . . . . 21

1.3.6 Interação luz-tecido biológico: a laserterapia de baixa intensidade 22 
2 Estatística do Biospeckle $\quad 24$

2.1 Estatística Espacial de Primeira Ordem . . . . . . . . . . . . . . 24

2.1.1 Soma incoerente de dois padrões speckle . . . . . . . . . . . 28

2.1 .2 Soma com fundo uniforme . . . . . . . . . . . . . 30

2.2 Estatística temporal de primeira ordem . . . . . . . . . . . 30

2.3 Estatística de Segunda Ordem . . . . . . . . . . . . . . . 32

2.3.1 A função de autocorrelação e a densidade espectral de potência . . 32

2.3.2 Coeficiente de correlação . . . . . . . . . . . . . 35

2.4 Conexão entre as estatísticas espacial e temporal . . . . . . . . . . . . 36

3 Métodos de análise do biospeckle $\quad 37$

3.1 História Temporal de Padrões Speckle . . . . . . . . . . . . . 37

3.2 Função de Autocorrelação e Densidade Espectral de Potência . . . . . . . . 39

3.3 Matrizes de Co-Ocorrências . . . . . . . . . . . . . . . . 41

3.4 O Contraste de Briers . . . . . . . . . . . . . . . 43

3.5 Métodos de Fujii e Diferenças Generalizadas . . . . . . . . . . . . . . 46

3.6 Análise de Contraste do Laser Speckle: o método LASCA . . . . . . . . . . 47

3.7 Análise de Contraste Temporal do Laser Speckle: o método LASTCA . . 50

3.8 Método proposto: Contraste de correlações sucessivas . . . . . . . . . . . 51

4 Simulações $\quad 53$

4.1 O modelo de Rabal et al. . . . . . . . . . . . . . . . 53

4.1 .1 Testes do modelo . . . . . . . . . . . . . . 55

4.2 Simulações Numéricas . . . . . . . . . . . . . . . . . . . 58

4.2.1 Contraste de Briers das Simulações . . . . . . . . . . . . . . . 59

4.2.2 Momentos de Inércia das Simulações . . . . . . . . . . . . . . . 60

4.2.3 Contraste das Correlações Sucessivas das Simulações . . . . . . . . 61

4.2.4 Autocorrelação Normalizada das Simulações . . . . . . . . . . . . . 62

4.3 Simulações em Sistemas Físicos . . . . . . . . . . . . . . 65

4.3.1 Modulação da Fonte: Uma Aplicação da Densidade Espectral de

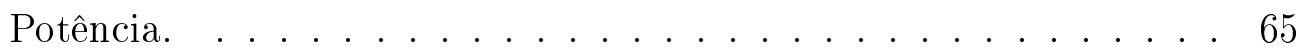

4.3.2 Visualização de Relevo Sob Camada de Tinta . . . . . . . . . . . 67 
5 Ensaios in vivo $\quad 69$

$5.1 \quad$ Arranjo experimental . . . . . . . . . . . . . . . . . 69

5.1.1 Programas usados na análise dos dados . . . . . . . . . . . 73

5.1 .2 Dependência do nível de cinza . . . . . . . . . . . . . . 73

5.2 Monitoramento de atividade em folhas . . . . . . . . . . . . 75

5.2 .1 Senescência . . . . . . . . . . . . . . . . 75

5.2 .2 Mapeamento de Vascularização . . . . . . . . . . . . . 76

5.2 .3 Mapeamento de Fitopatologia . . . . . . . . . . . . . . 79

5.3 Monitoramento de Atividade em Frutos . . . . . . . . . . . . . . . 81

5.3.1 Mapeamento em morangos . . . . . . . . . . . . 81

5.3 .2 Mapeamento em Laranjas . . . . . . . . . . . . . . 84

5.3.3 Mapeamento em Amoras . . . . . . . . . . . . . . . . . 84

5.4 Monitoramento de Atividade em Flores . . . . . . . . . . . . . . 86

5.5 Microscopia de biospeckle . . . . . . . . . . . . . . 88

$5.6 \quad$ Biospeckle em Tecidos Animais . . . . . . . . . . . . . . 89

5.6.1 Estudo do processo de cicatrização em ratos . . . . . . . . . . . 90

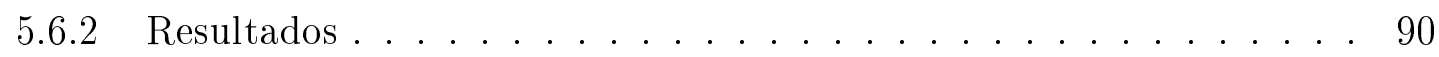

5.7 O biospeckle como ferramenta de diagnóstico em tecidos humanos . . . . . 91

5.7 .1 Protocolo de tratamento . . . . . . . . . . . . . . 92

5.7 .2 Metodologia de registro e análise de imagens . . . . . . . . . . 93

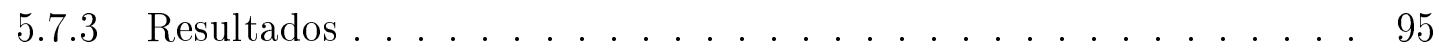

$\begin{array}{ll}\text { A Tópicos em estatística } & 104\end{array}$

A.1 Teorema do Limite Central . . . . . . . . . . . . . . . . . . 104

A.2 F.D.P. Marginal . . . . . . . . . . . . . . . . 105

A.3 Função Característica . . . . . . . . . . . . . . . . . . 105

A.4 O teorema de Wiener-Khintchine . . . . . . . . . . . 105

B Códigos-fonte dos softwares desenvolvidos 106

$\begin{array}{ll}\text { Referências Bibliográficas } & 117\end{array}$ 


\section{Lista de Figuras}

1 Peças de xadrez iluminadas com luz coerente. . . . . . . . . . . . 2

2 Intensidades de um pixel de padrão speckle espalhado a partir de um objeto inanimado e de um tecido biológico. . . . . . . . . . . . . . . . 4

3 Folha vegetal com as regiões de maior atividade circulatória em evidência. 4

1.1 Reflexão especular e difusa. . . . . . . . . . . . . . 7

1.2 Perfis típicos de espalhamento Mie. À medida em que o raio da partícula aumenta (da esquerda para a direita), há perda de simetria. . . . . . 8

1.3 Desenho esquemático de espalhamento geométrico em partículas. . . . . . . 9

1.4 Perfil de distribuição de um feixe laser em tecidos biológicos. . . . . . . . 9

1.5 Sistema para análise do fenômeno do speckle. Os vetores $\xi$ e $\mathbf{x}$ indicam pontos no plano objeto e de observação, respectivamente. . . . . . . . . . . 10

1.6 Típico padrão de speckle objetivo. . . . . . . . . . . . . . . . . . 11

1.7 Configurações para observação do speckle nos planos de Fraunhoffer (a) e imagem (b) . . . . . . . . . . . . . . . . . . . 12

1.8 Modelo representando defasagens introduzidas pelo fenômeno da turbulência. 13

1.9 Padrões speckle observados a diferentes distâncias. . . . . . . . . . . . . . 14

1.10 Desenho esquemático representando as estruturas internas de células. . . . 16

1.11 Desenho esquemático do espalhamento de luz em hemácias. . . . . . . . . 17

1.12 Corte transversal da pele humana e suas principais camadas. . . . . . . . 20

1.13 Janela terapêutica: espectros de absorção da água, da melanina e da oxi-

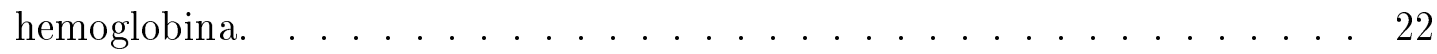

1.14 Esquema do efeito foto-físico-químico do laser de baixa potência em nível

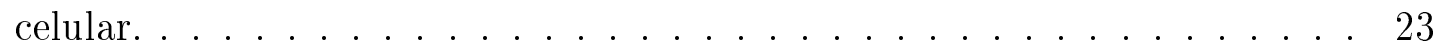


2.1 FDP de (a) padrão completamente desenvolvido e (b) soma incoerente de dois padrões. . . . . . . . . . . . . . . . . . 29

3.1 Construção do THSP: A fila central é registrada em instantes sucessivos e colada em uma imagem 2D. . . . . . . . . . . . . . . . . 39

3.2 THSP de (a) uma superfície estática e (b)processo de secagem de tintas. $\quad 39$

3.3 Exemplo didático para cálculo das matrizes de co-ocorrêncis de THSPs estático (acima) e dinâmico (abaixo). . . . . . . . . . . . . 42

3.4 THSPs e respectivas matrizes de co-ocorrências. . . . . . . . . . . . . 43

3.5 Fotografias instantâneas de (a) um padrão estático e (b) um padrão dinâmico e imagens médias de (c) padrões estáticos e (d) padrões dinâmicos. 45

3.6 Diagrama esquemático da construção de um mapa tipo LASCA. . . . . . . 48

3.7 Perda de resolução com uso do LASCA. . . . . . . . . . . . . . . . 49

3.8 A partir das variações de intensidade de cada pixel é construído um mapa com o contraste temporal. . . . . . . . . . . . . . 50

3.9 Correlação entre instantes sucessivos para uma placa metálica e um espé-

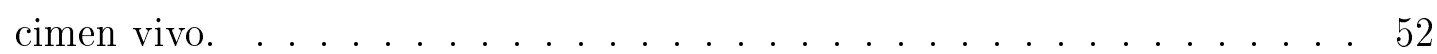

4.1 Diagrama esquemático do modelo numérico de Rabal et al. . . . . . . . . 54

4.2 Histogramas da simulação de padrões speckle. . . . . . . . . . . . . 56

4.3 Perfis de intensidades de um pixel em simulações distintas. . . . . . . . . 56

4.4 THSP obtido com os centros espalhadores estáticos. . . . . . . . . . . 57

4.5 THSP de uma simulação de movimento de corpo rígido. . . . . . . . . 57

4.6 THSPs simulados. Velocidades em unidades arbitrárias: (a) v=2, (b) v= $4,(\mathrm{c}) \mathrm{v}=8$ e $(\mathrm{d}) \mathrm{v}=10 \ldots \ldots \ldots \ldots \ldots \ldots$

4.7 Curva teórica e pontos experimentais do contraste de Briers das simulações. 59

4.8 Matrizes de co-ocorrências obtidas através da simulação. Os valores de velocidade aumentam da esquerda para a direita, de cima para baixo. . . . 60

4.9 Momentos de Inércia obtidos para as distribuições simuladas. . . . . . . . . 61

4.10 Comportamento do contraste de correlações sucessivas para as distribuições

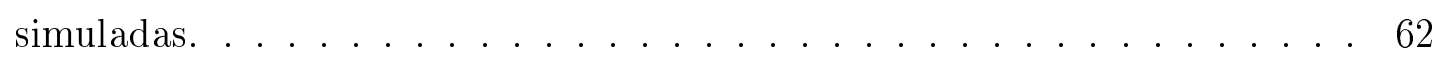

4.11 Autocorrelações obtidas para as distribuições gaussiana e maxwelliana. . 63 
4.12 Autocorrelações obtidas para as distribuições parabólica e uniforme. . . . . 63

4.13 Comprimentos de correlação eficaz das simulações. . . . . . . . . . . . . . . 64

4.14 Montagem para modular a iluminação. . . . . . . . . . . . . . 65

4.15 Espectro de potência para as três modulações. . . . . . . . . . . . . 66

4.16 Moeda coberta por camada de tinta. . . . . . . . . . . . 67

4.17 Mapa de Fujii mostrando o relevo de uma moeda de $\mathrm{R} \$ 1,00$ encoberta por

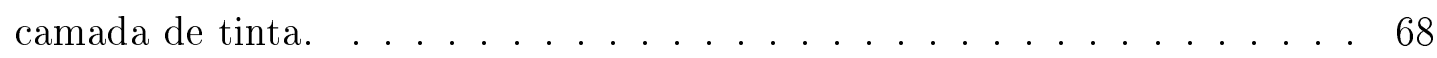

5.1 Esquema básico da montagem experimental com propagação em espaço livre e speckle obtido por reflexão. . . . . . . . . . . . . . . . 71

5.2 Arranjo experimental para observações no plano imagem e speckle obtido por transmissão. . . . . . . . . . . . . . . . . . . 71

5.3 Arranjo para observações de biospeckle obtido por transmissão no plano de

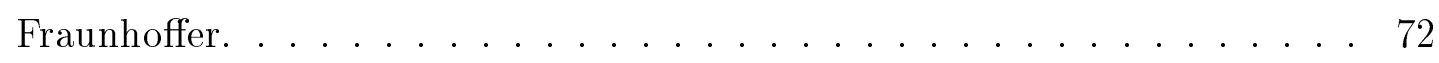

5.4 Arranjo para observações de biospeckle obtido por reflexão no plano imagem. 72

5.5 Espécime utilizado para estudo da influência do nível de intensidade da

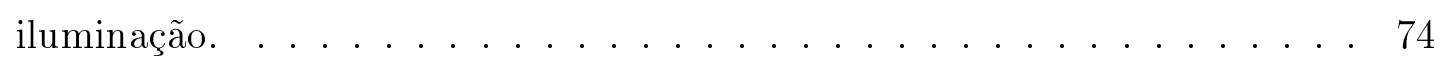

5.6 Perfis de autocorrelação em função do nível de cinza (atividade mantida

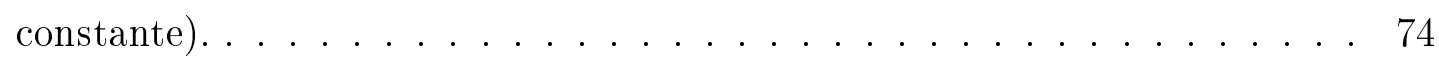

5.7 THSP e matrizes de co-ocorrência de folhas de seringueira. . . . . . . . 75

5.8 Mapeamento de folha de Bauhinia forficata. . . . . . . . . . . 77

5.9 Mapa pseudo-colorido construído pelo método LASTCA. . . . . . . . . 77

5.10 (a) Fotografia simples de folha de amoreira iluminada com laser e (b) o respectivo mapa de Fujii. . . . . . . . . . . . . . . . 78

5.11 Mapa pseudo-colorido construído através do método de Fujii. As zonas avermelhadas indicam a venação principal da folha. . . . . . . . . . 78

5.12 Mapeamento de folha contaminada com pulgões. . . . . . . . . . . . . 79

5.13 Mapa pseudo-colorido construído com o método de Fujii. As zonas avermelhadas indicam ataque de pulgões (Macrosiphum avenae). . . . . . . 80

5.14 Detalhe do morango iluminado com laser. . . . . . . . . . . . . . 81

5.15 Mapa de Fujii de morango saudável. . . . . . . . . . . . . . . . . . 82 
5.16 Morango contaminado por fungo. . . . . . . . . . . . . . . 82

5.17 Mapa pseudo-colorido apontando o perfil de atividade em morango contaminado com fungo. . . . . . . . . . . . . . . . . 83

5.18 Detalhe da região de inserção do pedúnculo e respectivo mapa de atividade em laranja. . . . . . . . . . . . . . . . . . . . . 84

5.19 (a) Detalhe da amora observada e (b) respectivo mapa de atividade. . . . . 85

5.20 Mapa de Fujii de uma amora em avançado estágio de maturação. . . . . . 85

5.21 Flor preparada para mapeamento. . . . . . . . . . . . . . . 86

5.22 Mapeamento de flores pelo método de Fujii. . . . . . . . . . . . . 87

5.23 Arranjo para microscopia de biospeckle. . . . . . . . . . . . . 88

5.24 Mapas construídos através da microscopia de biospeckle. . . . . . . . . . 89

5.25 Detalhe da cirurgia e fotografia do arranjo experimental. . . . . . . . . 90

5.26 Mapas construídos através da microscopia de biospeckle. . . . . . . . . . 93

5.27 Evolução da lesão ao longo das semanas de tratamento. . . . . . . . . . . . 94

5.28 Arranjo para registro fotográfico do biospeckle em paciente, com a iluminação da lesão exibida em detalhe. . . . . . . . . . . . . . . . . . . 95

5.29 Mapas de atividade da lesão na primeira semana. . . . . . . . . . . . 95

5.30 Mapas de atividade na região do maléolo saudável. . . . . . . . . . . 96

5.31 Mapas de atividade na lesão na segunda semana. . . . . . . . . . . . 97

5.32 Mapas de atividade na lesão na vigésima semana. . . . . . . . . . . . . 97 


\section{Lista de Tabelas}

1.1 Dimensões típicas de estruturas celulares. . . . . . . . . . . . . 18

1.2 Velocidades típicas de fluxos e estruturas em tecidos biológicos. . . . . . . 19

1.3 Características do tecido cutâneo humano. . . . . . . . . . . . . . . 21

3.1 Momentos de intensidades das MCOs da figura 3.4 (unidades arbitrárias). . 43

5.1 Principais componentes usados e especificações. . . . . . . . . . . 70

5.2 Momentos de inércia do biospeckle de folhas em diferentes estágios após a colheita. ........................ 76

5.3 Contrastes de correlação de processo de cicatrização em ratos. . . . . . . . . 91

5.4 Resumo das aplicações de laser de baixa intensidade. . . . . . . . . . . . . 94 


\section{Prefácio e Agradecimentos}

Escrever uma dissertação não é tarefa fácil! Ao longo da redação deste trabalho vivi esta realidade. De um lado, ela é a compilação de um projeto acadêmico de pesquisa que tem por objetivo expôr de forma clara as conclusões e resultados atingidos e, de outro, também é uma fonte de informações para aqueles que se dedicam a estudar alguns dos temas nela contidos. Ao redigí-la tive em mente esses dois fatores, sempre lembrando que, devido a certo teor interdisciplinar da temática abordada, ela eventualmente seria útil a investigadores de áreas que não a Física. Outro ponto que levei em conta foi a particular percepção de que possíveis leitores deste trabalho (além de mim mesmo e da banca examinadora) seriam alunos de pós-graduação e iniciação científica. Por isso, ao escrevê-la, visei esse perfil de pessoas, permitindo, inclusive, que as técnicas aqui apresentadas fossem reprodutíveis em poucos meses sem consulta demasiada a outras fontes. Tenho consciência de que o trabalho ganhou um certo caráter generalista, todavia, creio que ele abarca bastante informação útil no tema proposto. Não sei se esses objetivos foram atingidos, todavia, ficam registradas as intenções.

Com essas considerações em mente, iniciei a dissertação com o tradicional capítulo de fundamentos teóricos. Nele faço uma breve revisão da teoria do espalhamento da luz e de conceitos básicos cuja compreensão facilita muito o entendimento do fenômeno do speckle e permite averiguar que tipo de informação é possível extrair dele e quais as suas limitações. No capítulo dois são expostas as estatísticas espaço-temporais de primeira e segunda ordem. No capítulo três são apresentados os métodos tradicionais de análise do biospeckle, sempre buscando a fundamentação teórica indispensável (afinal, trata-se de um "Estudo das Propriedades do Biospeckle...”) sem, porém, se estender a um rigor demasiado, pois a tônica deste trabalho é seu caráter experimental (“... e suas Aplicações”). No capítulo 
quatro faço uma pequena exposição de um modelo numérico desenvolvido pelo grupo do Centro de Investigaciones Opticas, da Universidad Nacional de La Plata, Argentina, apresentando os resultados obtidos com o uso de algumas distribuições de velocidades que supostamente governam o movimento de partículas em tecidos biológicos. Meu objetivo com a introdução deste capítulo foi avaliar o potencial de técnicas computacionais no estudo de um fenômeno de grande complexidade como o speckle. Os ensaios in vivo são descritos no capítulo cinco. Nele são mostrados resultados de monitoramento de atividade em folhas vegetais, mapeamento de vascularização em plantas e estudos da evolução do processo de cicatrização em animais e humanos. Esses resultados revelaram que o biospeckle é uma ferramenta em potencial no acompanhamento desses processos, podendo ter, inclusive, aplicações clínicas. Por fim, são apresentadas as conclusões e as perspectivas futuras. Nos apêndices, são apresentados alguns tópicos em estatística e as rotinas computacionais criadas para este projeto. Na bibliografia, as referências mais importantes, e cuja leitura é recomendada a interessados, foram destacadas com o sinal *. Vários dos trabalhos utilizados ao longo da dissertação estão compilados na referência [66], sendo esta também fortemente recomendada.

Certamente eu não teria a capacidade de compôr esta dissertação sem a ajuda de várias outras pessoas e a lista daqueles que colaboraram de maneira direta ou indireta para a realização deste trabalho é extensa e, infelizmente, nem todos poderão ser citados, porém, quero externar de maneira especial meus sinceros agradecimentos às seguintes pessoas e instituições:

- Em primeiro lugar, ao Deus Eterno, por estar sempre presente em todos os momentos e me dar a graça da vida.

- À minha mãe, Sra. Odete Gonçalves Colombo da Silva, por todos os sacríficios e por ter, ao lado de meu pai, me ensinado a ser um homem de bem.

- Ao meu orientador, Prof. Dr. Mikiya Muramatsu, pela generosidade em conceder uma oportunidade a um garoto que bateu em sua porta à procura de iniciação científica e pela orientação paciente.

- À minha amada esposa, amiga e "psicóloga" Karina Alves Teixeira da Silva, que com 
seu jeito terno e doce, sem que eu sequer percebesse, deu novo significado à minha vida e me mostrou a força do amor entre um homem e uma mulher. Além de a cada dia mostrar-se uma companheira formidável, superando todas as expectativas que jamais tive. Em grande parte, este trabalho se deve a ela.

- Ao meu irmão, Elieste da Silva Júnior, que também abraçou essa tortuosa vida de cientista e, quem diria, dividiu laboratório comigo unindo a Óptica à Ciência dos Alimentos.

- Aos colegas, Dr. Marcos Roberto da Rocha Gesualdi, Josmar de Carvalho Gomes, Flávia Matioli (minha prima mais querida), Mauro Favoretto Júnior, Glaura Caroena de Oliveira, Carlos Rossati, João Neves, Rubens Zemith, Dr. Eduardo Ferrara, Diogo Soga, Edson Rodrigues, Luis Alberto Borbely, Dr. Gélio Mendes Ferreira, Nicolas José da Silveira, Rodrigo Yoshikazu Sahara e tantos outros insanos que, de um jeito ou de outro, foram parar no memorável Laboratório de Óptica e Sistemas Amorfos do IFUSP.

- Al equipo del Centro de Investigaciones Opticas, de la Universidad Nacional de La Plata, Argentina. En especial al professor Dr. Héctor Jorge Rabal, por estimular mi viaje a Argentina y por las valiosas discusiones y sugerencias para este trabajo, además de proveer todas las informaciones concernientes al modelo numerico presentado en el capítulo cuatro. También manifiesto mis sinceros agradecimientos a Roberto Torroba, Ricardo Arizaga, Nelly Lúcia Cap (la mejor programadora que he conocido), Maria Alícia Caussati, Joaquín Hasperue y Marcelo Trivi por la gentil acogida en su país. Gracias por todo, hermanos.

- À médica da UNICAMP Dra. Tâmara Maria Nieri, cujo trabalho de doutorado (seção 5.6) me despertou para aplicações do biospeckle em tecidos animais.

- À professora Dra. Elisabeth Mateus Yoshimura, por ceder as dependências de seu laboratório para o ensaio de microscopia apresentado na seção 5.5. À Dra. Maria Cristina Chavantes, por supervisionar o experimento apresentado na seção 5.7, por fornecer inúmeras informações sobre a parte médica e por ser a grande estimuladora do uso do biospeckle em diagnóstico. 
- Ao meu colega do Pará, o talentoso físico Charles da Rocha Silva, pelos auxílios durante as disciplinas de Mecânica Quântica I e Eletrodinâmica Clássica I.

- Aos professores Dr. Marcelo Martineli e Dra. Elisabeth Andreoli de Oliveira, pela oportunidade de ser monitor em seus cursos de óptica e pela grande aprendizagem proporcionada durante esse período.

- Aos funcionários do Departamento de Física Geral. Aos Srs. Rubens e Marcelino, da oficina mecânica. Às Sras. Dirce e Ivone, secretárias do departamento. Ao Samuel, office boy, e aos porteiros, especialmente ao "Seu" Wilson, pelos cafés concedidos nos fins de semana e por nossas divertidíssimas análises futebolísticas.

- Aos funcionários da Comissão de Pós-Graduação do IFUSP, Francislene, Éber e Cláudia, por cuidarem tão bem das questões administrativas e por todos os esclarecimentos acerca dos trâmites burocráticos que, na maioria das vezes, complicam a nossa existência.

- À Multipurpose Optical Network (MON), pelo financiamento das passagens e custos de estadia e alimentação durante o período em que estive na Argentina.

- À CAPES pela concessão da bolsa de mestrado que permitiu minha manutenção durante os vinte e quatro meses de realização deste trabalho. 
Dedico este trabalho à memória de Elieste da Silva, meu pai, que sem dúvida alguma seria a pessoa mais orgulhosa de mim neste momento. 
"No princípio criou Deus os céus e a terra. A terra, porém, era sem forma e vazia; havia trevas sobre a face do abismo e o Espírito de Deus pairava sobre a face das águas. E disse Deus: Haja luz! E houve luz. E viu Deus que a luz era boa..." (Gênesis 1:1-4, Bíblia Sagrada)

"Todos nós sabemos o que é luz; mas não é fácil dizer o que ela é." (Samuel Johnson, escritor inglês do século XVIII)

"Meu objetivo [neste livro] não é explicar as propriedades da luz por hipóteses, mas propô-las e prová-las pelo raciocínio e por experiências..." (Sir Isaac Newton, acerca de seu livro Optiks)

“...na verdade [o speckle] não é ruído, é informação que não desejamos, informação (...) na qual não estamos interessados." (Dennis Gabor, inventor da Holografia) 


\section{Introdução}

\section{Contexto Histórico}

Quando um feixe de luz é espalhado ou transmitido por uma superfície com rugosidades da ordem do comprimento de onda da fonte ocorre a formação de uma estrutura granular no espaço livre à qual é dado o nome de speckle ${ }^{1}$. Trata-se de um fenômeno de interferência, tipicamente ondulatório, observado não apenas no vísivel, mas também em outras partes do espectro eletromagnético e na acústica. Objetos iluminados com laser geralmente apresentam-se cobertos pela estrutura granular do speckle. Essa característica é devida ao fato de, na escala microscópica, grande parte das superfícies serem extremamente rugosas. A figura 1 mostra dois objetos iluminados com luz coerente. A peça da esquerda (1(a)) possui a superfície rugosa e a estrutura granular do padrão speckle fica evidente.

O interesse no granulado óptico ${ }^{2}$ não é recente. Newton, no célebre tratado Opticks, já o descreveu de forma qualitativa [1] e outros grandes pesquisadores depois dele relataram sua observação. Os primeiros estudos sistemáticos dos quais se têm notícias são atribuídos a Exner [2], que em 1877 descreveu a estrutura fibrosa vista quando a luz de uma lâmpada de mercúrio atravessava uma placa de vidro onde condensara vapor de sua respiração. Mais tarde, por volta dos anos 1900, De Haas atribuiu a estrutura fibrosa à não monocromaticidade da radiação incidente. O formalismo matemático, dentro de um corpo teórico mais consistente, foi introduzido por von Laue e lord Rayleigh, na primeira

\footnotetext{
${ }^{1} \mathrm{O}$ termo deriva do inglês e uma possível tradução literal seria "salpicado". Na literatura mundial o fenômeno é sempre designado pela palavra inglesa e, por isso, esta será empregada ao longo deste trabalho.

${ }^{2}$ Quando houver referência a "granulado óptico" fica subentendido que se trata de sinônimo de speckle.
} 


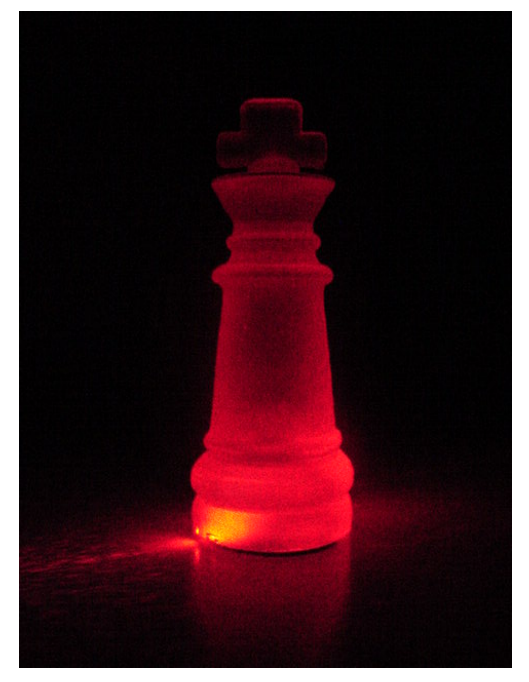

(a) Superfície rugosa

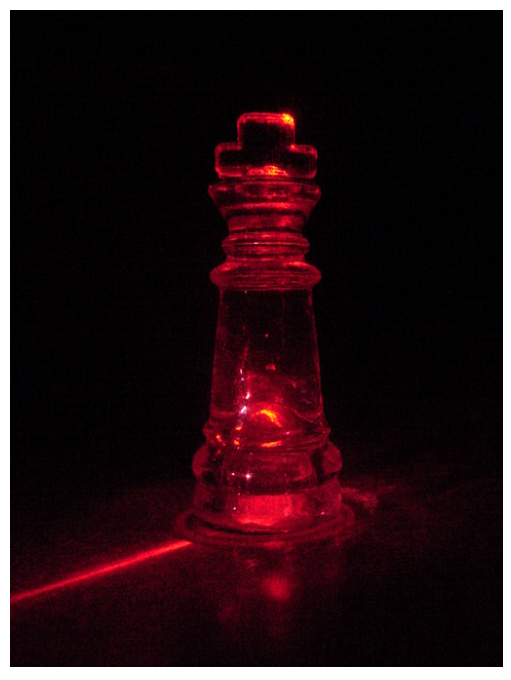

(b) Surperfície lisa

Figura 1: Peças de xadrez iluminadas com luz coerente.

década do século XX, quando mostraram que a densidade de probabilidade da distribuição espacial do granulado obedece a uma função exponencial negativa. Ainda no século XX, outros trabalhos sobre o tema foram realizados por Raman, Buchwald e Ramachandran.

A invenção do laser em 1960 e as inúmeras aplicações daí decorrentes deram novo impulso às pesquisas no campo, pois, se por um lado a coerência permitia o registro e a reconstrução das frentes de onda nos processos holográficos, por outro, provocava de maneira inevitável o surgimento do speckle. À primeira vista, o granulado foi interpretado como mero ruído óptico indesejável, todavia, pesquisas dirigidas no sentido de minimizá-lo logo demonstraram que ele era portador de informações sobre a superfície. Nas palavras do próprio Gabor, durante a cerimônia de entrega do prêmio Nobel [3]:

"It is not really noise; it is information which we do not want, information on the microscopic uneveness of the paper in which we are not interested. What can we do against it?". 3

Em fins da década de 1960 já era apresentada por Groh a primeira aplicação dos padrões speckle à metrologia e desde então surgiram inúmeras outras envolvendo, principalmente, medidas de micro deslocamento [4], determinação da coerência de fontes e

\footnotetext{
3“na verdade não é ruído; é informação que não desejamos, informação das irregularidades microscópicas do papel na qual não estamos interessados. O que podemos fazer contra isso?"
} 
rugosidade superficial.

A descrição formal do granulado óptico só pode ser realizada no contexto da teoria estatística e, paralelamente ao desenvolvimento das aplicações citadas, foram realizados estudos com objetivo de fornecer as bases teóricas necessárias. Entre esses trabalhos destacam-se os de J.W. Goodman [5] e J.C. Daint [6], responsáveis por desenvolvimentos nas estatísticas espaço-temporais de primeira e segunda ordem do granulado óptico.

\section{O Biospeckle}

Caso os elementos espalhadores da superfície estejam em movimento, o padrão speckle resultante também evolui no tempo, dando origem ao speckle dinâmico. Vários sistemas apresentam essa caracterítica, entre os quais, destacam-se áreas recém-pintadas, superfícies em processo de oxidação, colóides e, em particular, os tecidos biológicos. Neste último caso o granulado recebe também o nome de biospeckle ${ }^{4}$. Talvez o relato mais antigo envolvendo o biospeckle seja devido à Abramson [7], quando ainda nos primórdios da era do laser afirmou: "when an apple is illuminated with laser light the speckles move!"5. Durante os anos 1960, vários estudos foram empreendidos para esclarecer speckle dinâmico e determinar sua estatística. Entre os trabalhos mais relevantes destacam-se os de Langmuir e Anisimov [8], que introduziram a função de correlação cruzada. Posteriormente, Briers foi responsável por importantes desenvolvimentos na estatística temporal de primeira ordem e no estudo da dependência das flutuações das intensidades em relação ao comprimento de onda usado na iluminação [7]. Na década seguinte, já eram mostradas algumas aplicações especialmente ligadas à velocimetria de partículas e, nos anos 1980, ganhou força o interesse por sua utilização em sistemas biológicos.

A figura 2 mostra as variações de intensidades de um pixel em padrões speckle espalhados a partir de uma placa de metal e de uma folha vegetal recém-colhida. A partir dos gráficos fica evidente que o comportamento das intensidades do padrão ao longo do tempo pode servir de estimador da atividade na amostra espalhadora. Os principais métodos de análise do biospeckle consistem no levantamento de sua autocorrelação temporal e da respectiva densidade espectral de potência. Entretanto, conforme será mostrado durante

\footnotetext{
${ }^{4}$ Frequentemente, na literatura, "speckle dinâmico" e "biospeckle" são referidos como sinônimos.

5"quando uma maçã é iluminada com laser os speckles se movem!"
} 
o trabalho, outros métodos também são largamente empregados tais como as matrizes de co-ocorrências, desvio-padrão das variações de intensidades e coeficientes de correlação temporal. Nesse sentido, também propomos um novo estimador baseado no contraste das correlações ao longo do tempo.

Uma amostra biológica extensa, em geral, apresenta diferentes níveis de atividade

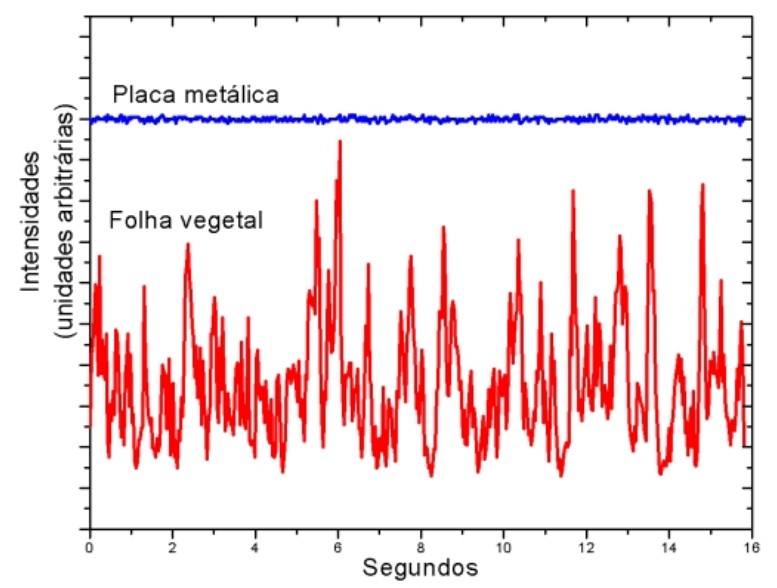

Figura 2: Intensidades de um pixel de padrão speckle espalhado a partir de um objeto inanimado e de um tecido biológico.

em regiões distintas. Nessa situação, o biospeckle pode ser utilizado para o mapeamento dessa atividade. A figura 3 mostra o mapeamento de uma folha vegetal onde as regiões de maior atividade (a venação) aparecem mais claras devido à circulação da seiva.

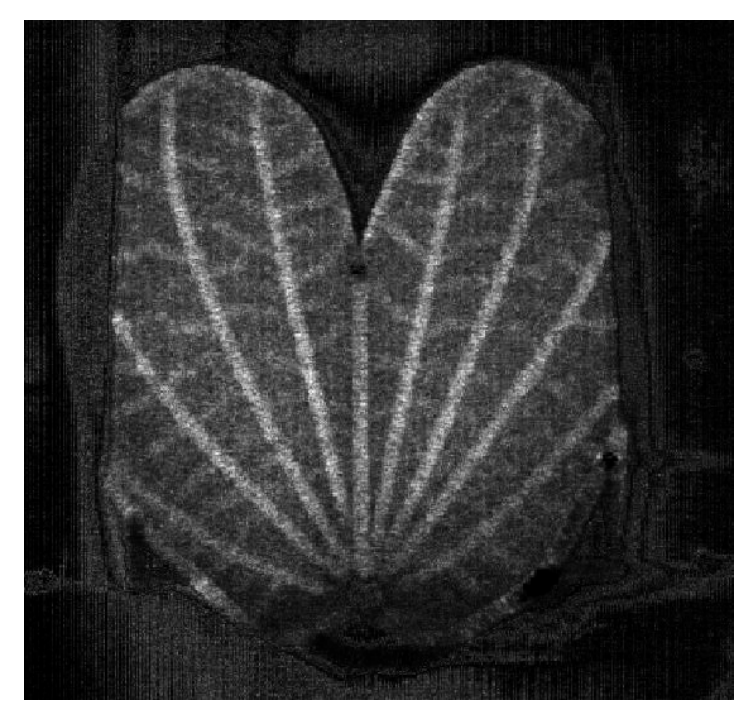

Figura 3: Folha vegetal com as regiões de maior atividade circulatória em evidência. 
As principais técnicas usadas na elaboração desses mapas baseiam-se na comparação entre imagens sucessivas do objeto. Através de coeficientes de correlação, subtração de imagens e análise de contraste espaço-temporal as zonas de maior atividade são identificadas.

\section{Justificativas e Objetivos}

O biospeckle configura-se como uma valiosa ferramenta no auxílio a estudos de diversas áreas do conhecimento, especialmente a Biologia, a Agronomia e a Biomedicina, onde pode, entre outras coisas, servir à avaliação do potencial germinativo de sementes e ao mapeamento de vascularização em organismos animais e vegetais. Devido ao seu baixo custo e facilidade de implementação, a técnica também pode ser largamente empregada na indústria para determinação do ponto de secagem de tintas, análise de vibrações e medidas de rugosidade com elevada precisão. O método possui ainda a vantagem de ser não destrutivo e não invasivo, sem necessitar de grande estabilidade mecânica ou térmica, complexidades inerentes a grande parte das técnicas ópticas mais usuais. Entretanto, apesar dessas características, métodos utilizando padrões speckle são pouco empregados no Brasil. As possibilidades de interdisciplinariedade são imensas e as aplicações à agricultura e alimentos são grandes, fato este que, no presente cenário econômico do país, torna-se altamente relevante. Por outro lado, seu potencial como técnica de diagnóstico médico justifica sua investigação nesse campo.

Nessa perspectiva, os principais objetivos deste trabalho foram a realização de um estudo sistemático das propriedades estatísticas do speckle dinâmico, a apresentação dos métodos mais empregados na sua análise e sua aplicação no monitoramento de tecidos vegetais e animais. Um novo estimador quantitativo para análise da atividade no biospeckle foi proposto.

Espero, através deste trabalho, colaborar para o desenvolvimento desse método óptico, não destrutivo e de grande potencial em campos científicos de largo interesse contemporâneo. Além disso, desejo contribuir para o enriquecimento do acervo bibliográfico sobre o tema em idioma português. 


\section{Capítulo 1}

\section{Fundamentos Teóricos}

O speckle é fruto da interferência entre múltiplos feixes espalhados a partir de uma superfície opticamente rugosa. Portanto, sua compreensão exige o entendimento de algumas propriedades fundamentais da luz, no contexto da teoria ondulatória. Neste capítulo são abordados alguns aspectos básicos da teoria do espalhamento e introduzidas as bases físicas que descrevem o fenômeno do biospeckle. Também são apresentados tópicos relevantes acerca das estruturas que compõem os tecidos biológicos estudados ao longo da dissertação, assim como o processo de interação luz-tecido.

\subsection{Espalhamento de Luz}

Vários são os fenômenos envolvidos no processo de interação da luz com a matéria, entre os quais se podem destacar absorção, transmissão, dispersão, reflexão e espalhamento, sendo este último essencial na formação do granulado óptico.

Quando a radiação luminosa incide sobre uma superfície lisa ${ }^{1}$, a reflexão especular ocorre de maneira bastante intensa. No caso em que essa superfície é rugosa ${ }^{2}$, a reflexão que ocorre é do tipo difusa. A figura 1.1 mostra esses dois casos.

O espalhamento de luz pode ser elástico, inelástico ou quasi-elástico. No espalhamento ineslático a luz espalhada possui comprimento de onda significativamente maior que a

\footnotetext{
${ }^{1} \mathrm{O}$ termo "lisa" empregado aqui significa que a superfície possui rugosidades inferiores ao comprimento de onda.

${ }^{2}$ Novamente o termo empregado está relacionado ao comprimento de onda. Ou seja, a superfície possui rugosidades da ordem de $\lambda$.
} 


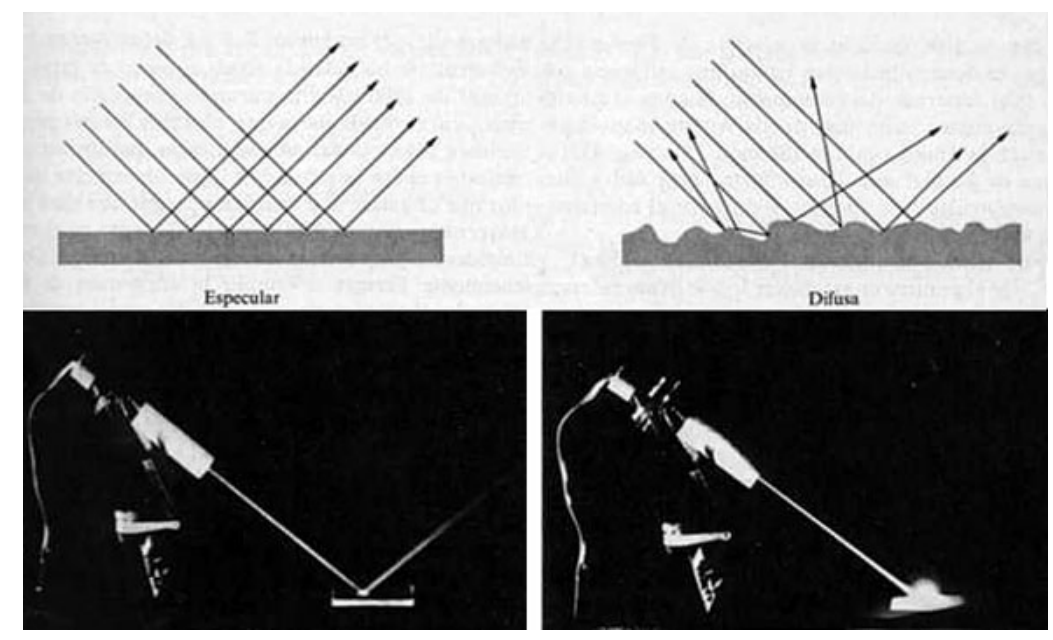

Figura 1.1: Reflexão especular e difusa.

incidente. Esse fenômeno se deve, entre outras coisas, ao fato de elétrons excitados na interação decaírem para estados intermediários, emitindo fótons de energias menores. Esse tipo de espalhamento encontra grande aplicação na espectroscopia e, normalmente, requer o uso de fótons com energia superior à do espectro visível (especialmente ultra-violeta e raios X). Já o espalhamento elástico não altera o comprimento de onda da radiação. Essa situação ocorre quando os centros espalhadores são estáticos, mudando apenas a direção de propagação das ondas incidentes. No espalhamento quasi-elástico, a freqüência da onda espalhada é ligeiramente distinta da onda incidente. Esse caso ocorre quando os centros espalhadores estão em movimento, havendo deslocamento nas ondas espalhadas pelos diferentes centros espalhadores. Quando há formação do granulado óptico, a interferência entre ondas com freqüências ligeiramente diferentes dá origem ao fenômeno do batimento, provocando as flutuações de intensidades observadas no speckle dinâmico. Os fenômenos estudados aqui supõem que os espalhamentos envolvidos sejam do tipo elástico ou quasielástico.

\subsubsection{Espalhamentos Rayleigh, Mie e geométrico}

O espalhamento também pode ser classificado em três categorias, de acordo com o tamanho das partículas do meio espalhador. Quando os centros espalhadores apresentam dimensões inferiores ao comprimento de onda da radiação incidente, tem-se o espalhamento Rayleigh. Quando as dimensões são da mesma ordem do comprimento de onda 
tem-se o espalhamento Mie. No caso em que as dimensões dos centros espalhadores são grandes quando comparadas ao comprimento de onda, de modo que a luz penetra seu interior e sofre refrações e reflexões múltiplas, o espalhamento é dito geométrico [11].

No espalhamento Rayleigh, a radiação é espalhada em todas as direções. Isso ocorre, por exemplo, em gases rarefeitos onde a interação intermolecular virtualmente inexiste e cada molécula age como um pequeno dipolo elétrico. O perfil de irradiância resultante é uma superposição de perfis dipolares. A atmosfera terrestre é o exemplo mais típico deste espalhamento. De acordo com essa teoria, a intensidade da radiação espalhada varia com $\lambda^{-4}$ e, portanto, comprimentos de onda menores são mais espalhados. Com isso, o azul $(\lambda \approx 500 \mathrm{~nm})$ é mais espalhado que o vermelho $(\lambda \approx 600 \mathrm{~nm})$, dando ao céu aspecto azulado e ao pôr do sol e à aurora tons avermelhados [10].

No espalhamento Mie, raios oriundos de pontos distintos da mesma partícula podem interferir entre si. As diferenças de fase entre as ondas espalhadas são menores na direção da onda incidente, levando a interferências construtivas mais intensas e irradiâncias maiores nesta direção. Este tipo de espalhamento é importante em sistemas coloidais, fumaças, névoas e nas nuvens, sendo independente do comprimento de onda da radiação. Isto explica, por exemplo, porque as nuvens são brancas, pois as gotículas de água que as formam têm dimensões da ordem do comprimento de onda visível.

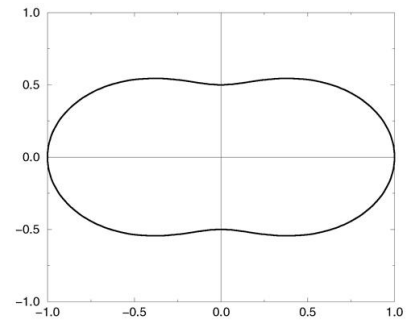

(a)

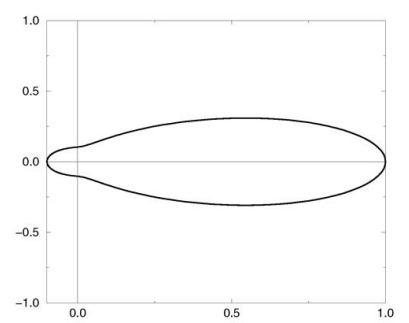

(b)

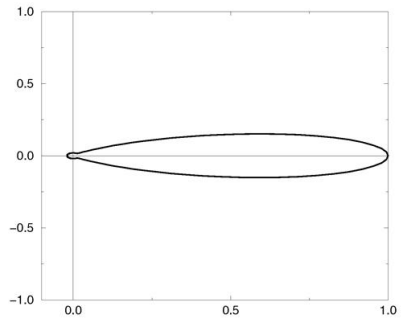

(c)

Figura 1.2: Perfis típicos de espalhamento Mie. À medida em que o raio da partícula aumenta (da esquerda para a direita), há perda de simetria.

A figura 1.2 ilustra o espalhamento de luz no regime Mie, com partículas de raios diferentes. À medida em que o raio aumenta, a distribuição da irradiância perde simetria em relação ao plano da partícula. Este fenômeno é conhecido como efeito Mie.

No espalhamento geométrico, a luz penetra a partícula e sofre reflexões e refrações em 
seu interior, desenvolvendo trajetórias que podem ser descritas por meio das leis da óptica geométrica (figura 1.3). Todavia, a descrição completa dessas trajetórias é complexa, pois os espalhamentos são múltiplos e a quantidade de parâmetros envolvidos é grande. Simulações numéricas, baseadas no método de Monte Carlo, são utilizadas para descrever esses espalhamentos. Ensaios desse tipo realizados em tecidos biológicos apontam que um feixe de laser se espalha em forma de gota (figura 1.4).

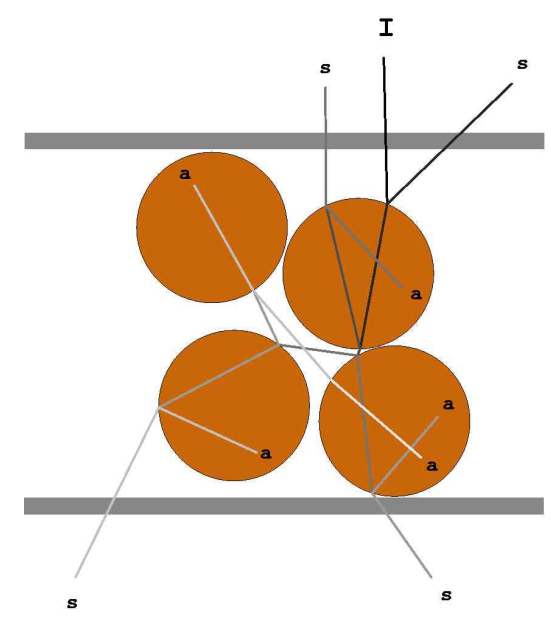

Figura 1.3: Desenho esquemático de espalhamento geométrico em partículas.

Nos sistemas estudados nesta dissertação ocorrem estes três tipos de espalhamento, pois os tecidos biológicos apresentam estruturas cujas dimensões variam desde poucos nanômetros (cadeias enzimáticas, por exemplo) até dezenas de micrômetros (a própria célula). Entretanto, os espalhamentos Mie e geométrico são predominantes na formação do granulado óptico.

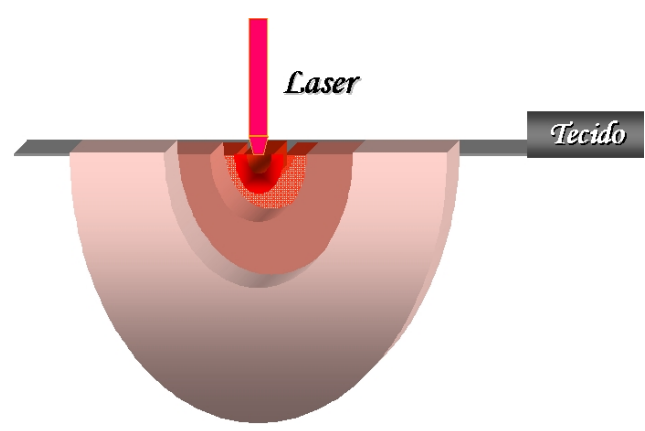

Figura 1.4: Perfil de distribuição de um feixe laser em tecidos biológicos. 


\subsection{Origens físicas do Biospeckle}

De acordo com o princípio de Huygens, quando um raio de luz atinge uma superfície, cada ponto desta atua como um emissor de ondículas secundárias. No caso em que tal superfície é opticamente rugosa, com os centros espalhadores distribuídos ao acaso, estas ondículas são espalhadas com fases iniciais variando aleatoriamente. Os caminhos ópticos percorridos por estas frentes de onda são distintos para cada ponto do plano de observação e a superposição coerente dessas ondas dá origem a um padrão de interferência cujas intensidades também variam ao acaso. Nos pontos de interferência construtiva ou destrutiva ocorre a formação de grãos claros e escuros, respectivamente. Tais características conferem caráter estatístico ao granulado óptico, de forma que sua análise segue tratamento semelhante ao dado para o passeio aleatório no plano complexo. A figura 1.5 apresenta de forma esquemática um sistema para análise do fenômeno do speckle. Note-se que foi incluída a coordenada de tempo, tornando possível uma análise mais geral para o caso do speckle dinâmico.

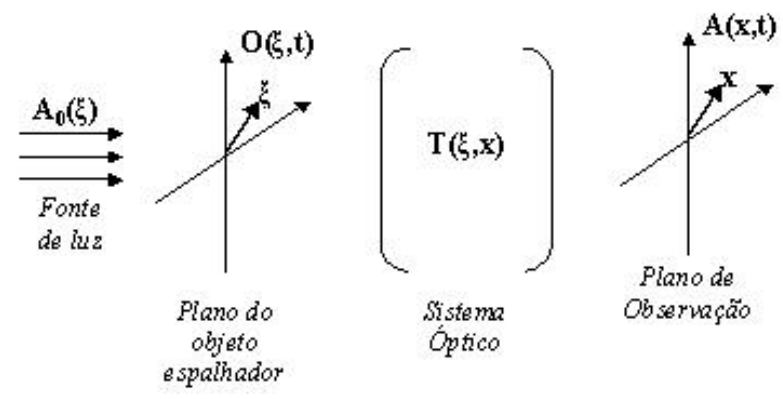

Figura 1.5: Sistema para análise do fenômeno do speckle. Os vetores $\xi$ e $\mathbf{x}$ indicam pontos no plano objeto e de observação, respectivamente.

A amplitude complexa em um ponto qualquer do plano de observação pode ser descrita em termos do esquema apresentado na figura 1.5, da seguinte forma:

$$
A(\mathbf{x}, t)=\iint_{S} A_{0}(\xi) O(\xi, t) T(\xi, \mathbf{x}) d^{2} \xi
$$

Onde $A_{0}(\xi)$ é a distribuição de amplitude da iluminação, $O(\xi, t)$ é uma modulação introduzida pelo objeto e $T(\xi, \mathbf{x})$ é a propagação ou a função resposta do sistema óptico. 
Portanto, tanto a fonte de luz, quanto o objeto e o meio de propagação influenciam no padrão observado.

\subsubsection{Geometrias de observação}

A observação do fenômeno pode ser realizada em duas configurações distintas. A primeira delas é a chamada propagação em espaço livre, na qual nenhum elemento óptico é colocado entre a superfície espalhadora e o plano de registro(figura 1.7(a)). Nessa configuração, geralmente, apenas um ponto da superfície é iluminado por um feixe laser e a luz espalhada é registrada em um filme ou sensor CCD colocado em um plano distante ${ }^{3}$, denominado plano de Fraunhofer. A figura 1.6 mostra um padrão típico observado nessa configuração, quando o speckle é também chamado objetivo.

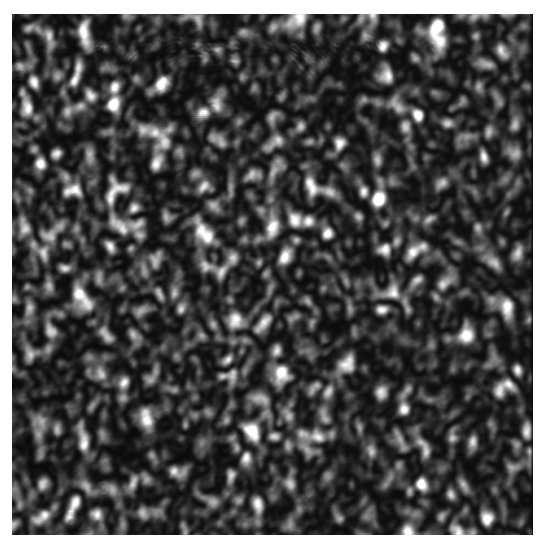

Figura 1.6: Típico padrão de speckle objetivo.

Quando a observação é realizada com auxílio de uma lente, por exemplo, de modo que haja uma relação bi-unívoca entre os pontos do objeto e os pontos do plano de observação, têm-se a geometria imagem e o plano de observação é denominado de plano imagem (figura 1.7(b)). Nessa configuração, normalmente uma região extensa da amostra é iluminada por um feixe expandido de laser. A figura 1, apresentada na introdução deste trabalho, mostra um objeto observado nessas condições, quando o speckle também é chamado subjetivo.

\footnotetext{
${ }^{3} \mathrm{O}$ termo distante significa que a separação entre o plano da superfície e o plano de observação corresponde a um grande número de comprimentos de onda.
} 


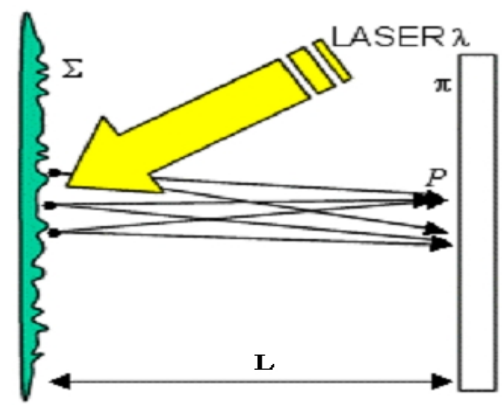

(a) Speckle objetivo

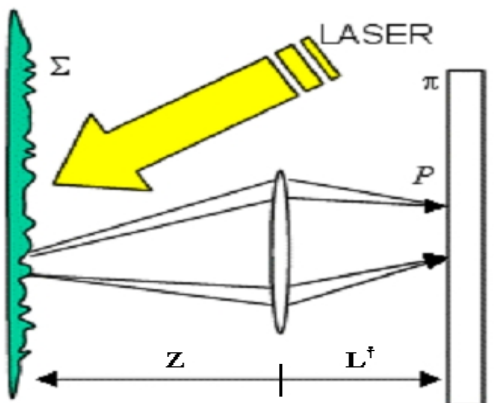

(b) Speckle subjetivo

Figura 1.7: Configurações para observação do speckle nos planos de Fraunhoffer (a) e imagem (b).

\subsubsection{Efeito Doppler, turbulência e difusão}

Nos casos em que a superfície do objeto ou o meio de propagação introduzem modulações nas ondas espalhadas, o padrão resultante é dinâmico, apresentando aspecto de fervilhamento. Tais flutuações nas intensidades são devidas a variações de fase dos diferentes raios interferentes em determinado ponto do plano de observação. As causas dominantes na modulação de fase no granulado óptico são o efeito Doppler, a turbulência e a difusão no objeto espalhador ou na propagação [12].

A frequência dos fótons espalhados está diretamente relacionada às velocidades das partículas. Centros espalhadores mais velozes, provocam maiores deslocamentos em frequência e, consequentemente, variações mais rápidas de fase e intensidades. Esse deslocamento é o conhecido efeito Doppler [10]. As diferenças entre frequências provocadas por esse efeito são pequenas (alguns Hertz) e o espalhamento é do tipo quasi-elástico. Na superposição resultante, ocorre o batimento de frequências. As variações de fase são independentes da direção do movimento das partículas, ou seja, não importa se as ondas são espalhadas a partir de partículas que se aproximam ou se afastam do plano de observação. De acordo com o teorema do limite central, desde que esses movimentos possuam velocidades completamente aleatórias, as frequências espalhadas tendem à distribuição gaussiana (apêndice A).

O fenômeno da turbulência é bastante comum em observações astronômicas, onde variações no índice de refração da atmosfera, devido a correntes de convecção, afetam de maneira significativa a imagem final. Possivelmente, o mesmo fenômeno também ocorre 
em tecidos biológicos uma vez que normalmente há presença de fluxos tais como sangue, linfa ou seiva. Uma maneira de modelar a turbulência é representar o tecido com múltiplas camadas, cada qual com índice de refração distinto variando ao acaso (figura 1.8).

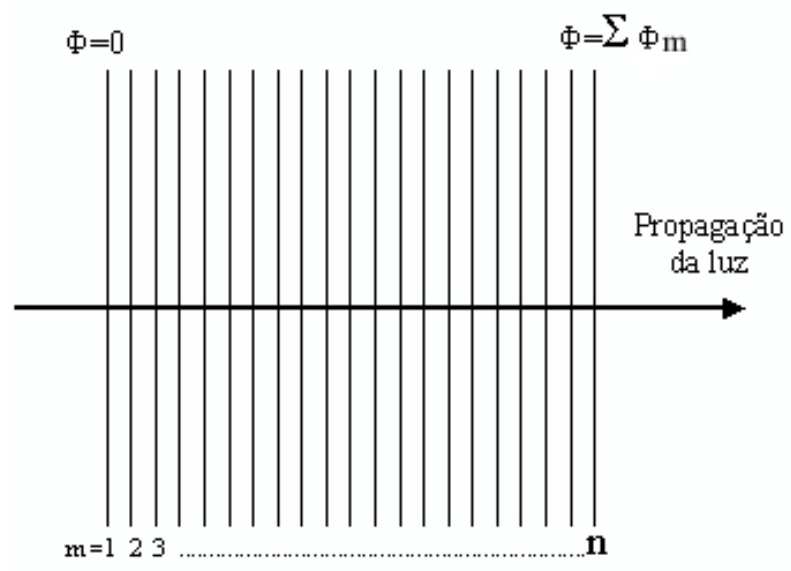

Figura 1.8: Modelo representando defasagens introduzidas pelo fenômeno da turbulência.

A defasagem resultante é dada pelas contribuições individuais de cada camada, de forma que:

$$
\phi_{\text {total }}=\phi_{1}+\phi_{2}+\ldots+\phi_{m}, \quad \operatorname{com} \phi_{m}=\frac{2 \pi}{\lambda}\left(n_{m} . \Delta l_{m}\right)
$$

Onde $\Delta l_{m}$ representa a largura da camada, $n_{m}$ é o índice de refração e $\phi_{m}$ é a variação de fase introduzida.

Uma mistura de líquidos compõe o meio intercelular e o citoplasma. Esses líquidos não fluem necessariamente, porém, apresentam gradientes de concentração estando, portanto, sujeitos ao fenômeno da difusão. A concentração desses líquidos obedece à equação da difusão:

$$
\frac{\partial^{2} C}{\partial t}=\mathbf{D} \nabla^{2} C
$$

Onde D é a constante de difusão.

A dependência temporal da concentração é dada pela solução de 1.2, a qual é do tipo $\exp \{-\beta t\}$. Como em outros sistemas termodinâmicos, as concentrações em líquidos biológicos também oscilam em torno do equilíbrio e, no caso de tecidos vivos, esse processo é contínuo. Portanto, as ondas espalhadas terão frequências variando em torno de um 
valor central $\omega_{0}$ com amplitudes amortecidas. Nessa situação, as frequências espalhadas se distribuem sobre um espectro que possui perfil Lorentziano ${ }^{4}$.

\subsubsection{Tamanho dos Grãos de Speckle}

Na propagação em espaço livre, é observado que os grãos do padrão de speckle mudam seu tamanho em função do comprimento de onda da luz incidente, da distância de observação e do diâmetro da área iluminada. A figura 1.9 apresenta uma seqüência de padrões espalhados a partir da mesma superfície, porém observados a distâncias diferentes. À medida em que a distância aumenta, também aumentam os tamanhos dos grãos constituintes do padrão.

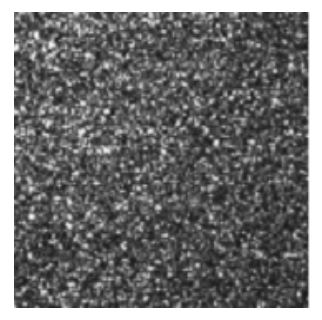

(a) $5 \mathrm{~cm}$

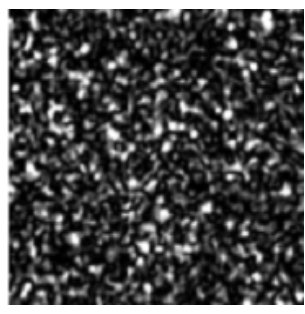

(b) $20 \mathrm{~cm}$

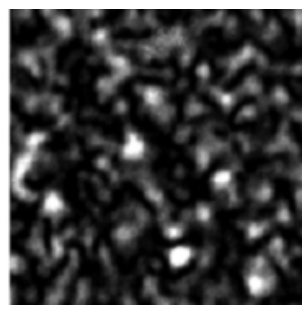

(c) $50 \mathrm{~cm}$

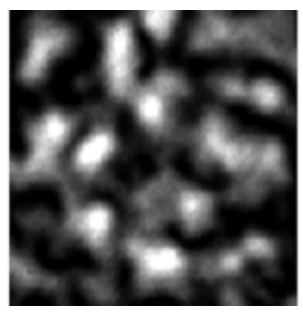

(d) $1 \mathrm{~m}$

Figura 1.9: Padrões speckle observados a diferentes distâncias.

A origem da dependência desses parâmetros pode ser compreendida, com grandes simplificações, de forma análoga à difração por orifício circular. Por "tamanho do grão" entende-se uma área fechada na qual a intensidade não é nula. Desse ponto de vista, cada grão é uma figura de difração com um máximo central, cuja intensidade vai decaindo até se anular nas bordas. Tomando-se os grãos como figuras de formato aproximadamente circular, em um padrão objetivo, o respectivo raio é dado por:

$$
q=1,22 \frac{\lambda \cdot L}{D}
$$

Onde Z é a distância ao plano de observação e D é o diâmetro da área iluminada sobre a superfície espalhadora. A expressão 1.3 é idêntica à obtida para o diâmetro do

\footnotetext{
${ }^{4}$ Mais informações sobre o espectro de frequências de funções do tipo $\exp \left\{-\beta t \cos \left(\omega_{0} t\right)\right\}$ podem ser obtidas no capítulo 11 da referência [10].
} 
disco central de Airy [10]. Vale ressaltar que o raio encontrado através da equação 1.3 é mínimo, ou seja, supõem-se que o grão seja formado a partir da interferência entre raios que partem dos extremos da região iluminada. A composição entre raios que partem de pontos no interior da área iluminada resultará, portanto, em grãos com diâmetros superiores a este.

Já o speckle subjetivo pode ser interpretado como uma imagem de um padrão objetivo. Em uma situação como a ilustrada na figura 1.7(b), tem-se que as ondas espalhadas a partir de todos os pontos de $\Sigma$ atravessam a abertura A da lente. Dessa forma, podemos interpretar a lente como uma superfície rugosa irradiando a imagem de um padrão objetivo. No plano de observação (plano imagem da lente), os grãos desse padrão terão raio mínimo dado por:

$$
q=1,22 \frac{\lambda \cdot L^{\dagger}}{A}
$$

No entanto, a distância $L^{\dagger}$ pode ser expressa em função de parâmetros da lente. Em particular, para uma superfície distante $(Z \rightarrow \infty), L^{\dagger}=f$. Definindo-se $F=\frac{f}{A}$, a equação 1.4 pode ser reescrita como:

$$
q=1,22 \lambda \cdot F
$$

A equação 1.5 corresponde ao poder de resolução do sistema óptico. Para o caso geral em que a superfície espalhadora não está no infinito, com auxílio da equação das lentes e da definição de aumento $V=\frac{L^{\dagger}}{Z}$ tem-se que:

$$
q=1,22(1+V) \lambda F
$$

Logo, o tamanho dos grãos em um padrão subjetivo está asssociado ao aumento do sistema óptico, bem como à abertura e distância focal.

\subsection{Características dos tecidos biológicos}

Os tecidos biológicos possuem como unidade elementar a célula, a qual, por sua vez, é subdividida em organelas (figura 1.10). As células são, em grande parte, constituídas 
por água e compostos orgânicos. Elementos extra-celulares, tais como as fibras de colágeno e outros componentes de sustentação, também fazem parte da estrutura histológica. Do ponto de vista deste trabalho, as características mais relevantes dizem respeito às dimensões das organelas celulares, aos índices de refração envolvidos e às propriedades de absorção presentes no meio. Outro aspecto fundamental é a ordem de grandeza das velocidades dos movimentos empreendidos pelas partículas em seu interior.

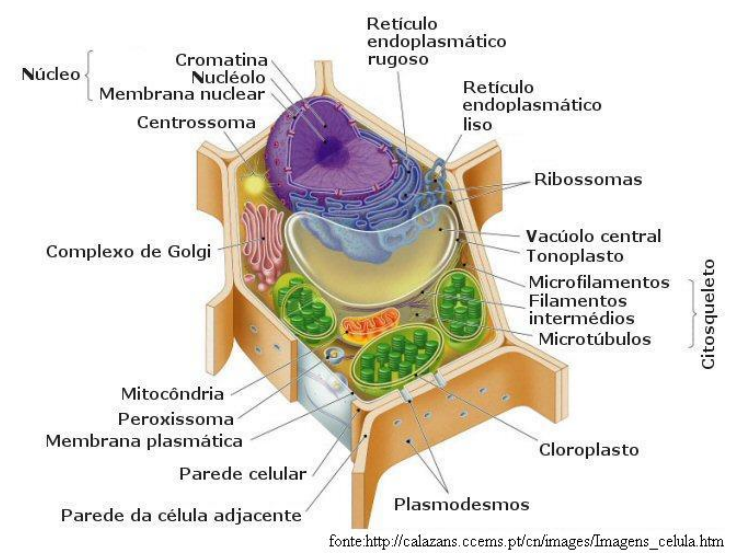

(a) Célula vegetal

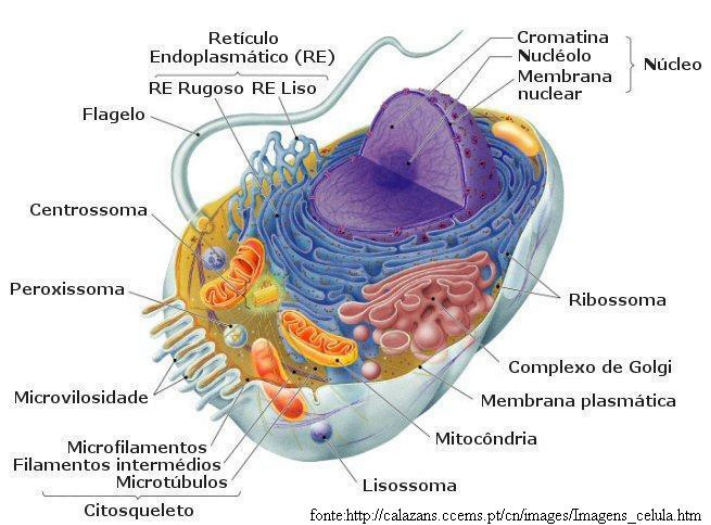

(b) Célula animal

Figura 1.10: Desenho esquemático representando as estruturas internas de células.

\subsubsection{Dimensões típicas das estruturas histológicas}

As dimensões típicas das estruturas citológicas cobrem uma faixa bastante ampla que vai de algumas dezenas de nanômetros até alguns mícrons. Levando-se em conta os laseres normalmente usados na análise desses sistemas, os quais emitem no espectro vísivel ou no infravermelho próximo, a relação entre o tamanho dos centros espalhadores e o comprimento de onda coloca o espalhamento nos regimes Mie ou geométrico. Evidentemente, o regime Rayleigh também está presente, aumentando consideravelmente a complexidade dos fenômenos de espalhamento em tecidos biológicos.

Uma modelagem bastante simplificada de um tecido biológico consiste em considerá-lo como um colóide povoado por um "ensemble" de partículas com índices de refração distintos do substrato. Nesse caso, a origem do espalhamento reside na variação abrupta entre os índices de refração das organelas e do citoplasma que as envolve. 
Uma célula, por si só, pode atuar como forte centro espalhador. Todavia, em geral, esse espalhamento obedece ao regime geométrico, de modo que a luz penetra a membrana e os espalhamentos dominantes ocorrem nas estruturas internas. Entre as organelas, as mitocôndrias apresentam-se como principais centros espalhadores. Suas dimensões (na faixa de $500 \mathrm{~nm}$ a $2 \mu \mathrm{m}$ ), aliadas à sua estrutura intrinsecamente rugosa, além da composição lipídica, lhe conferem elevado contraste óptico com o citoplasma, produzindo fortes efeitos de espalhamento. O núcleo é a maior das organelas, com diâmetros (em seres humanos) que variam de 4 a $6 \mu \mathrm{m}$. O retículo endoplasmático e o complexo de Golgi também são algumas das maiores estruturas, sendo incrustados de vesículas como os lisossomos, com dimensões situadas entre 250 e $500 \mathrm{~nm}$.

Na pele, os melanissomos são importantes espalhadores, cobrindo dimensões de 100 nm a $2 \mu m$. No sangue, as hemácias são as principais responsáveis pelo espalhamento (figura 1.11), possuindo diâmetros que variam de 7 a $9 \mu m$ e larguras da ordem de $2 \mu m$. Nos vegetais, os cloroplastos, com tamanhos em torno de $7 \mu m$, são os principais espalhadores.

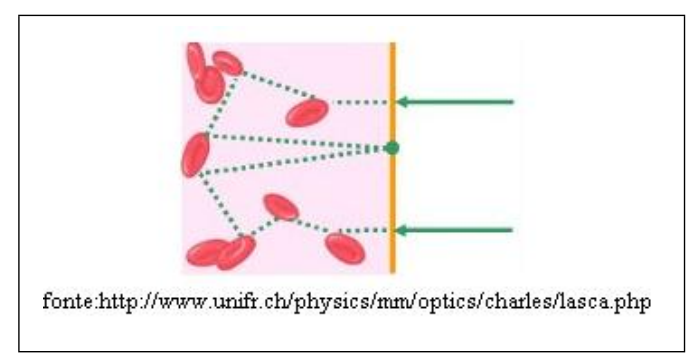

Figura 1.11: Desenho esquemático do espalhamento de luz em hemácias.

No meio intercelular é mais provável a ocorrência de estruturas com dimensões inferiores ao comprimento de onda. Por exemplo, as fibras de colágeno possuem periodicidade típica da ordem de 70nm. Isto implica em espalhamento tipo Rayleigh nessas estruturas. A tabela 1.1 apresenta as dimensões típicas das principais estruturas celulares.

\subsubsection{Velocidades dos movimentos presentes em tecidos}

A medida precisa de velocidades de fluxos e partículas no meio intercelular, ou no interior das células, é um processo complexo de ser realizado na prática. Além das dimen- 
Tabela 1.1: Dimensões típicas de estruturas celulares.

\begin{tabular}{cc}
\hline Estrutura & $\begin{array}{c}\text { Dimensões } \\
(\mu \mathrm{m})\end{array}$ \\
\hline mitocôndrias & $0.5-2$ \\
\hline lisossomos & $0.25-0.50$ \\
\hline melanissomos & $0.1-2$ \\
\hline hemácias & $7-9$ \\
\hline cloroplastos & $5-10$ \\
\hline fibras de colágeno & 0.07 \\
\hline vacúolo digestivo & 0.5 \\
\hline Complexo de Golgi & $1-3$ \\
\hline
\end{tabular}

sões reduzidas das estruturas participantes, as variações nos fluxos entre indivíduos (até mesmo da mesma espécie) podem ser muito grandes e depende de parâmetros intrínsecos ao metabolismo estudado. Por exemplo, no caso de plantas, a insolação, a quantidade de determinados nutrientes no solo, a umidade relativa do ar, a estação do ano, etc, são fatores que afetam completamente o fluxo nas folhas.

No sistema vascular humano, a pulsação ou o diâmetro dos capilares é determinante para a velocidade das hemácias. Em média, a velocidade do fluxo sanguíneo na saída da aorta é da ordem de $30 \mathrm{~cm} . \mathrm{s}^{-1}$, enquanto nos capilares este valor varia de 0,3 a $1,5 \mathrm{~mm} . \mathrm{s}^{-1}$. Estudos realizados em vegetais [16] mostram que as velocidades de transporte do floema estão situadas numa faixa entre $0,08 \mathrm{~mm} . \mathrm{s}^{-1}$ e $0,6 \mathrm{~mm} . \mathrm{s}^{-1}$, com médias variando muito de espécie para espécie.

No nível celular, as velocidades de transporte através das membranas e dos movimentos empreendidos pelas organelas citoplasmáticas apresentam valores bem menores. A maioria dos estudos disponíveis foram realizados em seres unicelulares, cujas dimensões facilitam o uso de técnicas de microscopia. Em protozoários, as velocidades dos movimentos do vacúolo digestivo (com dimensões da ordem de 500nm) cobrem valores que vão de 0,1 a $2 \mu m \cdot s^{-1}[17]$. No caso da oogênese ${ }^{5}$ em insetos foram observadas velocidades

\footnotetext{
${ }^{5}$ Processo de produção de óvulos.
} 
Tabela 1.2: Velocidades típicas de fluxos e estruturas em tecidos biológicos.

\begin{tabular}{|c|c|}
\hline Estrutura/Fluxo & Velocidade \\
\hline $\begin{array}{l}\text { Sangue na saída da aorta } \\
\text { (humanos) }\end{array}$ & $30 \mathrm{~cm} \cdot \mathrm{s}^{-1}$ \\
\hline $\begin{array}{l}\text { Sangue nos capilares } \\
\text { (humanos) }\end{array}$ & $0,3-1,5 \mathrm{~mm} . \mathrm{s}^{-1}$ \\
\hline Floema & $0,80-600 \mu m . s^{-1}$ \\
\hline $\begin{array}{c}\text { Transporte de sais pela membrana nuclear } \\
\text { (protozoários) }\end{array}$ & $2 n m . s^{-1}$ \\
\hline $\begin{array}{l}\text { Vacúolos digestivos } \\
\text { (Actinophrys sol) }\end{array}$ & $0,1-2 \mu m . s^{-1}$ \\
\hline $\begin{array}{l}\text { Folículos ovarianos } \\
\qquad(\text { Drosophila })\end{array}$ & $150 n m . s^{-1}$ \\
\hline
\end{tabular}

da ordem de $80 \mathrm{~nm} / \mathrm{s}$ no interior do citoplasma [18]. Extrapolações feitas para tecidos vegetais e animais mais evoluídos também colocam os movimentos das organelas nessa escala de valores, indo de dezenas de nanômetros a algumas unidades de micrômetros. Todavia, conforme já destacado, é extremamente difícil estabelecer valores precisos.

\subsubsection{Morfologia do sistema vascular vegetal}

As plantas vasculares são constantemente percorridas por duas correntes de líquidos. Da raiz para as folhas, o vegetal é percorrido pela seiva bruta através de um tecido especializado denominado xilema. O xilema, também chamado de lenho, é constituído por células mortas perfiladas que formam micro tubos, os quais conduzem água e sais minerais até as folhas, onde é realizada a fotossíntese. Os produtos da fotossíntese, que formam a seiva elaborada, são conduzidos através de um tecido especializado denominado floema, também chamado líber. O floema é constituído por células vivas ligadas entre si através de poros nas paredes contíguas. A seiva elaborada é conduzida das folhas para a raiz.

A parte do sistema vascular visível nas folhas é chamada de venação. Do ponto 
de vista da estrutura vascular, monocotiledôneas e dicotiledôneas apresentam distinções morfológicas. Nas monocotiledôneas há um conjunto de vasos paralelos, enquanto nas dicotiledôneas há um vaso primário que se ramifica em vasos secundários.

\subsubsection{Morfologia do tecido cutâneo}

O tecido da pele pode ser dividido em duas camadas principais: a epiderme e a derme. Há ainda uma terceira camada, a hipoderme, que é subcutânea, porém intimamente relacionada ao funcionamento da pele (figura 1.12).

A epiderme é a camada exterior. Sua espessura pode variar de acordo com a zona corporal em que se encontra, atingindo profundidades que vão de $300 \mu m$ nas pálpebras até $2 \mathrm{~mm}$ nas palmas das mãos e solas dos pés. Algumas camadas de células mortas formam a cobertura mais superficial, denominada córnea. As principais células constituintes da epiderme são os queratinócitos, que produzem a queratina, proteína resistente e responsável pela proteção contra agentes externos. Nessa camada também estão os melanócitos que são produtores de melanina e importantes centros espalhadores. A epiderme não é vascularizada, recebendo nutrientes e oxigênio por meio de difusão a partir de camadas interiores.

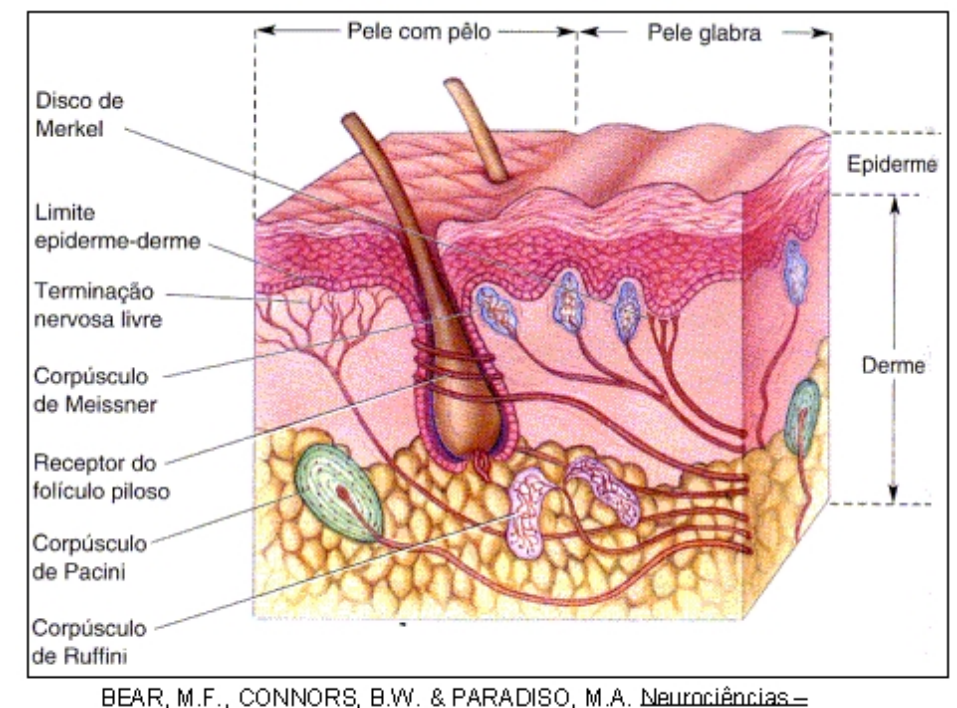

BEAR, M.F., CONNORS, B.W. \& PARADISO, M.A. Neulanciências-
Desiendando o Sistema Nervoso. Porto Aleqre $z^{2}$ ed. Artmed Editora, 2002.

Figura 1.12: Corte transversal da pele humana e suas principais camadas.

A derme é um tecido conjuntivo de sustentação à epiderme. Seus principais consti- 
tuintes são fibras de colágeno e elastina. Está densamente povoada por vasos sangüíneos e linfáticos, além de inúmeras terminações nervosas responsáveis pelas sensações táteis. Apresenta profundidades que variam de 1 a $4 \mathrm{~mm}$.

A hipoderme é o tecido mais interior e tem caráter adiposo, ou seja, é constituída basicamente por células de gordura responsáveis pelo isolamento térmico e reserva energética. Sua espessura pode variar muito, de alguns milímetros a dezenas de centrímetros.

Tabela 1.3: Características do tecido cutâneo humano.

\begin{tabular}{ccc}
\hline Camada & $\begin{array}{c}\text { Tecido } \\
\text { Constituinte }\end{array}$ & $\begin{array}{c}\text { Espessura } \\
(\mathrm{mm})\end{array}$ \\
\hline Epiderme & Epitélio & $0.3-2$ \\
\hline Derme & Conjuntivo & $1-4$ \\
\hline Hipoderme & Adiposo & $5-100$ \\
\hline
\end{tabular}

\subsubsection{Propriedades de absorção: a janela terapêutica}

O poder de penetração da luz nos tecidos depende, entre outros fatores, do coeficiente de absorção. Há uma estreita faixa do espectro eletromagnético, denominada de "janela terapêutica", na qual a grande maioria dos tecidos animais absorvem com menor intensidade, permitindo maior penetração. Esta janela se estende de aproximadamente $600 \mathrm{~nm}$ a 1300nm, do laranja ao infravermelho próximo. Essencialmente, as características da janela terapêutica dependem do espectro de absorção de substâncias como a água, hemoglobina ou melanina. No caso dos tecidos vegetais, a clorofila também desempenha papel relevante. De maneira geral, no contexto desta dissertação, o fenômeno da absorção é importante para determinar a penetração da luz no tecido e, portanto, conhecer a(s) camada(s) de origem da informação contida no biospeckle resultante. Na figura 1.13 são mostrados os espectros dos principais componentes responsáveis pela absorção no tecido cutâneo humano. 


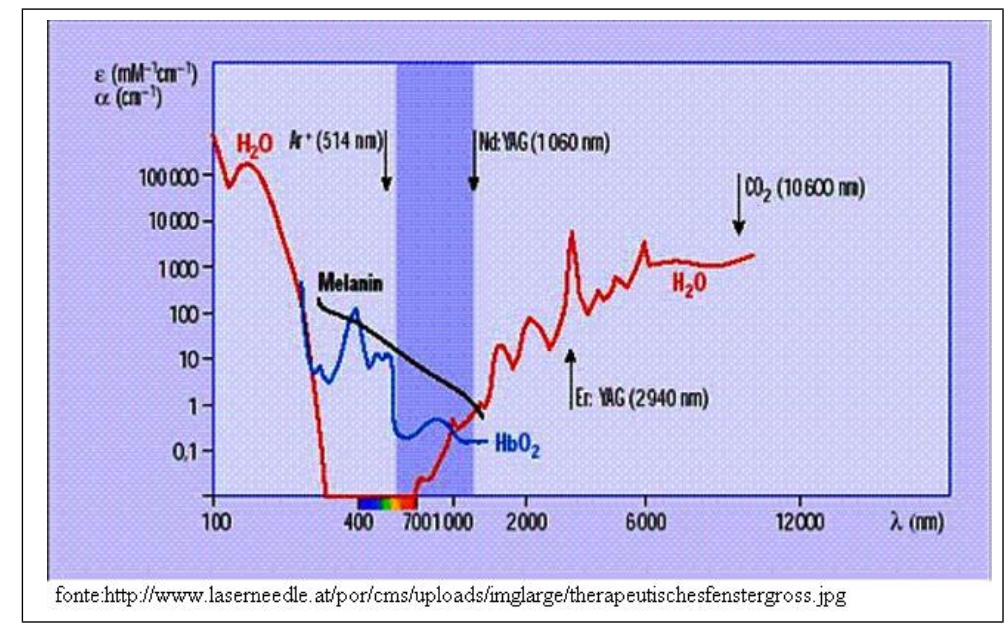

Figura 1.13: Janela terapêutica: espectros de absorção da água, da melanina e da oxihemoglobina.

\subsubsection{Interação luz-tecido biológico: a laserterapia de baixa in- tensidade}

Denomina-se laserterapia de baixa intensidade técnicas terapêuticas nas quais são empregados laseres que não provocam elevações de temperatura superiores a $1^{\circ} \mathrm{C}$, de forma que efeitos fototérmicos podem ser desprezados. Há pelo menos quatro décadas, vários estudos na literatura sugerem a existência de um processo de "biomodulação", em células que não realizam fotossíntese, quando estas são submetidas à irradiação de pequenas doses de luz $\left(10^{2} \mathrm{~J} / \mathrm{m}^{2}-10^{3} \mathrm{~J} / \mathrm{m}^{2}\right)$. Esses estudos [27] mostram, entre outras coisas, uma estreita relação entre o crescimento de bactérias Escherichia coli e a dose e comprimento de onda irradiados. Atualmente, têm sido reportadas várias aplicações médicas da laserterapia como técnica substituta ou coadjuvante na recuperação de tecidos lesados [26]. Apenas para exemplificar essas aplicações, podemos citar alguns artigos recentes relatando o uso da irradiação de luz em tratamentos odontológicos [30], inibição de processos tumorais [32] e tratamento de úlcera gástrica causada por Helicobacter pylori [31].

Dentre as várias hipóteses para explicar o mecanismo de ação da biomodulação, a mais consensual afirma que ocorre interação entre a luz e a cadeia respiratória na matriz mitocondrial [27]. De acordo com essa hipótese, os fótons de comprimento de onda no vermelho, por exemplo, alteram o estado vibracional das moléculas do par $N A D^{+} \rightleftharpoons N A D H$ (Dinucleotídeo de nicotinamida adenina), facilitando a produção de ATP (Tri-fosfato de 
adenosina) no ciclo de Krebs [28]. Por outro lado, ainda de acordo com a mesma teoria, a radiação infravermelha altera o potencial de membrana citoplasmática, alterando a permeabilidade, facilitando a entrada dos compostos alimentares indispensáveis ao processo de produção de energia [29].

A ação do laser no nível celular é ilustrada de forma esquemática no diagrama da figura 1.14. A coluna da esquerda expõe a atuação em termos das organelas envolvidas, enquanto no lado direito estão listados os processos decorrentes da aplicação da luz.

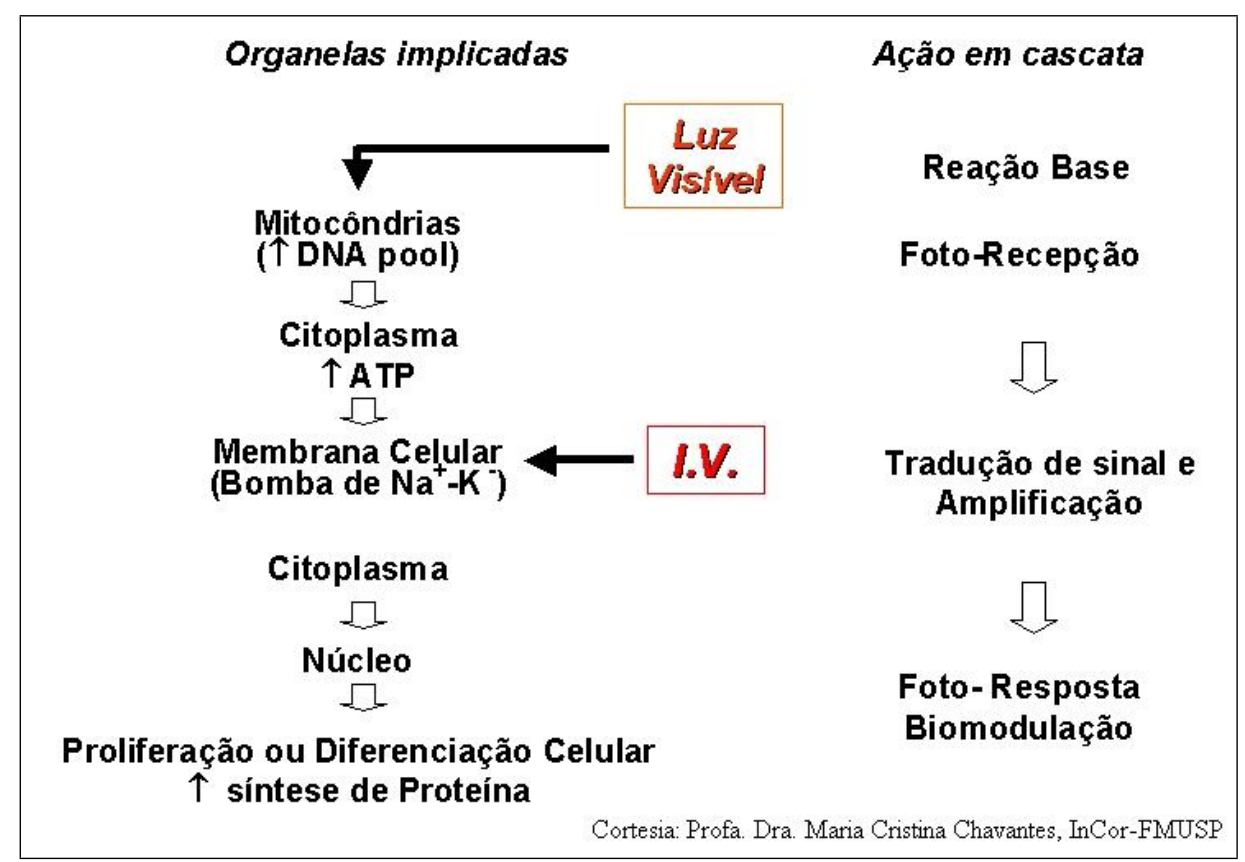

Figura 1.14: Esquema do efeito foto-físico-químico do laser de baixa potência em nível celular. 


\section{Capítulo 2}

\section{Estatística do Biospeckle}

\subsection{Estatística Espacial de Primeira Ordem}

A aparência final de um padrão speckle não guarda relação com a estrutura detalhada da superfície espalhadora. A descrição só pode ser realizada no contexto da Teoria Estatística. Conforme discutido no capítulo anterior, o granulado é o resultado de um complexo fenômeno de interferência entre múltiplas ondas. A fim de simplificar sua análise, adotaremos a seguir a abordagem proposta por Goodman [5]. Um padrão speckle é dito completamente desenvolvido quando obedece às condições impostas pelo modelo de Goodman.

A determinação da FDP (Função Densidade de Probabilidade) das amplitudes, fases e intensidades do campo em um padrão speckle é chamada de "Estatística de Primeira Ordem". Os estimadores de primeira ordem mais utilizados na descrição do granulado são a média e a variância das intensidades. Já a determinação da Função de Autocorrelação e da Densidade Espectral de Potência é chamada de "Estatística de Segunda Ordem". Coeficientes de correlação também são ferramentas bastante utilizadas neste tipo de estudo.

O modelo de Goodman está fundamentado sobre três premissas básicas:

(i) As ondas espalhadas possuem o mesmo plano de polarização, sendo o padrão resultante nesse caso chamado de "speckle polarizado";

(ii) As amplitudes $\frac{a_{k}}{\sqrt{N}}$ e as fases $\phi_{k}$ de cada fasor são estatisticamente independentes entre si;

(iii) As fases $\phi_{k}$ são uniformemente distribuídas no intervalo $[-\pi, \pi]$. De- 


\section{fasagens superiores a $2 \pi$ produzem uma distribuição uniforme no intervalo primário.}

Além das três condições descritas anteriormente, também pressupõem-se iluminação coerente. É interessante discutirmos neste ponto as bases físicas que sustentam as premissas do modelo. A primeira delas (i) decorre naturalmente do fato de que fenômenos de interferência só ocorrem entre ondas com mesmo estado de polarização. A condição (ii) tem origem na independência dos centros espalhadores, ou seja, eles estão distribuídos de maneira aleatória e possuem as mesmas propriedades estatísticas. Finalmente, a condição (iii) advém da hipótese de que a superfície é rugosa comparada ao $\lambda$ empregado.

O problema da soma das ondas assume, então, a mesma forma do "passeio aleatório no plano complexo".

Seja $u_{k}(\mathbf{x}, t)$ a representação de uma componente do campo elétrico em um ponto de observação $\mathbf{x}$, em um instante t:

$$
u_{k}(\mathbf{x}, t)=a_{k}(\mathbf{x}) \exp \{i \omega t\}
$$

Onde $a_{k}$ representa um fasor elementar da amplitude complexa do campo:

$$
a(\mathbf{x})=|a(\mathbf{x})| \exp \{i \theta(\mathbf{x})\}
$$

A soma das contribuições de um grande número de fasores elementares assume a forma:

$$
A(\mathbf{x})=\sum_{k=1}^{N} \frac{1}{\sqrt{N}} a_{k}(\mathbf{x})=\frac{1}{\sqrt{N}} \sum_{k=1}^{N}\left|a_{k}\right| \exp \left\{i \theta_{k}\right\}
$$

Façamos a seguir a dedução da FDP da amplitude e da intensidade em um padrão speckle completamente desenvolvido. Por razões de simplificação matemática, seja a (2.3) dividida nas partes real e imaginária do campo:

$$
\begin{aligned}
& A^{(r)}=\Re[A(\mathbf{x})]=\frac{1}{\sqrt{N}} \sum_{k=1}^{N}\left|a_{k}\right| \cos \phi_{k} \\
& A^{(i)}=\Im[A(\mathbf{x})]=\frac{1}{\sqrt{N}} \sum_{k=1}^{N}\left|a_{k}\right| \sin \phi_{k}
\end{aligned}
$$

Os respectivos valores médios são: 


$$
\begin{aligned}
& \left\langle A^{(r)}\right\rangle=\frac{1}{\sqrt{N}} \sum_{k=1}^{N}\left\langle\left|a_{k}\right|\right\rangle\left\langle\cos \phi_{k}\right\rangle=0 \\
& \left\langle A^{(i)}\right\rangle=\frac{1}{\sqrt{N}} \sum_{k=1}^{N}\left\langle\left|a_{k}\right|\right\rangle\left\langle\sin \phi_{k}\right\rangle=0
\end{aligned}
$$

Pois $\sum_{k=1}^{N}\left\langle\cos \phi_{k}\right\rangle=\sum_{k=1}^{N}\left\langle\sin \phi_{k}\right\rangle=0$, para $N \rightarrow \infty$. Por outro lado:

$$
\begin{aligned}
\left\langle\left[A^{(r)}\right]^{2}\right\rangle & =\frac{1}{N} \sum_{k=1}^{N} \sum_{m=1}^{N}\left\langle\left|a_{k}\right|\left|a_{m}\right|\right\rangle\left\langle\cos \phi_{k} \cos \phi_{m}\right\rangle=\frac{1}{N} \sum_{k=1}^{N} \frac{\left\langle\left|a_{k}\right|^{2}\right\rangle}{2} \\
\left\langle\left[A^{(i)}\right]^{2}\right\rangle & =\frac{1}{N} \sum_{k=1}^{N} \sum_{m=1}^{N}\left\langle\left|a_{k}\right|\left|a_{m}\right|\right\rangle\left\langle\sin \phi_{k} \sin \phi_{m}\right\rangle=\frac{1}{N} \sum_{k=1}^{N} \frac{\left\langle\left|a_{k}\right|^{2}\right\rangle}{2}
\end{aligned}
$$

Onde a condição (iii) foi usada, implicando em:

$$
\left\langle\cos \phi_{k} \cos \phi_{m}\right\rangle=\left\langle\sin \phi_{k} \sin \phi_{m}\right\rangle= \begin{cases}\frac{1}{2} & \text { para } k=m \\ 0 & \text { para } k \neq m\end{cases}
$$

Das equações 2.6, 2.7, 2.8 e 2.9, deduz-se que $A^{(r)}$ e $A^{(i)}$ são independentes, possuem valor médio igual a zero e variância:

$$
\sigma_{A}^{2}=\left\langle\left[A^{(r)}\right]^{2}\right\rangle-\left\langle A^{(r)}\right\rangle^{2}=\lim _{N \rightarrow \infty} \frac{1}{N} \sum_{k=1}^{N} \frac{\left\langle\left|a_{k}\right|^{2}\right\rangle}{2}
$$

Partindo-se da premissa de que os fasores são estatisticamente independentes e seu número é extremamente grande (ou seja, $N \rightarrow \infty$ ), as condições do teorema do limite central são satisfeitas ${ }^{1}$. Portanto, as amplitudes obtidas em 2.4 e 2.5 tendem a uma distribuição normal em torno das respectivas médias calculadas em 2.6 e 2.7. A FDP conjunta de $A^{(r)}$ e $A^{(i)}$ no plano complexo é uma função gaussiana circular, dada por:

$$
p_{r, i}\left(A^{(r)}, A^{(i)}\right)=\frac{1}{2 \pi \sigma_{I}^{2}} \exp \left\{\frac{-\left(\left[A^{(r)}\right]^{2}+\left[A^{(i)}\right]^{2}\right)}{2 \sigma_{I}^{2}}\right\}
$$

Eventualmente, de acordo com a obediência ou não às condições do modelo de Goodman, distribuições distintas são possíveis. Entretanto, na grande maioria dos casos, os resultados acima podem ser usados com grande aproximação.

\footnotetext{
${ }^{1}$ Vide apêndice $\mathrm{A}$
} 
As FDPs da intensidade e da fase podem ser obtidas a partir de uma mudança de variável em 2.11:

$$
\begin{gathered}
A^{(r)}=\sqrt{I} \cos \theta \\
A^{(i)}=\sqrt{I} \sin \theta \\
p_{I, \theta}(I, \theta)=p_{r, i}(\sqrt{I} \cos \theta, \sqrt{I} \sin \theta)\|J\|
\end{gathered}
$$

Onde $\|J\|$ é o módulo do Jacobiano da transformação:

$$
\|\mathbf{J}\|=\left\|\begin{array}{cc}
\frac{\partial A^{(r)}}{\partial I} & \frac{\partial A^{(r)}}{\partial \theta} \\
\frac{\partial A^{(i)}}{\partial I} & \frac{\partial A^{(i)}}{\partial \theta}
\end{array}\right\|=\frac{1}{2}
$$

Substituindo em 2.12 têm-se:

$$
p_{I, \theta}(I, \theta)= \begin{cases}\frac{1}{4 \pi \sigma_{A}^{2}} \exp \left\{\frac{-I}{2 \sigma_{A}^{2}}\right\} & \text { para } I \geq 0 \mathrm{e}-\pi \leq \theta \leq \pi \\ 0 & \text { de outra maneira. }\end{cases}
$$

Agora é possível a obtenção das FDPs separadas da intensidade e da fase a partir do cálculo das FDPs marginais ${ }^{2}$ :

$$
\begin{gathered}
p_{I}(I)=\int_{-\pi}^{\pi} p_{I, \theta}(I, \theta) d \theta= \begin{cases}\frac{1}{2 \sigma_{A}^{2}} \exp \left\{\frac{-I}{2 \sigma_{A}^{2}}\right\} & I \geq 0 \\
0 & \text { de outra maneira. }\end{cases} \\
p_{\theta}(\theta)=\int_{0}^{\infty} p_{I, \theta}(I, \theta) d I= \begin{cases}\frac{1}{2 \pi} & -\pi \leq \theta \leq \pi \\
0 & \text { de outra maneira. }\end{cases}
\end{gathered}
$$

Portanto, a intensidade de um padrão speckle em um ponto de observação obedece a uma FDP exponencial negativa e a respectiva fase possui distribuição uniforme.

Verifica-se a independência entre I e $\theta$ através da constatação que a equação 2.13 é igual ao produto das distribuições calculadas em 2.14 e 2.15. Tal característica decorre da proposição (ii) do modelo de Goodman, enquanto a FDP verificada em 2.15 tem origem na proposição (iii).

\footnotetext{
${ }^{2}$ vide apêndice $\mathrm{A}$
} 
A partir da equação 2.10, conclui-se que $\langle I\rangle=2 \sigma_{A}^{2}$ e 2.14 pode ser compactada na forma:

$$
p_{I}(I)=\frac{1}{\langle I\rangle} \exp \left\{\frac{-I}{\langle I\rangle}\right\}
$$

A variância das intensidades do padrão pode ser obtida calculando-se:

$$
\begin{gathered}
\left\langle I^{2}\right\rangle=\int_{0}^{\infty} I^{2} p_{I}(I) d I=2\langle I\rangle^{2} \\
\Rightarrow \sigma_{I}^{2}=\left\langle I^{2}\right\rangle-\langle I\rangle^{2}=\langle I\rangle^{2}
\end{gathered}
$$

A definição de contraste é:

$$
C=\frac{\sigma_{I}}{\langle I\rangle}
$$

Portanto, substituindo 2.18 em 2.19, temos que o contraste de um padrão speckle completamente desenvolvido é igual a um.

\subsubsection{Soma incoerente de dois padrões speckle}

A FDP da intensidade deduzida em 2.14 é válida somente na situação em que o padrão é completamente desenvolvido. Todavia, uma situação de grande interesse prático é aquela em que há a superposição de dois padrões speckle com polarizações ortogonais. No caso em que os dois padrões são independentes entre si, essa soma é dita incoerente.

Cada um dos padrões obedece, individualmente, à FDP deduzida em 2.16. Portanto, a FDP da soma será uma combinação de duas distribuições. Quando se tem variáveis independentes, a distribuição combinada corresponde ao produto das FDPs das variáveis. Essa situação foi observada quando mostramos que a distribuição conjunta da intensidade e da fase (vide equação 2.13) correspondia ao produto das distribuições individuais (equações 2.14 e 2.15). Para que o mesmo tratamento possa ser aplicado a FDPs independentes é necessário lançar mão da função característica ${ }^{3}$ dessas distribuições. Para a FDP deduzida em 2.16, a função característica correspondente é:

\footnotetext{
${ }^{3}$ Vide apêndice $\mathrm{A}$
} 


$$
M_{I}(i v)=\frac{1}{1-i v\langle I\rangle}
$$

A função característica de dois padrões ortogonais e incoerentes é dada pelo produto das funções de cada padrão, portanto:

$$
M_{I}^{(2)}(i v)=\frac{1}{(1-i v\langle I\rangle)^{2}}
$$

Aplicando-se a transformada inversa de Fourier à 2.21, chega-se à FDP combinada da soma dos padrões:

$$
p_{I}^{(2)}(I)=\frac{4 I}{\langle I\rangle^{2}} \exp \left\{\frac{-2 I}{\langle I\rangle}\right\}
$$

A partir do cálculo do momento de segunda ordem de 2.22, a variância e o contraste do padrão podem ser definidos:

$$
\left\langle I^{2}\right\rangle=\int_{0}^{\infty} I^{2} p_{I}^{(2)} d I=\frac{3\langle I\rangle^{2}}{2} \Rightarrow\left\{\begin{array}{l}
\sigma_{I}^{2}=\frac{\langle I\rangle^{2}}{2} \\
C=0,7 .
\end{array}\right.
$$

A figura 2.1 ilustra as FDPs de um padrão completamente desenvolvido e da soma incoerente de dois padrões com polarizações ortogonais.

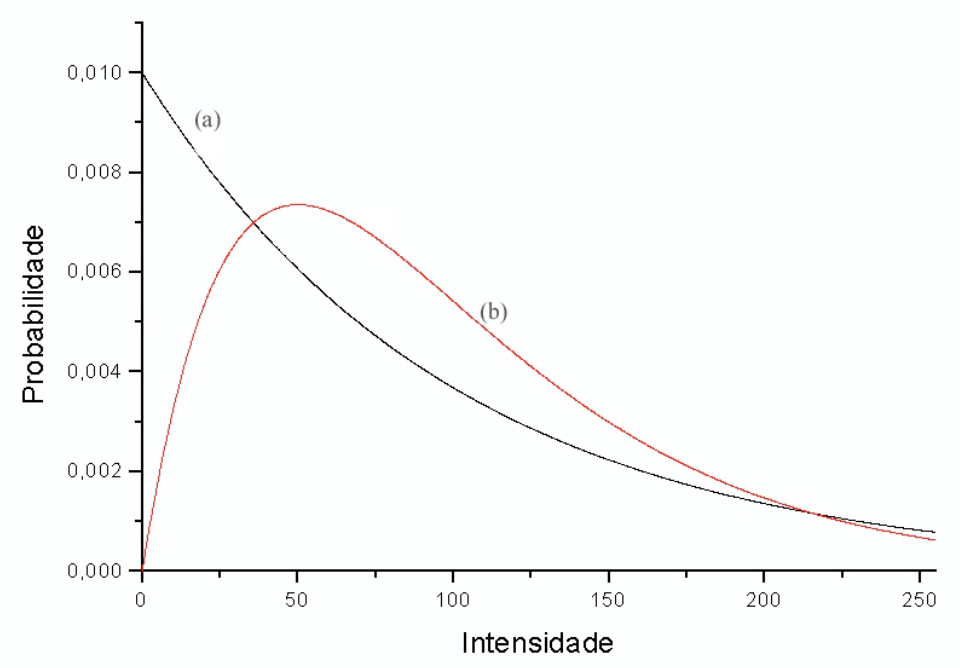

Figura 2.1: FDP de (a) padrão completamente desenvolvido e (b) soma incoerente de dois padrões. 


\subsubsection{Soma com fundo uniforme}

Um método usado em análises de biospeckle tem suas origens no estudo da superposição entre um padrão speckle e um fundo uniforme [19]. Por isso, nos dedicaremos a um estudo um pouco mais detalhado desta soma.

Na adição de um padrão completamente desenvolvido com um fundo incoerente e uniforme, é fisicamente razoável inferir que a intensidade do fundo $\left(I_{f}\right)$ provoca um aumento na intensidade média do padrão sem interferir na variância $\left(\sigma_{I}^{2}\right)$. Nessas condições, já foi observado que $\sigma_{I}^{2}=\left\langle I_{E}\right\rangle^{2}$ (vide equação 2.18). Definindo-se a contribuição do fundo na intensidade média total, temos:

$$
\rho=\frac{I_{f}}{\langle I\rangle}, \text { onde }\langle I\rangle=I_{f}+\left\langle I_{E}\right\rangle
$$

Reescrevendo 2.23 em função da variância e da intensidade média resultante, chegamos à:

$$
\rho=\frac{\langle I\rangle-\left\langle I_{E}\right\rangle}{\langle I\rangle} \Rightarrow 1-\frac{\sigma_{I}}{\langle I\rangle}
$$

Ou seja, a partir do contraste de um padrão completamente desenvolvido, é possível estabelecer a contribuição do fundo uniforme na intensidade total.

\subsection{Estatística temporal de primeira ordem}

Nesta seção nos dedicaremos ao estudo do comportamento das intensidades apresentadas por um único ponto em um padrão dinâmico ao longo do tempo. Quando uma amostra biológica é iluminada com luz coerente, o speckle resultante é fruto da superposição de duas componentes oriundas, separadamente, de espalhadores estáticos e móveis, localizados, de forma respectiva, na superfície e no interior do tecido [20]. A fim de simplificar a análise, suponhamos que tais padrões sejam completamente desenvolvidos.

Em um instante t, no plano de observação, a intensidade resultante é dada por:

$$
I(x, y ; t)=\left|A_{E}(x, y)+A_{M}(x, y ; t)\right|^{2}
$$


Onde $A_{E}(x, y)$ e $A_{M}(x, y ; t)$ são as amplitudes complexas das componentes estacionária e móvel, respectivamente. A variância $\sigma_{t}^{2}(x, y)$ das flutuações temporais da intensidade em um dado ponto é dada por ${ }^{4}$ :

$$
\sigma_{t}^{2}(x, y)=\left\langle I^{2}(x, y ; t)\right\rangle_{t}-\langle I(x, y ; t)\rangle_{t}^{2}
$$

Calculando-se as expressões para $\left\langle I^{2}(x, y ; t)\right\rangle_{t}$ e $\langle I(x, y ; t)\rangle_{t}^{2}$ :

$$
\left\langle I^{2}(x, y ; t)\right\rangle_{t}=I_{E}^{2}+\left\langle I_{M}^{2}\right\rangle+4 I_{E}\left\langle I_{M}\right\rangle
$$

Onde, os termos $I_{E}\left(x, y 0\right.$ e $I_{M}(x, y)$ foram denotados por $I_{E}$ e $I_{M}$ para simplificar a notação.

$$
\langle I(x, y ; t)\rangle_{t}^{2}=\left\langle I_{E}+\left\langle I_{M}\right\rangle\right\rangle^{2}=I_{E}^{2}+\left\langle I_{M}\right\rangle^{2}+2 I_{E}\left\langle I_{M}\right\rangle
$$

Chegamos à:

$$
\sigma_{t}^{2}(x, y)=2 I_{E}\left\langle I_{M}\right\rangle+\left\langle I_{M}^{2}\right\rangle-\left\langle I_{M}\right\rangle^{2}
$$

No entanto, como partimos da hipótese de que os padrões são completamente desenvolvidos, conforme demonstrado em 2.17, $\left\langle I_{M}^{2}\right\rangle=2\left\langle I_{M}\right\rangle^{2}$. Substituindo em 2.29, temos:

$$
\sigma_{t}^{2}(x, y)=2 I_{E}\left\langle I_{M}\right\rangle+\left\langle I_{M}\right\rangle^{2}
$$

A presença de $I_{E}(x, y)$ na expressão 2.30 denota que o comportamento das intensidades ao longo do tempo depende da posição no plano de observação. Para que $\sigma_{t}^{2}(x, y)$ tenha algum significado é necessário realizar-se uma média espacial sobre uma grande quantidade de pontos:

$$
\begin{aligned}
\left\langle\sigma_{t}^{2}(x, y)\right\rangle_{x y} & =2\left\langle I_{E}\right\rangle\left\langle I_{M}\right\rangle+\left\langle I_{M}\right\rangle^{2} \\
& \Rightarrow\left\langle I_{E}+I_{M}\right\rangle^{2}-\left\langle I_{E}\right\rangle^{2}
\end{aligned}
$$

Lembrando que $\left\langle I_{E}+I_{M}\right\rangle=\left\langle I_{t}\right\rangle_{x y}$ e lançando mão do coeficiente de proporção definido em 2.23, a equação 2.31 pode ser rearranjada na forma:

$$
\begin{aligned}
\frac{\left\langle\sigma_{t}^{2}(x, y)\right\rangle_{x y}}{\left\langle I_{t}\right\rangle_{x y}^{2}} & =1-\frac{\left\langle I_{E}\right\rangle^{2}}{\left\langle I_{t}\right\rangle_{x y}^{2}} \\
= & 1-(1-\rho)^{2}
\end{aligned}
$$

\footnotetext{
${ }^{4}$ Os índices $\mathbf{t}$ e $\mathbf{x y}$ dos colchetes \langle\rangle são referentes a médias temporais ou espaciais.
} 
A expressão 2.32 mostra que a partir da média espacial do contraste temporal a proporção dos espalhadores móveis no padrão resultante pode ser estimada. Isolando o parâmetro $\rho$, obtemos:

$$
\rho=1-\left[1-\frac{\left\langle\sigma_{t}^{2}(x, y)\right\rangle_{x y}}{\left\langle I_{t}\right\rangle_{x y}^{2}}\right]^{\frac{1}{2}}
$$

Comparando-se 2.33 com a abordagem feita na seção 2.1.2, nota-se que a diferença reside no fato de que, aqui, o índice $\rho$ incorpora informações sobre a variação temporal do padrão, enquanto antes apenas variações espaciais foram consideradas. Esse resultado será de particular importância na análise do método exposto na seção 3.4.

\subsection{Estatística de Segunda Ordem}

\subsubsection{A função de autocorrelação e a densidade espectral de po- tência}

A análise de correlação é uma maneira de se comparar dois sinais a fim de se estabelecer o grau de similaridade entre eles. Na autocorrelação um determinado sinal é comparado consigo mesmo em pontos ou instantes distintos com objetivo de se avaliar o comportamento de sua evolução no espaço ou no tempo. A estatística de segunda ordem de padrões speckle tem grande analogia com os métodos de análise normalmente empregados na espectroscopia de batimento de luz [22] e com os clássicos experimentos de detecção heterodina e homodina de fotocorrente, empreendidos por Forrester, Gudmundsen e Johnson [23]. Algumas referências básicas podem ser encontradas nos trabalhos de Anisimov[8] e Goldfischer[21], que introduziram a função de autocorrelação no estudo de padrões speckle, especialmente ligada à estatística espacial. No entanto, nosso interesse aqui está focado na estatística temporal, de modo que seguiremos a abordagem dada por Cummins [22]. Além disso, boa parte da teoria apresentada aqui pode ser encontrada no texto de Hecht [10]. 
Sejam definidas uma função $A(t)$ e sua respectiva transformada de Fourier:

$$
\left\{\begin{array}{l}
A(t) \\
\mathcal{A}(\omega)=\mathfrak{F}\{A(t)\}
\end{array}\right.
$$

A transformada de Fourier representa o espectro de frequências de $A(t)$. Seguindo esse raciocínio, $|\mathcal{A}(\omega)|$ funciona como uma densidade de amplitudes espectrais e $|\mathcal{A}(\omega)|^{2}$ é proporcional à energia por unidade de frequência. De forma análoga, $|A(t)|^{2}$ é proporcional à radiância e a energia total emitida é dada por $\int_{-\infty}^{\infty}|A(t)|^{2} d t$. Calculando-se a integral em termos da transformada de Fourier, temos:

$$
\begin{gathered}
|A(t)|^{2}=A(t) A^{*}(t)=A(t)\left[\mathfrak{F}^{-1}\{\mathcal{A}(\omega)\}\right]^{*} \\
\int_{-\infty}^{\infty}|A(t)|^{2} d t=\int_{-\infty}^{\infty} A(t)\left[\frac{1}{2 \pi} \int_{-\infty}^{\infty} \mathcal{A}^{*}(\omega) \exp \{i \omega t\} d \omega\right] d t \\
=\frac{1}{2 \pi} \int_{-\infty}^{\infty} \mathcal{A}^{*}(\omega)\left[\int_{-\infty}^{\infty} A(t) \exp \{i \omega t\} d t\right] d \omega \\
\Rightarrow \frac{1}{2 \pi} \int_{-\infty}^{\infty}|\mathcal{A}(\omega)|^{2} d \omega
\end{gathered}
$$

A expressão obtida em 2.34 corresponde à identidade de Paserval. Essa relação implica no fato de que a energia espectral total é proporcional à área sob a curva de $|\mathcal{A}(\omega)|^{2}$ e, por isso, esse termo é comumente referido na literatura como densidade espectral de potência ou ainda distribuição espectral de energia:

$$
\mathcal{P}(\omega)=|\mathcal{A}(\omega)|^{2}
$$

Definamos agora a função de autocorrelação. Vamos avaliar o grau de similaridade de uma função $A(t)$ com ela mesma em outro instante (ou ponto) arbitrário $t+\tau$, onde $\tau$ é conhecido como $l a g^{5}$. Nosso objetivo aqui é calcular $\int_{-\infty}^{\infty} A(t+\tau) A^{*}(t) d t$ em temos da transformada de Fourier de $A(t)$ :

$$
\int_{-\infty}^{\infty} A(t+\tau) A^{*}(t) d t=\int_{-\infty}^{\infty} A(t+\tau)\left[\frac{1}{2 \pi} \int_{-\infty}^{\infty} \mathcal{A}^{*}(\omega) \exp \{i \omega t\} d \omega\right] d t
$$

\footnotetext{
${ }^{5}$ Defasagem, tempo de atraso.
} 
Mudando a ordem de integração no último termo do lado direito, chegamos a:

$$
\begin{aligned}
\frac{1}{2 \pi} \int_{-\infty}^{\infty} \mathcal{A}^{*}(\omega) & {\left[\int_{-\infty}^{\infty} \mathcal{A}(t+\tau) \exp \{i \omega t\} d t\right] d \omega=} \\
& \Rightarrow \frac{1}{2 \pi} \int_{-\infty}^{\infty} \mathcal{A}^{*}(\omega) \mathfrak{F}\{\mathcal{A}(t+\tau)\} d \omega
\end{aligned}
$$

Usando a relação $\mathfrak{F}\{A(t+\tau)\}=\mathcal{A}(\omega) \exp \{-i \omega \tau\}$, temos:

$$
\int_{-\infty}^{\infty} A(t+\tau) A^{*}(t) d t=\frac{1}{2 \pi} \int_{-\infty}^{\infty} \mathcal{A}^{*}(\omega) \mathcal{A}(\omega) \exp \{-i \omega \tau\} d \omega
$$

O lado esquerdo desta expressão é definido como a função de autocorrelação de $A(t)$, denotada por:

$$
\gamma(\tau)=\int_{-\infty}^{\infty} A(t+\tau) A^{*}(t) d t
$$

A comparação de 2.39 com 2.35 nos leva a perceber que estas duas expressões estão intimamente relacionadas, formando um par de transformadas de Fourier [22].

$$
\mathcal{P}(\omega)=\frac{1}{2 \pi} \int_{-\infty}^{\infty} \gamma(\tau) \exp \{i \omega \tau\} d \tau
$$

Esta relação entre a função de autocorrelação e a densidade espectral de potência é uma forma do teorema de Wiener-Khintchine ${ }^{6}$ [13], de modo que, muitas vezes, a densidade espectral de potência também é conhecida como espectro de Wiener.

Em ambiente de laboratório, medimos um conjunto de intensidades, espacialmente distribuídas, em vários instantes sucessivos. Esse fato torna conveniente a definição da função de autocorrelação em termos de valores de intensidade. Por outro lado, é interessante trabalhar-se com esta função normalizada, de modo que 2.39 é reescrita como [20]:

$$
\gamma(\tau)=\frac{\langle I(t) I(t+\tau)\rangle_{x y}}{\langle I(t)\rangle_{x y}^{2}}
$$

As considerações acima foram realizadas com enfoque na estatística temporal de segunda ordem. Esse procedimento se deve ao fato do interesse desta dissertação ser o monitoramento da evolução temporal do biospeckle. No entanto, as idéias fundamentais

\footnotetext{
${ }^{6}$ vide apêndice $\mathrm{A}$
} 
de autocorrelação e o formalismo utilizado na descrição temporal também se aplicam à estatística espacial de padrões speckle. Nesse último caso, a função de autocorrelação nos fornece informações a respeito dos tamanhos dos grãos e a densidade espectral de potência é obtida no domínio das frequências espaciais. Ou seja, a partir da autocorrelação é possível conhecer-se os tamanhos dos grãos e, a partir de sua densidade espectral, as ocorrências desses tamanhos.

A estatística espacial de primeira ordem torna possível, a partir do cálculo da média e da variância das intensidades, uma medida do contraste do padrão. Já a estatística espacial de segunda ordem fornece informações a respeito do tamanho dos grãos. De maneira semelhante, a estatística temporal de primeira ordem (seção 2.1.2) nos permite conhecer a respeito da proporção entre espalhadores móveis e estáticos, enquanto a estatística temporal de segunda ordem fornece informações acerca da distribuição de velocidades desses espalhadores.

\subsubsection{Coeficiente de correlação}

A partir da função de autocorrelação também pode ser definido um coeficiente de correlação. Esse coeficiente corresponde a uma medida numérica do grau de semelhança do padrão speckle consigo mesmo em um instante (ou região) diferente e, em vias gerais, pode ser definido como [24]:

$$
\mu_{t_{0}, t}=\frac{\sum_{j=1}^{N}\left(I_{\left(t_{0}, j\right)}-\left\langle I_{\left(t_{0}, j\right)}\right\rangle\right)\left(I_{(t, j)}-\left\langle I_{(t, j)}\right\rangle\right)}{\sqrt{\sum_{j=1}^{N}\left(I_{\left(t_{0}, j\right)}-\left\langle I_{\left(t_{0}, j\right)}\right\rangle\right)^{2} \sum_{j=1}^{N}\left(I_{(t, j)}-\left\langle I_{(t, j)}\right\rangle\right)^{2}}}
$$

Onde $\mathrm{N}$ corresponde ao número total de valores de intensidades e $\mathrm{t}$ aos instantes de amostragem. Um espécime com baixo nível de atividade, tende a apresentar poucas variações no padrão espalhado ao longo do tempo (ou variações mais lentas), enquanto aqueles mais ativos apresentam grandes variações de intensidades no speckle resultante. Tais fatos implicam na queda mais acentuada do valor do coeficiente de correlação no segundo caso, fazendo desse coeficiente um índice de atividade da amostra. 


\subsection{Conexão entre as estatísticas espacial e temporal}

Em um sistema de aquisição real, como a câmera digital utilizada neste trabalho, o registro das intensidades necessita de um tempo de integração. Dessa forma, o valor de intensidade em determinado pixel do sensor CCD corresponde à energia média a qual o dispositivo foi exposto durante um intervalo de tempo. Quando a superfície espalhadora é estática, esse fato não interfere de maneira significativa no padrão resultante ${ }^{7}$, todavia, no caso em que os centros espalhadores são móveis, o contraste final apresenta dependência desse parâmetro.

A relação entre o tempo de integração e o contraste do speckle é extremamente complexa e seu tratamento detalhado não faz parte do escopo desta dissertação. Entretanto, é possível estabelecer uma ligação entre a estatística espacial de primeira ordem e a estatística temporal de segunda ordem do granulado óptico, permitindo que, através da análise do contraste espacial, sejam obtidas informações a respeito das variações temporais das intensidades. De acordo com Goodman [25], a variância espacial das intensidades é igual ao valor médio da autocovariância de suas flutuações temporais:

$$
\sigma_{s}^{2}(T)=\frac{1}{T} \int_{0}^{T} C_{t}(\tau) d \tau
$$

Onde T é o tempo de integração do dispositivo e $C_{t}(\tau)$ é a autocovariância central das flutuações temporais da intensidade:

$$
C_{t}(\tau)=\langle\{I(t)-\langle I\rangle\}\{I(t+\tau)-\langle I\rangle\}\rangle_{t}
$$

A quantidade no lado esquerdo de 2.43 representa a estatística espacial de primeira ordem, enquanto seu lado direito representa a estatística temporal de segunda ordem. Quando registramos apenas uma imagem do padrão speckle, trabalhamos, essencialmente, com a análise do lado esquerdo da expressão e, quando é feito um registro sucessivo de imagens, abrimos possibilidades de explorar o lado direito. No próximo capítulo serão expostas, de forma mais detalhada, as vantagens e desvantagens de cada análise na extração de informações do biospeckle.

\footnotetext{
${ }^{7}$ Exceto, talvez, pelo ruído inerente ao sistema eletrônico de aquisição. Todavia, esse ruído também representa um problema no caso de superfície dinâmica.
} 


\section{Capítulo 3}

\section{Métodos de análise do biospeckle}

Este capítulo é dedicado ao estudo dos principais métodos de análise do biospeckle, sendo quatro deles destinados ao plano de Fraunhoffer e quatro ao plano imagem. A grande maioria está baseada em conceitos expostos no capítulo anterior. Na geometria de espaço-livre, uma ferramenta bastante útil é a construção de um THSP (Time History Speckle Pattern), uma figura bidimensional que codifica informações espaciais e temporais das intensidades. Na geometria imagem, uma coleção de fotografias da superfície em estudo é registrada e, a partir de comparações ou subtrações entre as imagens, um mapa final é construído identificando as regiões mais ativas. Veremos que também é possível a construção desse mapa a partir da análise de contraste de um único registro fotográfico. Por fim, propomos um método original baseado no contraste temporal da correlação como estimador da atividade registrada em um THSP.

\subsection{História Temporal de Padrões Speckle}

Conforme discutido na seção 1.2, o biospeckle é caracterizado principalmente por flutuações temporais das intensidades. Uma maneira de se realizar o monitoramento dessas flutuações consiste no levantamento de um gráfico da intensidade em um ponto do plano de observação ao longo do tempo. Na introdução deste trabalho foram apresentados dois gráficos expondo os valores de intensidade de um pixel em espalhamentos a partir de superfície estática e superfície biológica (figura 2). Entretanto, uma modelagem mais fidedigna do biospeckle consiste em representá-lo como uma superposição de um padrão 
estático oriundo da superfície e um padrão dinâmico espalhado a partir de camadas mais profundas do tecido. Nesse caso, de acordo com o que foi observado na seção 2.2, as flutuações de intensidade apresentam dependência em relação à posição no plano de observação. Esse fato implica na necessidade de preservamos também alguma informação espacial do biospeckle que nos permita a realização de uma média sobre um conjunto de pontos.

Um método bastante elegante para visualização da evolução temporal de padrões speckle observados no plano de Fraunhoffer, e que paralelamente preserva as informações espaciais, foi proposto por Oulamara et al [33]. De acordo com este método, um registro da história temporal é feito em uma imagem bidimensional denominada THSP (Time History Speckle Pattern $)^{1}$. Essa imagem consiste na gravação de uma fileira de pixels em instantes sucessivos e na posterior colagem em uma única imagem. Dessa maneira, a primeira linha do THSP corresponde à linha registrada no primeiro instante. A segunda linha corresponde à mesma fila de pixels registrada no segundo instante e assim sucessivamente até compor uma nova imagem na qual fica registrada a evolução temporal de uma fila do padrão ${ }^{2}$. Na direção horizontal fica registrado um conjunto de pixels que correspondem à distribuição espacial do padrão e na direção vertical, a evolução temporal destes pixels ao longo dos instantes sucessivos. A figura 3.1 exibe de forma ilustrativa o processo de construção do THSP. A fila central de pixels foi escolhida (de forma arbitrária) como representante do padrão. Para facilitar a visualização, houve exagero nas dimensões da fila.

Na figura 3.2 são mostrados dois THSPs construídos com padrões speckle espalhados, respectivamente, a partir de uma superfície estática e de uma região recém pintada. O padrão estático apresenta pequenas variações de intensidade, de modo que o nível de cinza de cada pixel varia muito pouco ao longo do tempo (direção vertical). Por outro lado, no processo de secagem de tinta [34], percebe-se uma alta atividade no início, com a evaporação do solvente, e rápidas variações nas intensidades dos pixels. À medida em a tinta seca, tais variações tornam-se mais lentas e o THSP tende a apresentar barras

\footnotetext{
${ }^{1}$ Eventualmente o THSP também é designado como STS: Space-Time Speckle.

${ }^{2}$ Neste trabalho usamos filas com 480 pixels, registradas durante 480 instantes sucessivos. Portanto, os THSP finais possuiam $480 \times 480$ pixels.
} 


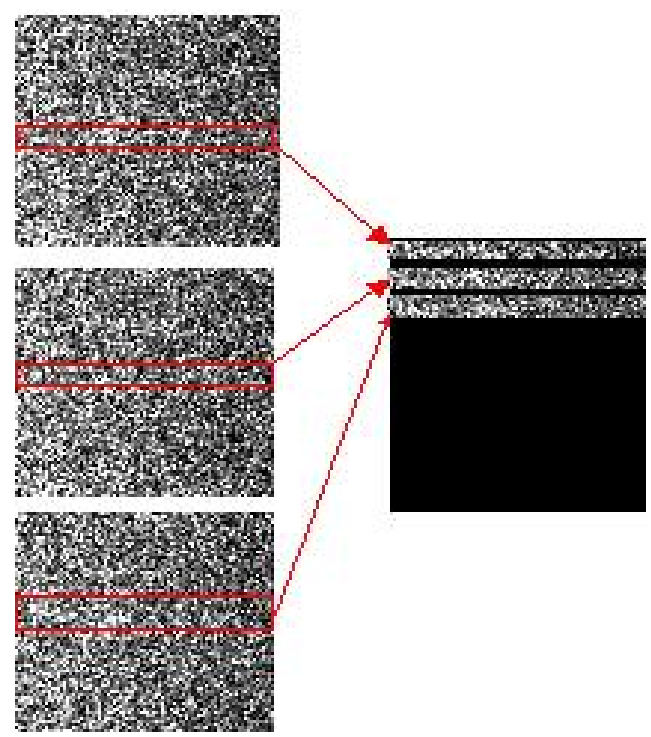

Figura 3.1: Construção do THSP: A fila central é registrada em instantes sucessivos e colada em uma imagem 2D.

verticais paralelas, tais como as vistas na situação de superfície estática. Assim, a simples observação do THSP permite uma análise qualitativa da evolução temporal da superfície. No entanto, na maior parte das situações práticas, há necessidade de valores quantitativos e, para isso, é necessário lançar mão das técnicas explicadas a seguir.

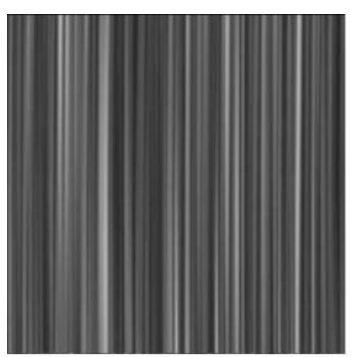

(a)

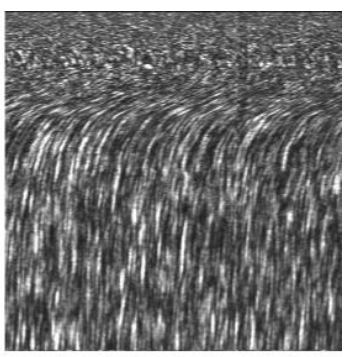

(b)

Figura 3.2: THSP de (a) uma superfície estática e (b)processo de secagem de tintas.

\subsection{Função de Autocorrelação e Densidade Espectral de Potência}

A função de autocorrelação é um dos métodos mais tradicionais na avaliação de atividade do biospeckle. O procedimento de análise consiste na avaliação da autocorrelação 
espaço-temporal das linhas do THSP e o algoritmo de cálculo é baseado na equação 2.41 . De igual maneira, a densidade espectral de potência também consiste numa ferramenta de estudo das variações do biospeckle, pois, conforme explicitado anteriormente, o espectro de Wiener permite estabelecer a distribuição das velocidades dos centros espalhadores.

Introduzimos aqui o comprimento de correlação eficaz $\tau_{c}$ como o tempo que a função de autocorrelação normalizada leva para assumir o valor $1 / \sqrt{2} \approx 0,71$. O critério de "valor eficaz" é frequentemente utilizado em vários ramos das engenharias, especialmente em sitemas eletro-eletrônicos [35]. Usamos esse valor como estimativa do comprimento de correlação ${ }^{3}$. Assim, quanto maior o valor de $\tau_{c}$, maior o comprimento de correlação e, portanto, as variações nas intensidades são mais lentas. De maneira semelhante, comprimentos de correlação mais curtos representam variações mais rápidas e maior atividade.

No espectro de potência, frequências maiores correspondem a velocidades mais elevadas. A potência média e a frequência média são dois parâmetros usuais na caracterização do espectro de flutuações das intensidades. A frequência média pode ser associada, com relativa aproximação, ao movimento dos espalhadores sobre um comprimento de onda e fornece uma estimativa grosseira da velocidade média das partículas no tecido. A título de exemplo, suponhamos que a frequência média do espectro de Wiener associado a um tecido seja da ordem de um Hertz. Isso significa que, em média, as partículas espalhadoras do tecido percorrem uma distância equivalente a um comprimento de onda da fonte usada na iluminação a cada segundo. Vale ressaltar que essa é uma estimativa relativamente grosseira, pois há uma forte dependência, entre outras $\operatorname{coisas}^{4}$, da distribuição de velocidades dos centros espalhadores.

Outros critérios usados na caracterização da função de autocorrelação são os tempos demandados para que seu valor máximo decaia a $50 \%$ ou $1 / e$ [36]. No entanto, neste trabalho, usamos apenas o "valor eficaz" acima definido.

\footnotetext{
${ }^{3} \mathrm{O}$ conceito de "valor eficaz" é usado aqui em um contexto distinto daquele empregado em engenharia. Normalmente, esse conceito caracteriza sinais periódicos, não sendo este o caso neste trabalho.

${ }^{4}$ Podemos citar, por exemplo, componentes de alta frequência associadas ao ruído eletrônico da instrumentação, frequências cardio-respiratórias no caso de animais, etc.
} 


\subsection{Matrizes de Co-Ocorrências}

O método das matrizes de co-ocorrências, desenvolvido por Arizaga et al [37], é baseado em uma técnica de mesmo nome largamente empregada na análise de texturas em processamento de imagens digitais [38].

A matriz de co-ocorrência é computada sobre o THSP, sendo definida como:

$$
M C O=\left[N_{i j}\right]
$$

O valor $N_{i j}$ corresponde ao número de vezes que o valor de intensidade $\mathbf{i}$ é imediatamente seguido pelo valor de intensidade $\mathbf{j}$ na direção e sentido da evolução temporal (em nosso caso, a vertical para baixo). A ordem da matriz $\mathrm{MCO}$ equivale ao número de tons de cinza do sistema de aquisição utilizado. Neste trabalho, a resolução usada foi de 8 bits e, portanto, as matrizes de co-ocorrência obtidas foram de 256 x 256 .

Quando a superfície espalhadora é estática, isto é, o THSP praticamente não apresenta variações de intensidade ao longo do tempo (figura 3.2(a), por exemplo), apenas a diagonal principal contém valores não nulos de ocorrências. Por outro lado, quando o THSP apresenta grande atividade (figura 3.2(b)), os elementos não nulos se espalham ao redor da diagonal principal. Assim, quanto mais ativa a amostra, mais dispersos em torno da diagonal se distribuem os pontos e vice-versa.

A título de exemplo, imagine-se uma situação em que a codificação dos tons de cinza seja realizada com apenas 2 bits, resultando em uma resolução de 4 tons de cinza. Na figura 3.3, temos essa representação ilustrando um caso de espalhamento por superfície estática e outro por superfície dinâmica. As imagens mais à esquerda correspondem aos THSPs hipotéticos. Na sequência, temos as respectivas matrizes numéricas com os níveis de intensidade desses THSPs e, logo em seguida, as matrizes de co-ocorrências onde cada elemento traz o número de vezes que o nível de cinza "i" foi seguido do nível de cinza "j". Por fim, à direita, têm-se as imagens das MCOs, onde o valores nulos são representados por pixels pretos e os valores não-nulos, por pixels brancos.

A figura 3.4 apresenta uma sequência de THSPs com as respectivas matrizes de coocorrências. Em 3.4(a) temos a situação gerada a partir do espalhamento de luz por uma 


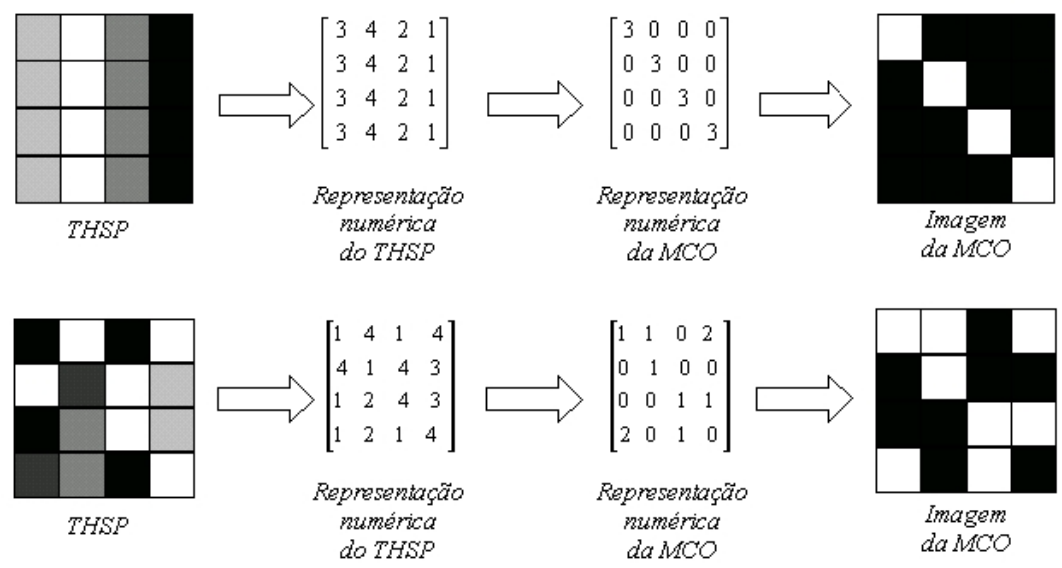

Figura 3.3: Exemplo didático para cálculo das matrizes de co-ocorrêncis de THSPs estático (acima) e dinâmico (abaixo).

superfície praticamente inativa, 3.4(d) está associada a uma superfície com elevado grau de atividade, enquanto as figuras 3.4(b) e 3.4(c) correspondem a níveis intermediários.

Para propósitos de cálculos, em geral, é mais conveniente o uso de uma forma modificada da equação $3.1^{5}$ :

$$
M_{i j}=\frac{N_{i j}}{\sum_{j} N_{i j}}
$$

A matriz modificada em 3.2 corresponde à normalização daquela obtida em 3.1, com a soma dos elementos de cada linha sendo igual a 1. Uma maneira de se quantificar a medida da dispersão dos pontos em torno da diagonal é através do cálculo do "momento de inércia" da matriz:

$$
M I=\sum_{i j} M_{i j}(i-j)^{2}
$$

A forma assumida pelo índice calculado em 3.3 tem grande analogia com o momento de inércia conhecido na Mecânica. Por isso, esse índice também recebe o nome de momento de intensidades. Esse indicador também é análogo à função estrutura utilizada na espectroscopia de foto-correlação, sendo aqui calculado em unidades arbitrárias. A tabela 3.1 apresenta os respectivos momentos de intensidades das matrizes mostradas na figura 3.4 .

\footnotetext{
${ }^{5}$ Esta conveniência advém do fato dos valores numéricos se tornarem muito elevados quando não se
} faz a normalização. 


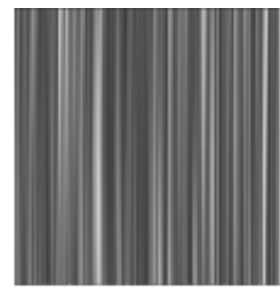

(a)
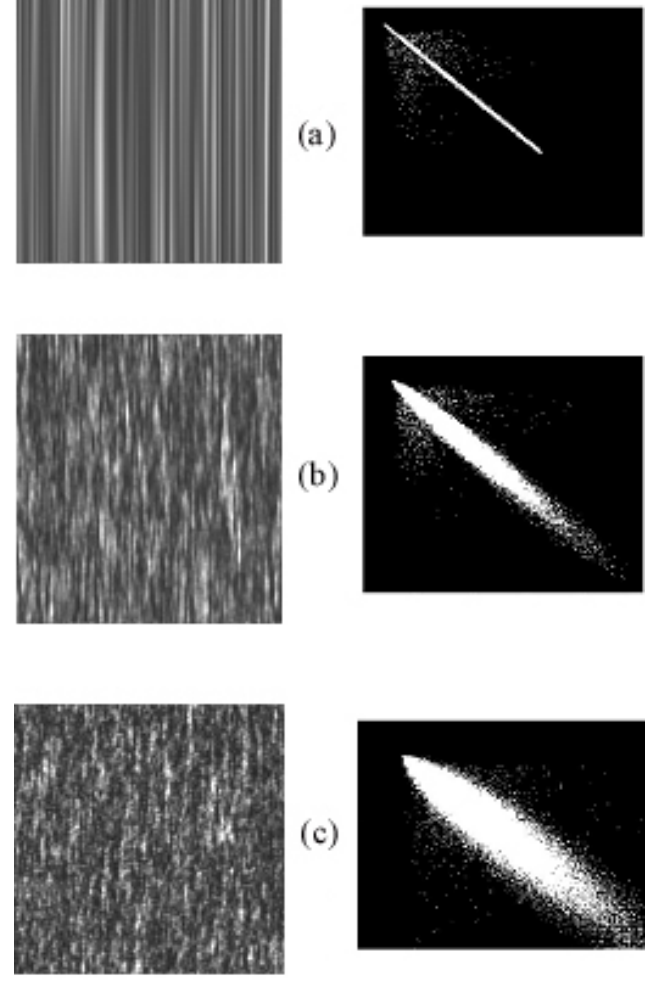

(c)
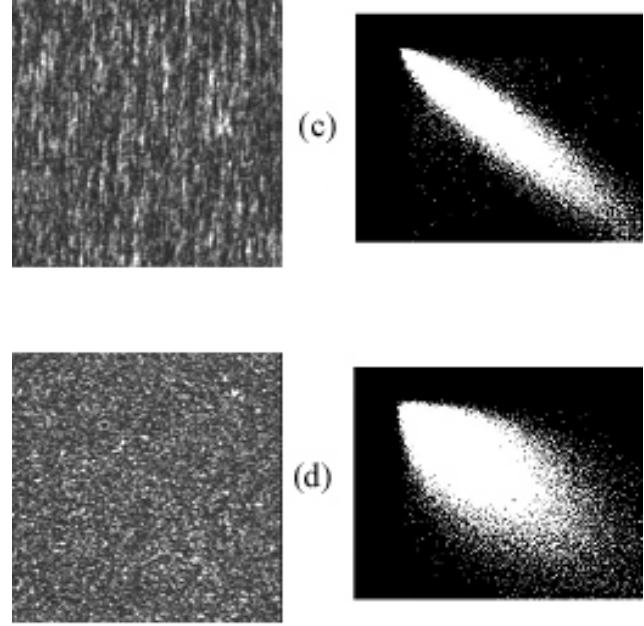

(d)

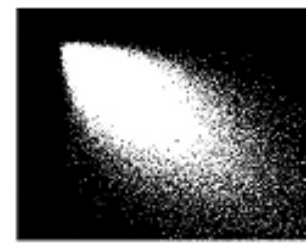

Figura 3.4: THSPs e respectivas matrizes de co-ocorrências.

Tabela 3.1: Momentos de intensidades das MCOs da figura 3.4 (unidades arbitrárias).

\begin{tabular}{cc}
\hline Matriz & MI \\
\hline (a) & 5,3 \\
\hline (b) & 11,8 \\
\hline (c) & 65,4 \\
\hline (d) & 325,7 \\
\hline
\end{tabular}

\subsection{O Contraste de Briers}

Na seção 2.2 foi estudado o caso da superposição de uma componente estática e outra dinâmica em um padrão speckle completamente desenvolvido. Foi deduzida uma expressão (2.32) que, na ocasião, correspondia a uma espécie de contraste temporal das intensidades. 
O objetivo agora é mostrar uma aplicação prática para esse raciocínio teórico e estabelecer um índice útil para análise do biospeckle [19].

Da mesma forma considerada anteriormente (seção 2.2), seja o biospeckle resultante em um plano de observação composto por uma mistura de dois padrões com origem em espalhadores estáticos e móveis. As intensidades médias são dadas respectivamente por $\left\langle I_{E}\right\rangle$ e $\left\langle I_{M}\right\rangle$. A componente estática não apresenta variações temporais, de modo que os valores instantâneos de intensidades são iguais à sua média temporal, ou seja:

$$
I_{E}(x, y)=\left\langle I_{E}(x, y)\right\rangle_{t}
$$

A componente dinâmica, porém, não apresenta esse mesmo comportamento. Isto quer dizer, por exemplo, que se tivermos uma coleção de imagens sucessivas de um padrão dinâmico (supondo-se que seja possível fotografar somente a componente móvel), ao realizarmos a média de todas essas imagens o padrão resultante será uniforme. Por outro lado, se tivermos uma coleção de fotografias apenas da componente estática, a imagem média final será idêntica às imagens da coleção. A figura 3.5 ilustra esse fato. Nela são apresentadas imagens instantâneas de um padrão estático e de um dinâmico, com as respectivas imagens médias. As figuras 3.5(a) e 3.5(c) são praticamente idênticas, confirmando a dedução feita em 3.4. Já as figuras 3.5(b) e 3.5(d) apresentam diferenças significativas e a média temporal dos padrões dinâmicos tende a um fundo uniforme. A análise do contraste dessas imagens também revela importantes diferenças: enquanto na imagem 3.5(c) o contraste é de 0.75 , na imagem 3.5(d) esse valor cai para 0.07 .

Por razões de ergoticidade, considerando-se que as intensidades da componente móvel variam aleatoriamente e assumem todos os valores possíveis ao longo do tempo ${ }^{6}$, temos:

$$
\left\langle I_{M}(x, y)\right\rangle_{t}=\left\langle I_{M}(t)\right\rangle_{x y}
$$

A expressão 3.5 confirma o resultado observado na figura 3.5(d), estabelecendo uma conexão entre as médias temporal e espacial da componente dinâmica. Isso implica em

\footnotetext{
${ }^{6} \mathrm{Ou}$ seja, admitimos que o tempo de integração do sistema de registro é suficientemente grande para que a partícula espalhadora mais lenta percorra pelo menos um comprimento de onda entre um registro e outro.
} 


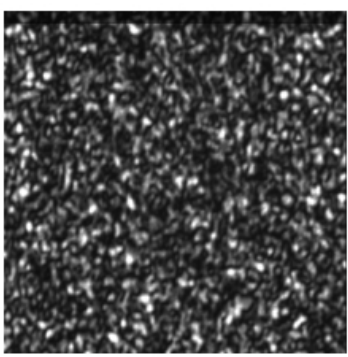

(a)

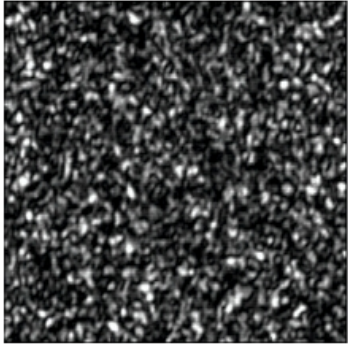

(c)

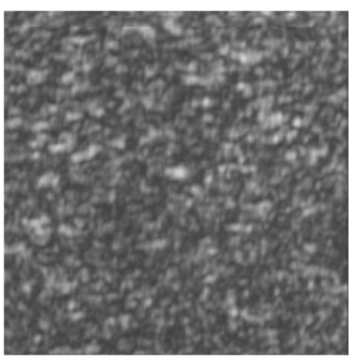

(b)

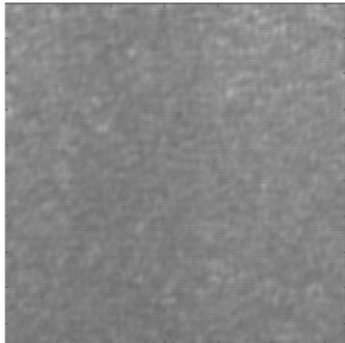

(d)

Figura 3.5: Fotografias instantâneas de (a) um padrão estático e (b) um padrão dinâmico e imagens médias de (c) padrões estáticos e (d) padrões dinâmicos.

que, a partir do estudo da média das intensidades espaciais em um dado instante, é possível obter informações a respeito da média das intensidades ao longo do tempo. Definindo-se agora o índice $\rho$ como uma relação entre a intensidade média da componente móvel e a intensidade total média, temos:

$$
\rho=\frac{\left\langle I_{M}(t)\right\rangle_{x y}}{\left\langle I_{M}(t)\right\rangle_{x y}+\left\langle I_{E}\right\rangle_{x y}}
$$

Seguindo o mesmo raciocínio adotado na seção 2.2, podemos escrever:

$$
\frac{\left\langle\sigma_{t}^{2}(x, y)\right\rangle_{x y}}{\left\langle I_{t}\right\rangle_{x y}^{2}}=1-(1-\rho)^{2}
$$

Ou seja, assumindo-se que os espalhadores estáticos e móveis possuem propriedades de espalhamento idênticas e que somente esses dois tipos de estrutura são responsáveis pela formação do biospeckle registrado, através da análise do contraste de uma única imagem instantânea é possível, teoricamente, estabelecer a proporção entre os centros móveis e estáticos. O lado esquerdo da equação 3.6 é conhecido como contraste de Briers, devido ao nome do autor que o deduziu [20]. Na prática, entretanto, é muito difícil verificar se esse índice de atividade é válido, pois não é possível conhecer com precisão, 
por outros métodos, as proporções de partículas estáticas e móveis em um tecido biológico, o que permitiria estabelecer um comparativo. Todavia, o modelo numérico apresentado no próximo capítulo possibilita um estudo mais abrangente dessa teoria, sugerindo a validade do contraste de Briers como estimador da proporção de espalhadores móveis em tecidos.

\subsection{Métodos de Fujii e Diferenças Generalizadas}

O método de Fujii [39] baseia-se no cálculo da visibilidade [10] entre os pixels de imagens gravadas ao longo do tempo. Matematicamente, o procedimento para a construção do mapa de Fujii é descrito por:

$$
I(x, y)=\sum_{k=1}^{N-1}\left|\frac{I_{k+1}(x, y)-I_{k}(x, y)}{I_{k+1}(x, y)+I_{k}(x, y)}\right|
$$

Onde $\mathrm{N}$ corresponde ao total de imagens gravadas e $I_{k}(x, y)$, ao valor de intensidade na posição $(\mathrm{x}, \mathrm{y})$ na imagem $\mathrm{k}$.

A partir do cálculo de 3.7 uma nova imagem é construída. Assim, os pixels de regiões onde não houve alterações de intensidade ao longo do tempo assumem valor nulo no mapa final, enquanto zonas em que os pixels sofreram grandes alterações assumem valores mais altos. Dessa maneira, a imagem resultante apresenta pontos claros nas zonas de grande atividade e pontos escuros naquelas de baixa atividade.

O método das Diferenças Generalizadas (DG) [40] é uma versão mais simplificada do método de Fujii. Nessa técnica, um mapa de atividade é construído a partir das diferenças entre os pixels das imagens gravadas durante o monitoramento. A equação que descreve o método DG é dada por:

$$
I(x, y)=\sum_{k} \sum_{l}\left|I_{k+l}(x, y)-I_{k}(x, y)\right|
$$

Da mesma maneira descrita na metodologia anterior, com as Diferenças Generalizadas as zonas de menor atividade aparecem mais escuras em relação àquelas em que as variações de intensidade foram maiores ao longo do tempo. No entanto, uma distinção significativa entre esse método e o de Fujii reside na sua maior sensibilidade a flutuações na intensidade da fonte. Por exemplo, se entre uma imagem e outra o laser se tornar mais intenso, uma 
região inativa será exibida com um tom mais claro no mapa final. No método de Fujii, devido ao denominador da expressão 3.7, essas eventuais flutuações são compensadas.

\subsection{Análise de Contraste do Laser Speckle: o método $L A S C A$}

Nas aplicações práticas, os métodos de Fujii e DG apresentam o grande inconveniente de exigirem uma coleção relativamente grande de imagens (tipicamente da ordem de centenas de imagens). Esse fato, em geral, não representa grandes dificuldades em trabalhos com espécimes vegetais ou culturas de fungos e bactérias. Todavia, quando o objetivo é o estudo de animais ou seres humanos, o nível de mobilidade é bem maior, tornando complicada a extração de informações de uma determinada região durante períodos de tempo da ordem de segundos ou mesmo minutos. Para contornar esse problema, uma alternativa bastante interessante é a análise de contraste do laser speckle, normalmente referida como LASCA $[41]^{7}$.

Como o próprio nome sugere, o LASCA é baseado no estudo do contraste de um objeto recoberto com o granulado óptico. Conforme visto na seção 2.4, quando um padrão dinâmico é capturado por um sistema com um tempo de integração finito, é natural que a imagem registrada apresente perda de contraste, pois as intensidades são integradas e o valor final exibido corresponde à uma média. Matematicamente, ocorre a diminuição na variância das intensidades e consequente redução no valor do contraste (equação 2.19). Esse fato pode ser observado na figura 3.5(b), onde é mostrada uma fotografia de um padrão dinâmico. Essa imagem apresenta contraste significativamente inferior ao da imagem 3.5(a) que foi registrada a partir do speckle de uma superfície estática. É intuitivo supor ainda que a queda no contraste do padrão speckle seja inversamente proporcional à velocidade dos centros espalhadores, ou seja, quanto mais rápidas as partículas do espécime, menor o contraste da imagem registrada.

A idéia básica do método LASCA consiste em dividir os pixels do registro fotográfico em células quadradas e calcular o contraste em seu interior. Em seguida, esses valores

\footnotetext{
${ }^{7}$ LASCA é um acrônimo do inglês: Laser Speckle Contrast Analysis.
} 
são atribuídos aos pixels centrais das células correspondentes e uma nova imagem é construída, formando um mapa de contrastes. Nas regiões de maior velocidade das partículas, o valor de contraste é mais baixo e estas zonas aparecem mais escuras no mapa final. Por outro lado, em locais de menor circulação, o contraste é maior e estes locais aparecem mais claros. A figura 3.6 mostra de maneira esquemática esse processo.

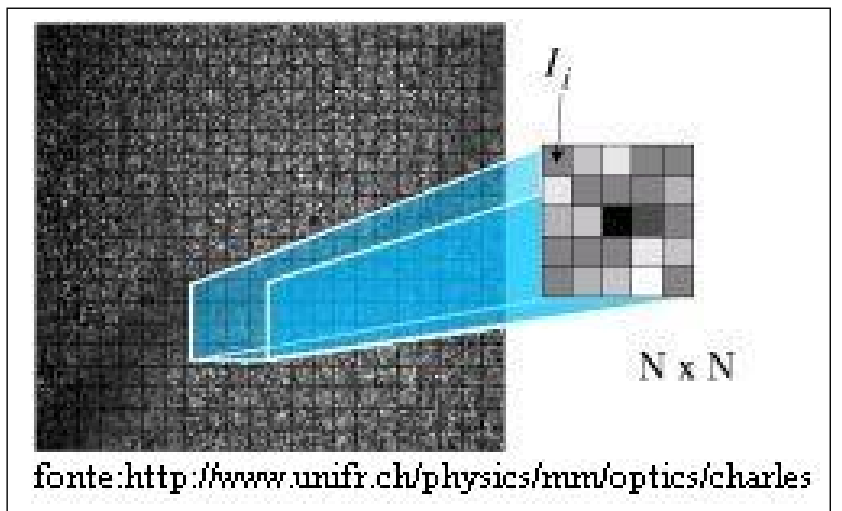

Figura 3.6: Diagrama esquemático da construção de um mapa tipo LASCA.

A grande vantagem do LASCA reside no fato dele requerer, pelo menos à princípio, apenas um registro fotográfico, realizado durante o tempo de integração da câmera CCD. Em geral, organismos animais se movem muito pouco durante esse intervalo de tempo ${ }^{8}$, minimizando os efeitos da repiração, da frequência cardíaca ou da locomoção. Entretanto, quando é realizada uma média de diversos mapas, construídos a partir de fotografias registradas sucessivamente, ocorre melhora na visualização das diferentes zonas de atividade devido ao aumento na relação sinal-ruído [42].

Por outro lado, a grande desvantagem do método está na perda de resolução espacial que lhe é inerente. Tipicamente, a imagem original é dividida em células de $5 \times 5$ a $7 \times 7$ pixels. Células menores comprometem a confiabilidade estatística do contraste e células maiores implicam em maior perda de resolução [46]. Assim, por exemplo, se o registro é feito com resolução de $640 \times 480$ e a célula utilizada é de $5 \times 5$, o mapa de contrastes possui resolução de $128 \times 96$. Ou seja, a resolução espacial da imagem cai a $\frac{1}{5}$ da resolução original. Na figura 3.7 está ilustrado esse processo. Quando trabalhamos com células de $3 \times 3$ a resolução cai para $2 \times 2$ e quando a célula utilizada possui $6 \times 6$ a estatística do processo é

\footnotetext{
${ }^{8} \mathrm{O}$ dispositivo $\mathrm{CCD}$ utilizado em nosso trabalho possuía tempos de integração entre $\frac{1}{10000}$ e $\frac{1}{60}$ segundos.
} 
melhorada, porém, a resolução é completamente perdida. Outra desvantagem do LASCA reside na contaminação do mapa pelo ruído espacial. Como vimos antes, o biospeckle é composto por uma mistura de um padrão estático e outro dinâmico. Para avaliação da atividade interessa apenas a componente dinâmica, contudo na imagem LASCA os valores de contraste da componente estática também influenciam no contraste final. Na próxima seção, apresentamos um método que contorna esse problema.

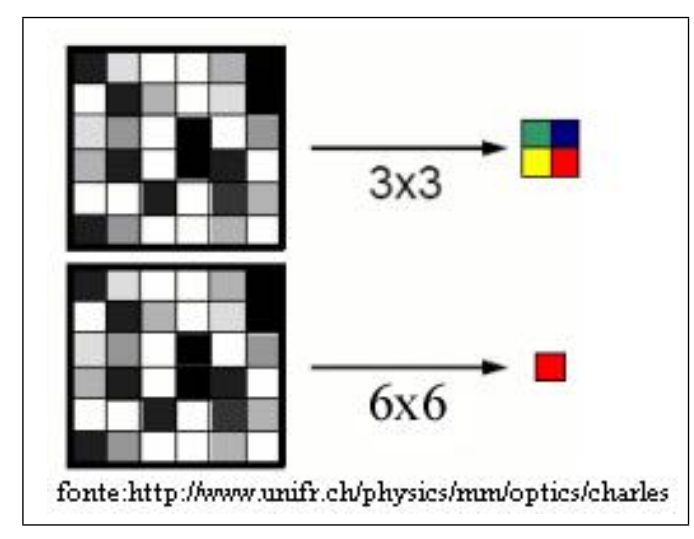

Figura 3.7: Perda de resolução com uso do LASCA.

Assim como nas demais técnicas de mapeamento, através do método LASCA são verificadas as zonas de atividade no tecido biológico. Várias são as estruturas responsáveis pela atividade em um tecido biológico (seção 1.3), no entanto, em tecidos animais vascularizados, as hemácias em fluxo sangüíneo são os principais espalhadores envolvidos nesse processo. A interpretação quantitativa de mapas LASCA é extremamente difícil, pois o sistema sob análise é bastante complexo, com luz espalhada a partir das diversas camadas do tecido, além do fluxo nos capilares. Vários modelos têm sido testados a fim de explicar tais sistemas, porém as simplificações utilizadas ${ }^{9}$ tornam esses modelos pouco confiáveis. Entretanto, do ponto de vista clínico, a simples visualização qualitativa da distribuição espacial do fluxo sangüíneo constitui-se em uma ferramenta de grande interesse para diagnóstico.

\footnotetext{
${ }^{9}$ Entre as várias simplificações, assume-se, por exemplo, que a distribuição de velocidades dos fluxos é Lorentziana, os fluidos envolvidos são Newtonianos, não ocorrem espalhamentos múltiplos e que nenhuma outra estrutura interfira no espalhamento.
} 


\subsection{Análise de Contraste Temporal do Laser Speckle: o método $L A S T C A$}

O método LASTCA ${ }^{10}$, ou análise de contraste temporal, consiste na construção de um mapa através do cálculo do contraste temporal das intensidades de cada pixel ao longo do tempo (figura 3.8). O valor de cada pixel do mapa é obtido com base na equação [47]:

$$
\begin{gathered}
I(x, y)=\frac{\sigma_{x y}}{\left\langle I_{x y}\right\rangle} \\
\Rightarrow \frac{\sqrt{\frac{1}{N-1}\left\{\sum_{n=1}^{N}\left[I_{x y}(n)-\langle I\rangle_{x y}\right]\right\}}}{\left\langle I_{x y}\right\rangle}
\end{gathered}
$$

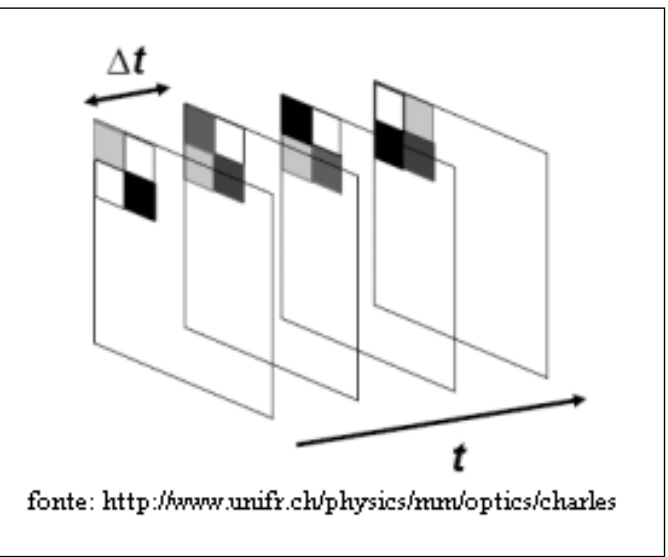

Figura 3.8: A partir das variações de intensidade de cada pixel é construído um mapa com o contraste temporal.

A grande vantagem dessa técnica em relação à anterior reside na sua imunidade ao ruído provocado pelo contraste espacial, pois, como pode ser observado na expressão 3.10, os valores de intensidade no mapa final só dependem das flutuações de intensidade de cada pixel ao longo do tempo. Assim, o contraste espacial não é computado na imagem final. Entretanto, a desvantagem desse método está na necessidade de uma coleção de imagens, o que dificulta ensaios em animais vivos ou seres humanos. Porém, em geral, a quantidade de imagens requerida é algo da ordem de dezenas [47], o que torna esta técnica vantajosa frente ao método de Fujii ou DG estudados na seção 3.5.

\footnotetext{
${ }^{10}$ Acrônimo do inglês: Laser Speckle Temporal Contrast Analysis.
} 


\subsection{Método proposto: Contraste de correlações suces-}

\section{sivas}

Na seção 2.3.2 introduzimos a idéia de coeficiente de correlação. O índice $\mu$ definido na equação 2.42 também pode ser empregado como descritor de atividade em um tecido [49]. De maneira geral, o coeficiente de correlação tem como referência os valores dos pixels do THSP em um determinado instante (na maioria dos casos, o primeiro instante de medida), de forma semelhante ao realizado com a função de autocorrelação vista anteriormente. No entanto, o coeficiente não precisa necessariamente ser calculado dessa maneira. Uma proposta que desenvolvemos ao longo deste trabalho foi realizar a comparação de uma fila de pixels com ela mesma no instante imediatamente posterior, de forma que o coeficiente de correlação se torna:

$$
\mu_{t, t+1}=\frac{\sum_{j=1}^{N}\left(I_{(t, j)}-\left\langle I_{(t, j)}\right\rangle\right)\left(I_{(t+1, j)}-\left\langle I_{(t+1, j)}\right\rangle\right)}{\sqrt{\sum_{j=1}^{N-1}\left(I_{(t, j)}-\left\langle I_{(t, j)}\right\rangle\right)^{2} \sum_{j=1}^{N-1}\left(I_{(t+1, j)}-\left\langle I_{(t+1, j)}\right\rangle\right)^{2}}}
$$

A expressão 3.11 significa que o índice $\mu$ é calculado entre linhas sucessivas da imagem de história temporal.

A fim de avaliar essa metodologia de análise, testamos o comportamento do coeficiente de correlação entre instantes sucessivos em um THSP obtido a partir de uma placa metálica e outro, a partir de uma folha vegetal. Percebemos que para a superfície sem atividade o coeficiente de correlação entre linhas manteve-se constante em torno do valor um. Isto decorre naturalmente do fato das linhas do THSP não variarem significativamente entre instantes sucessivos. Por outro lado, na folha vegetal o valor de correlação decaiu, conforme esperado. Entretanto, um resultado que nos chamou a atenção foram as flutuações mais acentuadas em torno da correlação média. Na figura 3.9 são apresentados esses dois resultados.

Diante desses fatos, pensamos no valor médio da correlação como um possível estimador de atividade. Contudo, estudos mais detalhados apontaram que o valor médio da correlação era pouco sensível a variações de atividade na amostra. Por exemplo, durante um processo de secagem de pinturas era comum uma superfície mais seca apresentar menor nível de correlação comparada a um instante em que se encontrava mais úmida. 


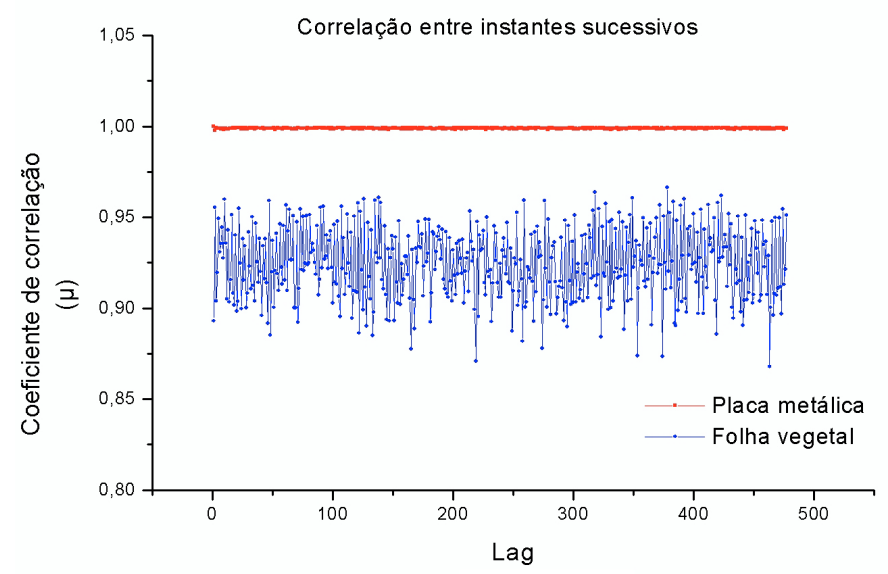

Figura 3.9: Correlação entre instantes sucessivos para uma placa metálica e um espécimen vivo.

Apesar desse contra senso no valor médio, percebemos que as flutuações obedeciam a um padrão regular, decaindo sistematicamente com o decréscimo de atividade. Portanto, inferimos que o contraste dessas flutuações poderia ser utilizado como um índice relativo de atividade. Diante de tais evidências, e inspirados na metodologia desenvolvida na seção 3.4, propomos o contraste das correlações sucessivas como um estimador relativo de atividade do biospeckle. Note-se que este índice, apesar da analogia com o contraste de Briers, não guarda nenhuma relação com ele, sendo calculado em um contexto completamente distinto.

Nos próximos dois capítulos apresentamos os resultados de simulações e ensaios que sugerem a validade de nosso índice. Matematicamente, o contraste da correlação sucessiva pode ser descrito como:

$$
\xi=\frac{\sqrt{\frac{1}{N-1} \sum_{t=1}^{N-1}\left(\mu_{t, t+1}-\langle\mu\rangle\right)_{t}^{2}}}{\langle\mu\rangle_{t}}
$$

Onde N é o número de lags, $\mu_{t, t+1}$ é a correlação entre cada linha e a sucessora dada pela equação 3.11 e $\langle\mu\rangle$ é a correlação média do THSP. 


\section{Capítulo 4}

\section{Simulações}

Devido às complexidades inerentes à dinâmica dos sistemas biológicos e à enorme quantidade de parâmetros que influenciam na bioatividade, é altamente desejável a existência de dados comparativos para validar os métodos de análise propostos anteriormente e fundamentar as interpretações in vivo. O objetivo primário desse capítulo é justamente fornecer tais dados.

Por outro lado, simulações computacionais consistem numa poderosa ferramenta de análise de fenômenos complexos como o biospeckle e, por isso, outro objetivo é a abertura de perspectivas nesse ramo, além da futura construção de modelos teóricos mais complexos que permitam uma descrição mais abrangente do espalhamento de luz por tecidos biológicos, bem como do tipo de informação que o biospeckle é capaz de oferecer. O modelo numérico aqui estudado foi proposto por Rabal et al. [50]. Algumas alterações foram introduzidas a fim de testar hipóteses presentes na literatura a respeito da distribuição de velocidades dos centros espalhadores em tecidos. Foram avaliadas as distribuições uniforme, gaussiana, quadrática e maxwelliana [51, 52].

\subsection{O modelo de Rabal et al.}

Apresentamos a seguir um modelo numérico, proposto por Rabal et al [50], o qual é baseado em uma série de simplificações que obedecem ao modelo de Goodman (seção 2.1). A idéia central dessa proposta consiste na construção de uma fila de centros espalhadores a uma distância D a partir de um detector também linear. Na figura 4.1 exibimos a 
configuração esquemática desse modelo.

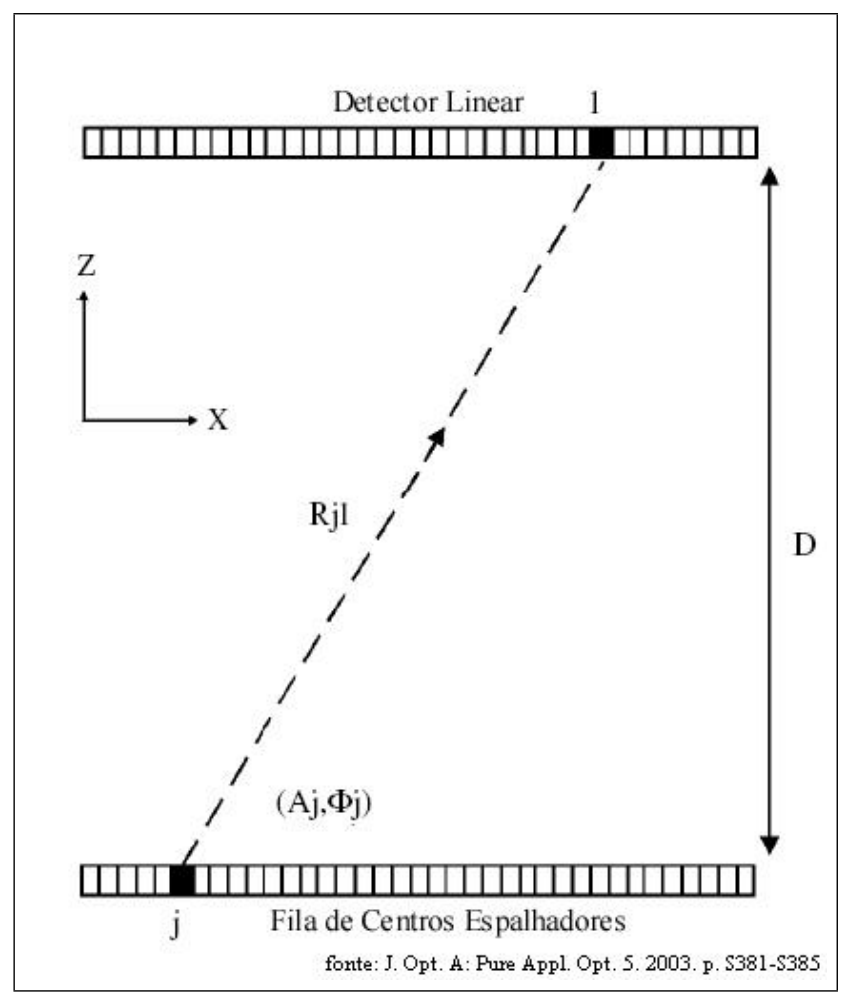

Figura 4.1: Diagrama esquemático do modelo numérico de Rabal et al.

Foram estabelecidos 512 centros espalhadores sobre o difusor e 512 pixels no detector. O campo resultante em cada pixel do detector consiste na superposição dos campos oriundos de todos os centros espalhadores situados no difusor:

$$
U(l)=\sum_{j} \frac{A_{j}}{R_{j l}} \exp \left\{i\left[k R_{j l}+\phi_{j}\right]\right\}
$$

Onde $k=\frac{2 \pi}{\lambda}$ e $R_{i j}$ é a distância entre um centro espalhador (j) e um pixel no detector (1). O fasor $U(l)$ tem fases e amplitudes iniciais uniformemente distribuídas nos intervalos $[-\pi, \pi]$ e $[-1,1]$, respectivamente. Essas características estão de acordo com as premissas do modelo de Goodman visto no capítulo 2.

A intensidade em cada pixel é dada por:

$$
I(l) \propto U(l) U^{*}(l)
$$

A equação 4.1 descreve o padrão de intensidades no detector em um instante fixo, digamos $t=0$. A fim de introduzir variações temporais de intensidades, e consequente 
atividade no padrão, o argumento da exponencial deve ser alterado em cada instante subsequente, de modo que:

$$
R(j, l, t)=R_{0}(j, l)+v(j) t
$$

Onde $R_{0}(j, l)$ é a posição inicial e $R(j, l)$ a posição final no instante t. A velocidade $v(j)$, atribuída ao centro espalhador $\mathrm{j}$, é dada por:

$$
v(j)=\epsilon r(j)
$$

O coeficiente $\epsilon$ é a amplitude da velocidade e $r(j)$ é uma variável aleatória, escolhida no intervalo $[0,1]$. No trabalho de Rabal, foram utilizados valores de $r(j)$ uniformemente distribuídos. Nesta dissertação, avaliamos também outras distribuições com objetivo de testar hipóteses feitas na literatura acerca das distribuições de velocidade presentes em tecidos biológicos [12, 41].

Com os valores de intensidade apresentados pelo detector em cada instante, foram construídos THSPs para exibir a evolução temporal da simulação.

\subsubsection{Testes do modelo}

A fim de se avaliar a qualidade das simulações, Rabal et al. empreenderam uma série de testes. Ao longo deste trabalho reproduzimos estes estudos e introduzimos mais alguns ensaios que verificam a estatística dos padrões simulados. O primeiro teste empreendido foi a verificação da estatística de primeira ordem de um padrão completamente desenvolvido. Isso foi realizado por meio do levantamento de um histograma dos valores de intensidade obtidos durante a simulação. O resultado é mostrado na figura 4.2(a), confirmando a previsão feita na seção 2.1, quando concluímos que a FDP que governa as intensidades de um padrão ideal é uma exponencial negativa (equação 2.16). A partir da construção de dois padrões independentes e a posterior superposição de ambos, simulamos o caso da soma incoerente estudado na seção 2.1.1. O histograma das intensidades exibido na figura 4.2(b) comprova a FDP deduzida em 2.22.

Na sequência, avaliamos o aspecto qualitativo do THSP em situações bem conhecidas. Primeiramente, foi atribuído o mesmo valor de amplitude e fase inicial a todos os centros 


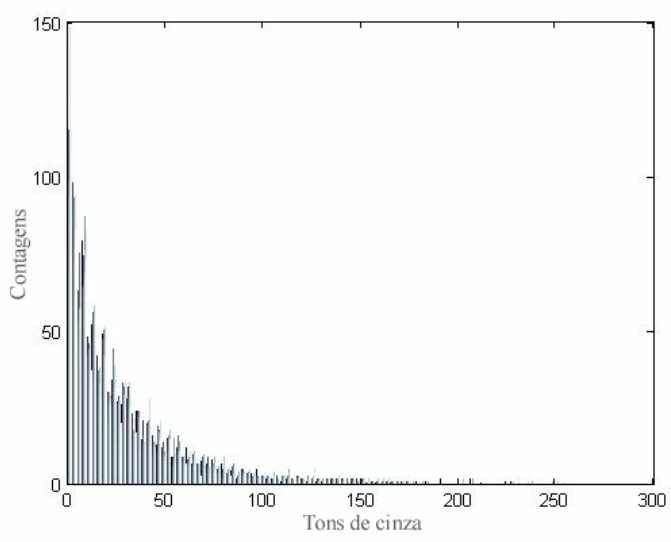

(a) Speckle polarizado

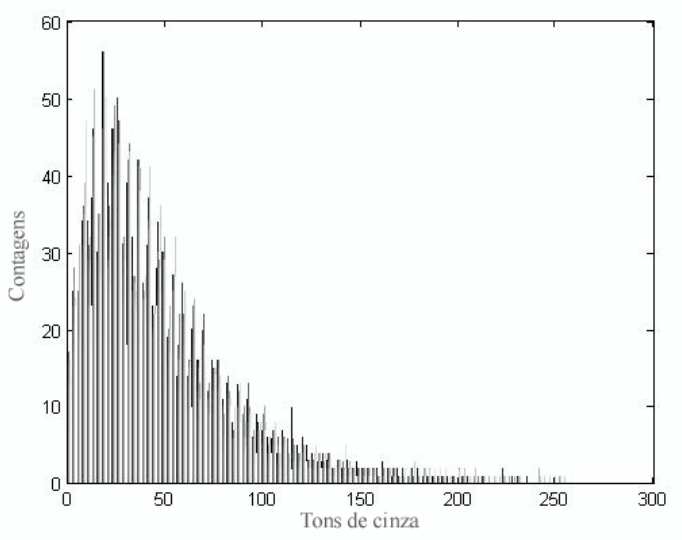

(b) Soma incoerente

Figura 4.2: Histogramas da simulação de padrões speckle.

espalhadores, os quais foram mantidos estáticos $(\epsilon=0)$. Devido à forte correlação entre fases e amplitudes, não há produção de speckle. Essa situação simula uma abertura iluminada por luz coerente e o padrão resultante corresponde à difração de Fresnel por uma fenda. A figura 4.3(a) mostra o comportamento das intensidades registradas ao longo do detector e o perfil qualitativo da difração pode ser observado [10].

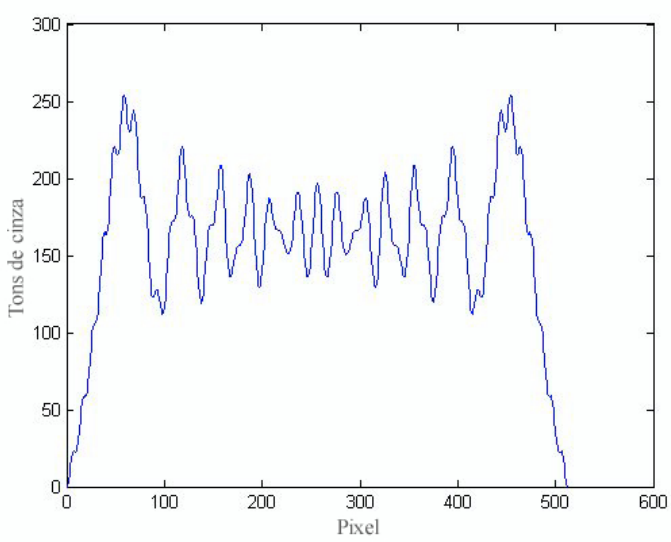

(a) Fases fixas e iguais

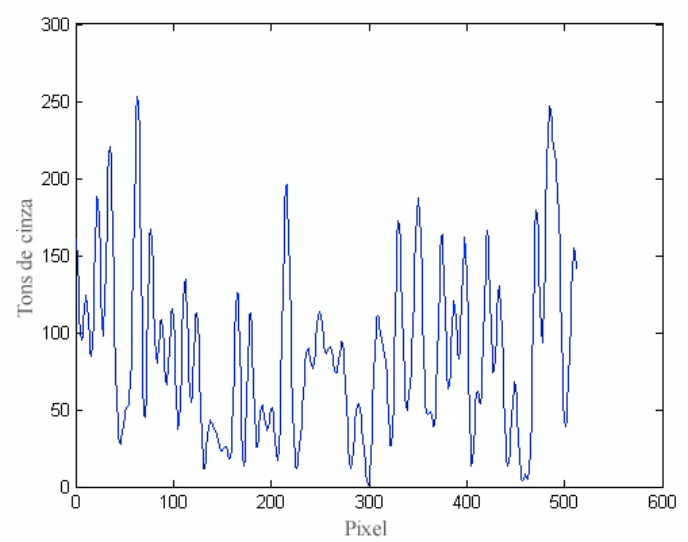

(b) Fases ao acaso

Figura 4.3: Perfis de intensidades de um pixel em simulações distintas.

Também foi analisada a situação em que os centros espalhadores foram mantidos estáticos, porém com fases e amplitudes iniciais distribuídas aleatoriamente de maneira uniforme. Nesse caso, sem a existência de correlação entre fases e amplitudes, ocorre a formação de speckle. De acordo com a discussão feita na seção 3.1, o THSP resultante 
deve ser composto por barras verticais paralelas. O resultado obtido é exibido na figura 4.4, confirmando essa previsão.

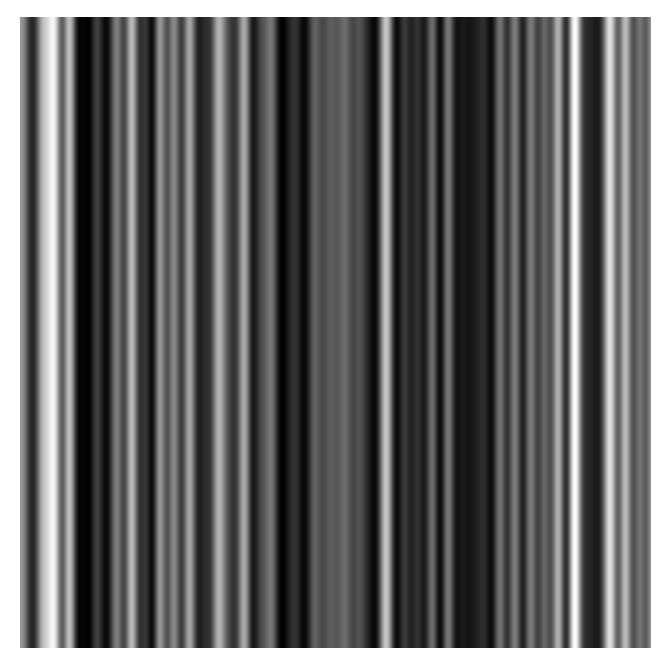

Figura 4.4: THSP obtido com os centros espalhadores estáticos.

O perfil de intensidades nessa última situação (figura 4.3(b)) difere bastante daquele observado na difração de Fresnel (figura 4.3(a)).

O passo seguinte foi o estudo do comportamento das simulações com os espalhadores em movimento. O primeiro caso analisado foi a situação de movimento de corpo rígido. Para isso, foram atribuídas amplitudes e fases iniciais aleatórias às ondas espalhadas por cada centro. Todos foram mantidos com velocidades constantes e idênticas, simulando o movimento da fila de espalhadores na direção z. O resultado é o THSP exibido na figura 4.5 .

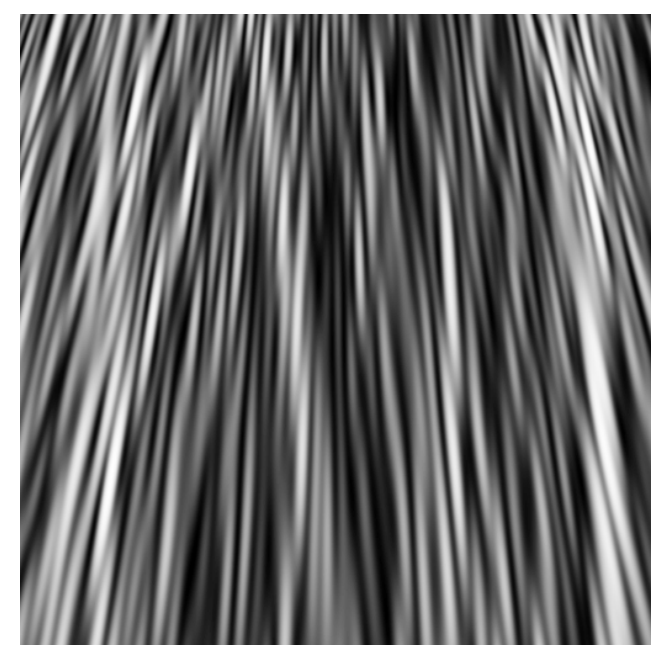

Figura 4.5: THSP de uma simulação de movimento de corpo rígido. 
Esse THSP é coerente com a previsão teórica, uma vez que, com o afastamento dos espalhadores, o tamanho dos grãos aumenta (seção 1.2.3), conferindo esse aspecto tipo "espaguete" observado no padrão de barras verticais.

Simulamos também diversos valores de velocidades para os espalhadores. Velocidades mais baixas apresentaram THSPs tendendo a um padrão de barras paralelas, enquanto velocidades mais altas apresentaram THSPs com pontos mais dispersos, revelando acordo com a previsão teórica. Nas próximas seções são apresentadas análises semi-quantitativas sobre essas imagens de história temporal, testando os métodos expostos no capítulo anterior. Além disso, avaliamos o comportamento desses estimadores de atividade em função da distribuição de velocidades diferentes para os centros espalhadores.

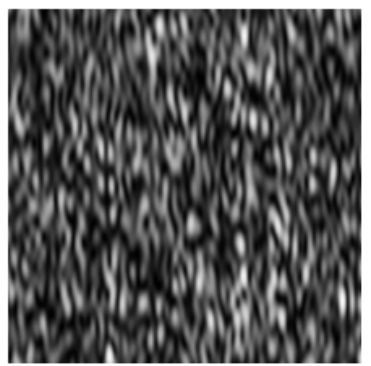

(a)

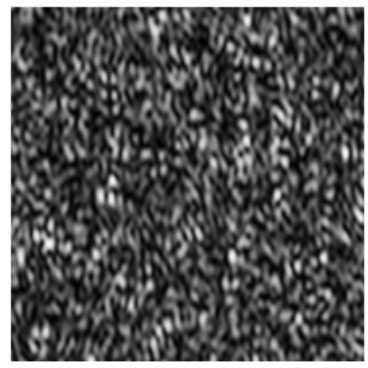

(b)

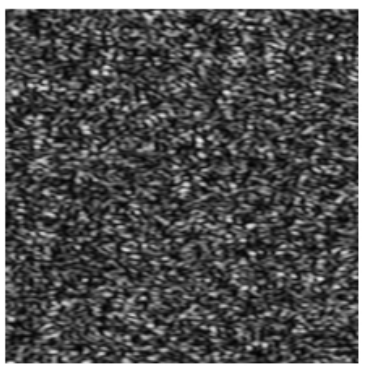

(c)

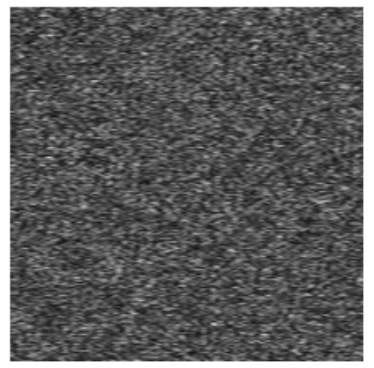

(d)

Figura 4.6: THSPs simulados. Velocidades em unidades arbitrárias: (a) v=2, (b) v=4, (c) $\mathrm{v}=8$ e $(\mathrm{d}) \mathrm{v}=10$.

\subsection{Simulações Numéricas}

Os métodos expostos no capítulo anterior foram utilizados na obtenção de informação semi-quantitativa a respeito das simulações realizadas. Vale lembrar que tais métodos têm esse caráter porque possuem validade somente dentro de um contexto comparativo.

Foram ensaiadas situações nas quais a amplitude de velocidade $(\epsilon)$ foi variada no intervalo $[0,10]$. Diferentes distribuições dessas velocidades foram testadas, assim como diversas proporções de espalhadores móveis e estáticos. As distribuições de velocidades estudadas foram a uniforme, a gaussiana, a parabólica e a maxwelliana. A escolha dessas distribuições se justifica pelo fato delas figurarem na literatura entre aquelas que governam o movimento de partículas e fluidos em sistemas biológicos [51, 52]. Foi utilizada a hipótese 
de que o speckle resultante possuía uma componente oriunda de espalhadores móveis e outra componente espalhada a partir de centros estáticos. Dessa forma, nos testes em que a velocidade foi o parâmetro variável, a proporção de partículas móveis foi mantida fixa em $50 \%$.

\subsubsection{Contraste de Briers das Simulações}

O primeiro método de análise estudado nas simulações foi o contraste de Briers (seção 3.4). O programa criado para as simulações permitia o estudo de dois tipos de padrão speckle: o speckle completamente desenvolvido e a soma incoerente de dois padrões gerados de forma independente. Nos ensaios descritos a seguir estudamos a primeira situação, uma vez que uma das premissas teóricas para a validade do método proposto por Briers parte da idéia que o speckle é completamente desenvolvido [20]. Outra possibilidade oferecida pelo modelo era a variação da taxa de espalhadores fixos e móveis.

Foram simulados 15 THSPs com proporções de centros fixos e móveis variando de 0 a 100\%. Os respectivos contrastes foram levantados. Através da expressão obtida em 2.32, foi possível construir a curva teórica do contraste de Briers $\left(\frac{\left\langle\sigma_{t}^{2}(x, y)\right\rangle_{x y}}{\langle I\rangle^{2}}\right)$ em função da taxa de espalhadores móveis $(\rho)$. O gráfico com os resultados são exibidos na figura 4.7.

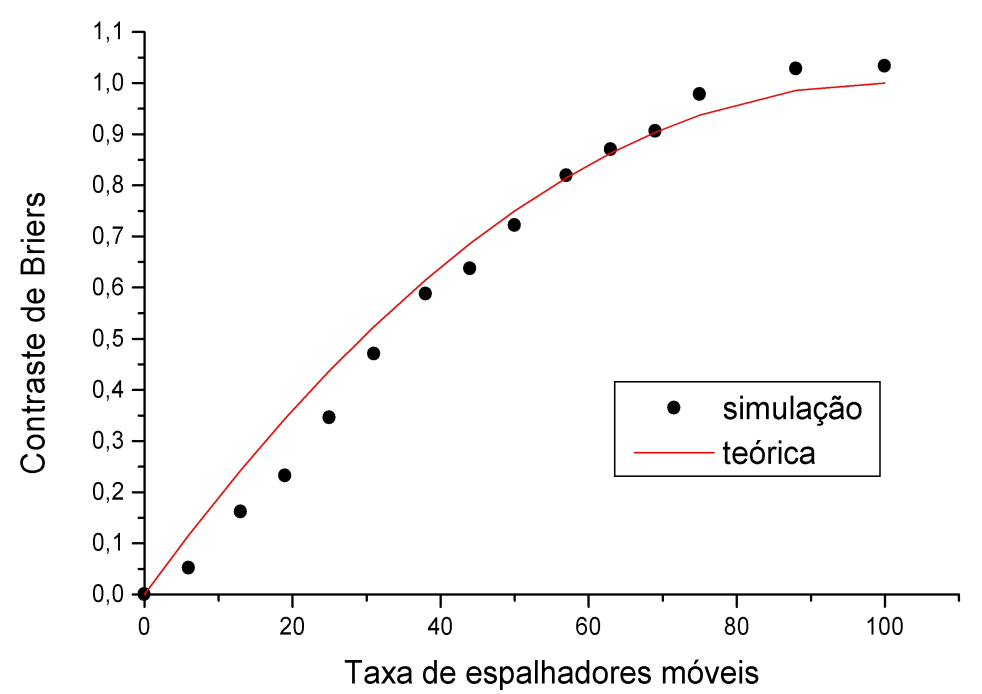

$(\%)$

Figura 4.7: Curva teórica e pontos experimentais do contraste de Briers das simulações.

Embora não haja plena concordância do modelo com a curva teórica, a distribuição dos dados simulados tem forma semelhante à previsão da equação 3.6. Um ajuste perfeito 
das simulações era possível quando um parâmetro era deixado livre (a distância entre os planos espalhdor e de observação, por exemplo). Entretanto, julgamos que esse fato decorre de algum efeito de segunda ordem que não foi considerado na construção do modelo, pois, em geral, os padrões gerados numericamente possuem grande semelhança com aqueles obtidos a partir de sistemas reais.

\subsubsection{Momentos de Inércia das Simulações}

Nesta seção utilizamos o método exposto em 3.3 na análise dos THSPs simulados. As matrizes de co-ocorrências foram construídas para cada valor de velocidade ensaiado e o respectivo índice de atividade calculado. A figura 4.8 mostra essas matrizes. À medida em que as velocidades aumentam (da esquerda para a direita, de cima para baixo), ocorre a dispersão dos valores de ocorrências em torno da diagonal principal.
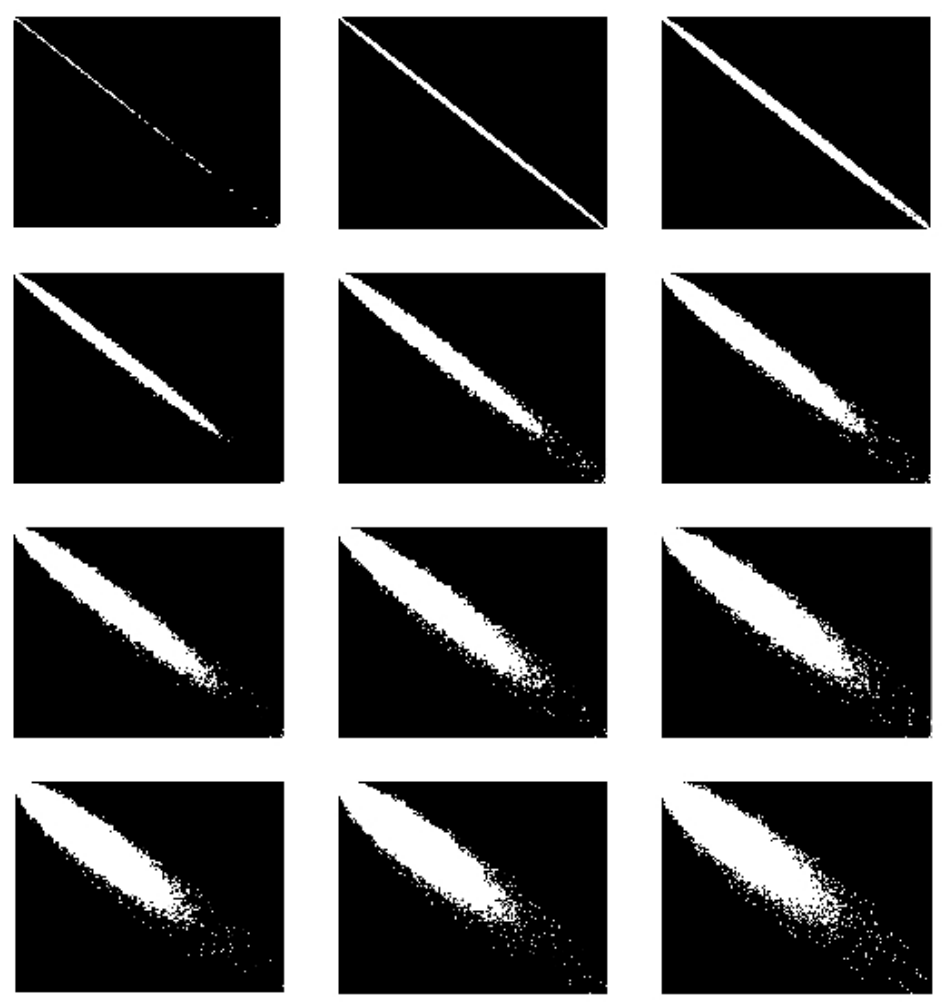

Figura 4.8: Matrizes de co-ocorrências obtidas através da simulação. Os valores de velocidade aumentam da esquerda para a direita, de cima para baixo.

Este procedimento foi repetido para cada uma das distribuições escolhidas, totalizando 48 simulações e a figura 4.9 mostra o resultados obtidos, permitindo uma comparação entre 
os momentos de inércia de cada distribuição.

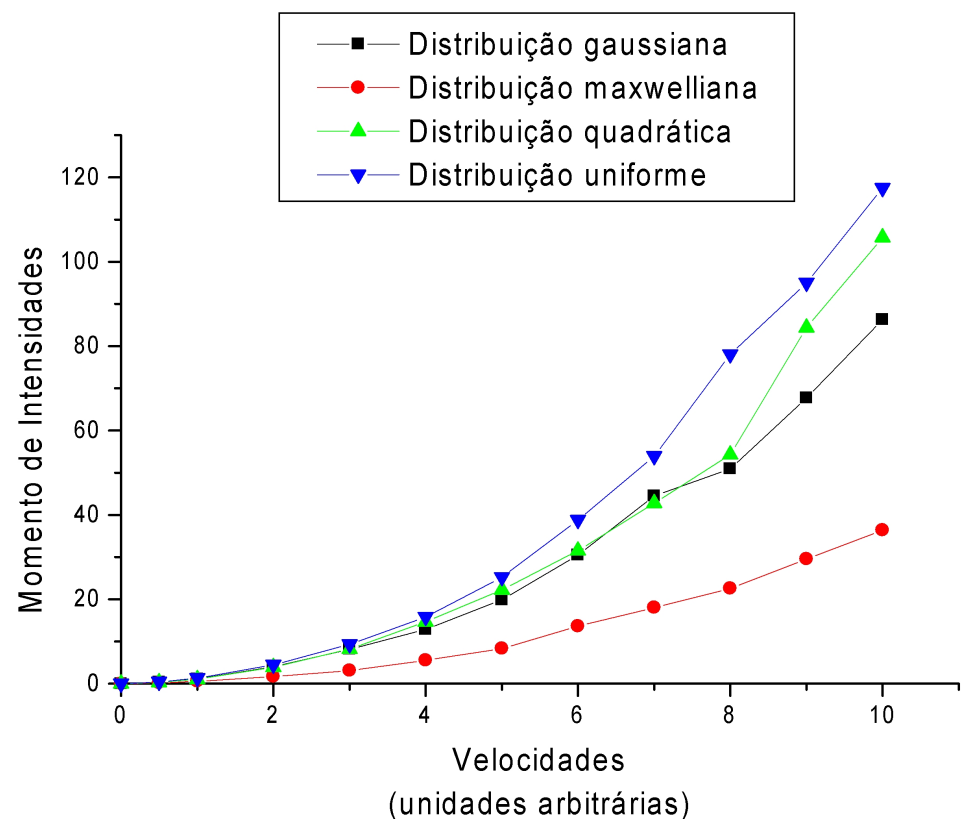

Figura 4.9: Momentos de Inércia obtidos para as distribuições simuladas.

Algumas diferenças significativas no comportamento dessas curvas podem ser notadas, de acordo com a distribuição das velocidades empregadas no ensaio. Embora o perfil qualitativo das curvas seja essencialmente o mesmo, a rapidez com que o momento de inércia aumenta em função da velocidade é bastante diferente em cada uma das distribuições, especialmente se considerarmos a uniforme e a maxwelliana. Provavelmente, tal característica se deva ao fato de, na distribuição uniforme, a oferta de espalhadores ser basicamente a mesma em todos os valores no intervalo de velocidades, enquanto a distribuição de Maxwell possui maior concentração de espalhadores mais lentos. De qualquer forma, esse resultado chama a atenção para a influência da distribuição das velocidades no comportamento desse índice.

\subsubsection{Contraste das Correlações Sucessivas das Simulações}

Na seção 3.8 propusemos um novo estimador baseado no contraste das correlações sucessivas entre as linhas do THSP. Nosso objetivo aqui é testar a validade deste estimador enquanto um método de análise da atividade do biospeckle.

As simulações foram realizadas nas mesmas condições da seção anterior e os resultados 
são apresentados no gráfico da figura 4.10.

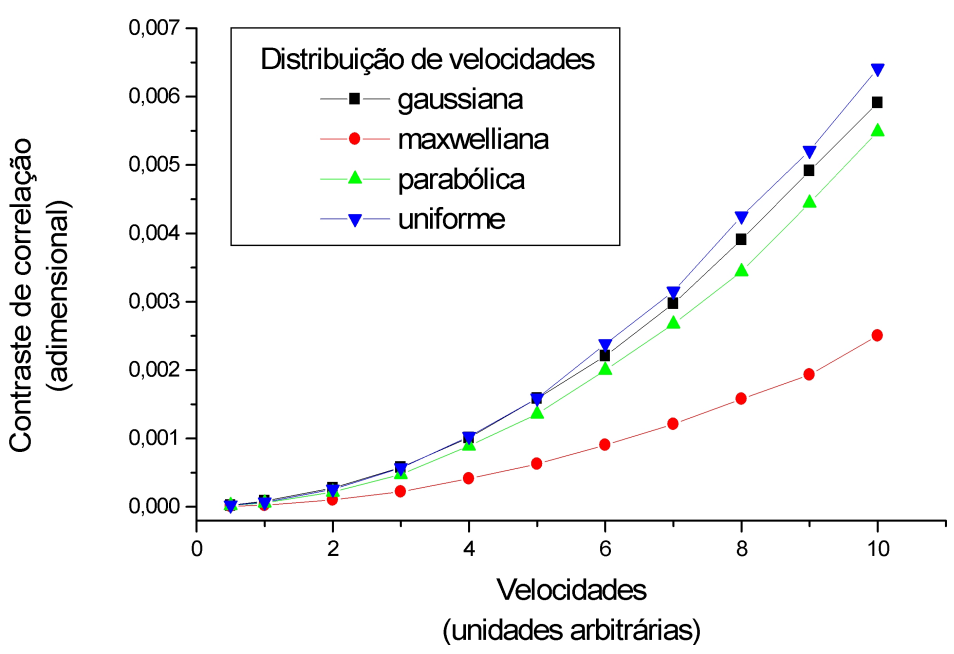

Figura 4.10: Comportamento do contraste de correlações sucessivas para as distribuições simuladas.

A evolução do estimador $\xi$ em função do valor de velocidade mostrou comportamento semelhante àquele observado para os momentos de inércia. No entanto, nosso estimador apresentou maior regularidade quando comparado ao método anterior, especialmente para as distribuições parabólica e gaussiana. Outro fato que nos chamou a atenção foi o ajuste praticamente perfeito $\left(\chi_{\text {red }}^{2} \approx 1\right)$ de parábola aos dados das quatro distribuições, diferentemente do que acontece com os momentos de inércia.

Esses resultados das simulações sugerem que o índice $\xi$ proposto é um estimador válido quando comparado a outros métodos existentes na literatura.

\subsubsection{Autocorrelação Normalizada das Simulações}

O método das autocorrelações também foi empregado na análise das simulações e os respectivos gráficos são expostos a seguir (figuras 4.11 e e 4.12).

A primeira característica percebida é que, com aumento do valor da velocidade, há significativa diminuição do comprimento de correlação. Esse resultado apresenta concordância direta com a previsão teórica. Por outro lado, um aspecto notório é o perfil periódico característico no decaimento das autocorrelações. Sua origem está diretamente ligada ao fato de as velocidades serem constantes para cada centro espalhador, apesar de serem aleatoriamente distribuídas. Isto significa que cada centro espalhador sempre per- 


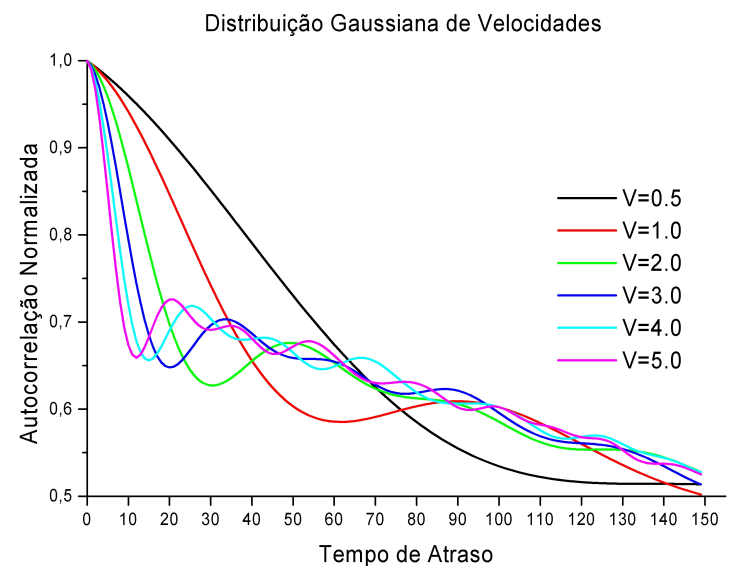

(a) Gaussiana

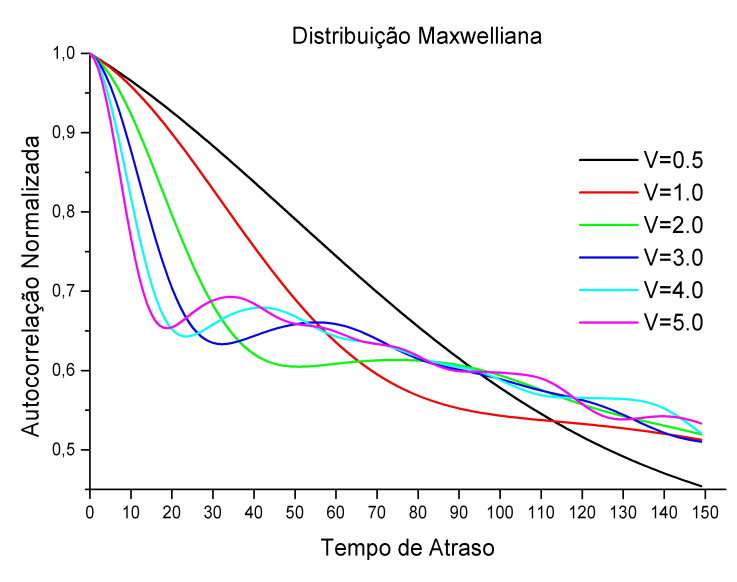

(b) Maxwelliana

Figura 4.11: Autocorrelações obtidas para as distribuições gaussiana e maxwelliana.

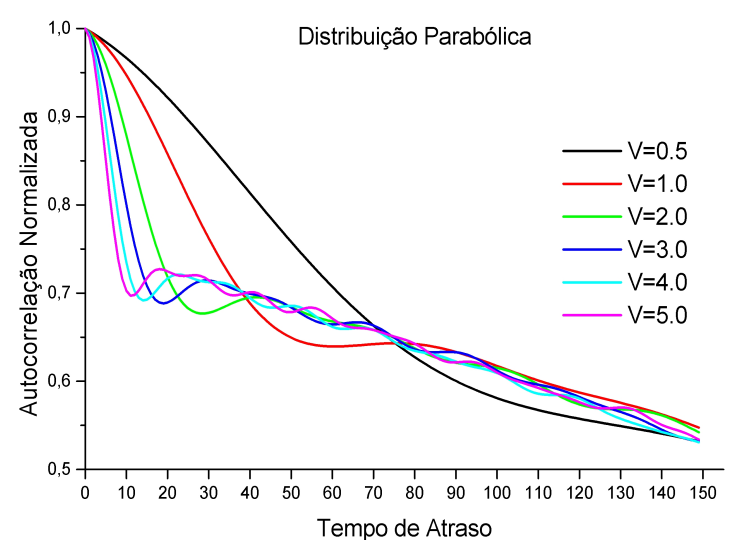

(a) Parabólica

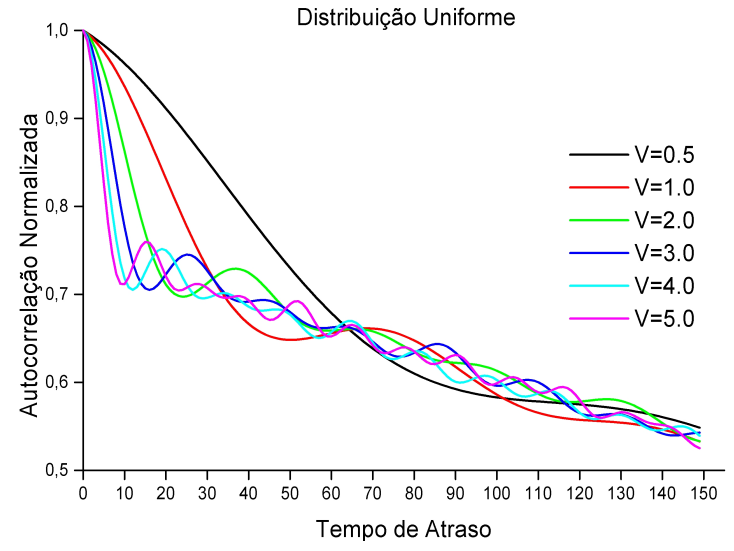

(b) Uniforme

Figura 4.12: Autocorrelações obtidas para as distribuições parabólica e uniforme.

corre a mesma porção de comprimento de onda em intervalos de tempos iguais, repetindo o tipo de interferência das ondas espalhadas periodicamente.

Conforme discutido na seção 3.2, uma maneira objetiva de se comparar a autocorrelação de THSPs é o cálculo do comprimento de correlação eficaz, ou seja, realizar o levantamento do tempo de atraso necessário para que a autocorrelação atinja o valor de $\approx 0,7071$. Esse procedimento foi realizado para as simulações já apresentadas e o resultado é apresentado na figura 4.13 .

Os comprimentos de correlação eficaz apresentaram praticamente o mesmo comportamento quantitativo para todas as distribuições analisadas. Esse fato chama a atenção, especialmente quando comparado aos dois índices de atividade estudados anteriormente, pois tanto os momentos de inércia quanto os contrastes de correlação mostraram-se mais 


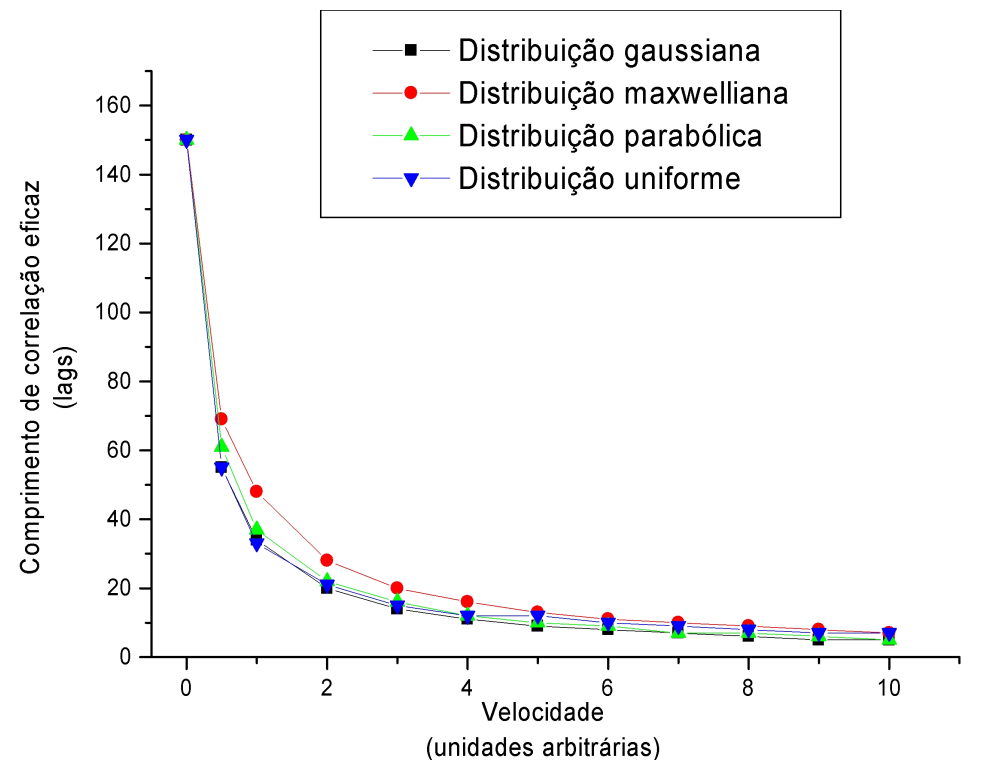

Figura 4.13: Comprimentos de correlação eficaz das simulações.

sensíveis às distribuições empregadas, apresentando diferenças significativas entre elas. 


\subsection{Simulações em Sistemas Físicos}

\subsubsection{Modulação da Fonte: Uma Aplicação da Densidade Espec- tral de Potência.}

O modelo numérico estudado até aqui mostrou-se satisfatório para avaliação de alguns índices de atividade apresentados no capítulo 3. Todavia, ele possui o inconveniente de não trabalhar com uma unidade de tempo bem definida, dificultando o estabelecimento de unidades precisas. Com os métodos anteriores, a providência tomada para contornar esse problema foi o uso de unidades arbitrárias para a velocidade, o que não interfere de maneira significativa nas conclusões tiradas, uma vez que os métodos são essencialmente comparativos e fornecem medidas semi-quantitativas.

No entanto, a fim de mostrar de maneira mais clara o potencial da Densidade Espectral de Potência enquanto método de análise, apresentamos, a seguir, um ensaio simulado não computacional.

O biospeckle é o resultado da modulação nas intensidades das ondas interferentes no plano de observação. No modelo de Rabal et al, a abordagem feita consiste basicamente na modulação introduzida pelo movimento dos centros espalhadores. No entanto, essa modulação também pode ser introduzida pela fonte de iluminação ou ainda por distúrbios no meio de propagação ${ }^{1}$.

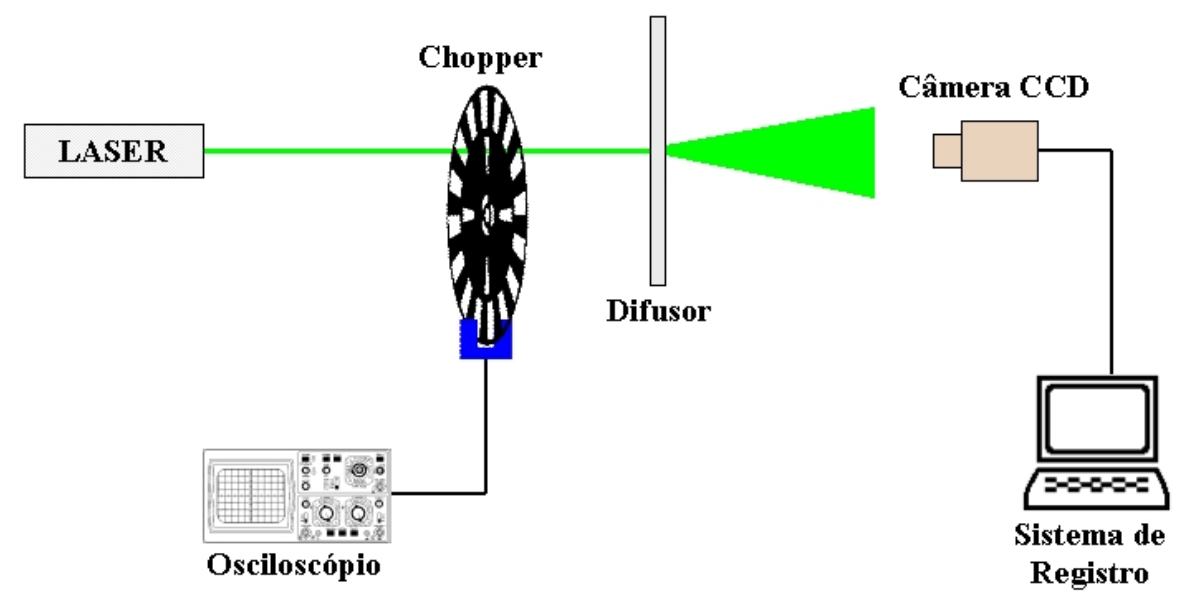

Figura 4.14: Montagem para modular a iluminação.

\footnotetext{
${ }^{1}$ vide, por exemplo, a figura 1.5 e a equação 1.1
} 
Dessa forma, montamos um experimento para introduzir modulações na fonte de luz. O arranjo utilizado foi bastante simples, consistindo basicamente de um laser, uma placa de vidro difusora, um chopper e uma câmera CCD. O esquema da montagem é exibido na figura 4.14 .

A taxa de aquisição utilizada no sistema de registro foi $18 \mathrm{~Hz}$, com incerteza estimada em $2 \mathrm{~Hz}$. O chopper foi ajustado nas frequências de $2 \mathrm{~Hz}, 4 \mathrm{~Hz}$ e $8 \mathrm{~Hz}$, todas com incertezas estimadas em torno de $0,5 \mathrm{~Hz}$.

Foram levantadas as autocorrelações e as respectivas densidades espectrais de potência foram calculadas (figura 4.15(a)). As curvas apresentaram picos de potência em torno das frequências de modulação introduzidas pelo chopper.

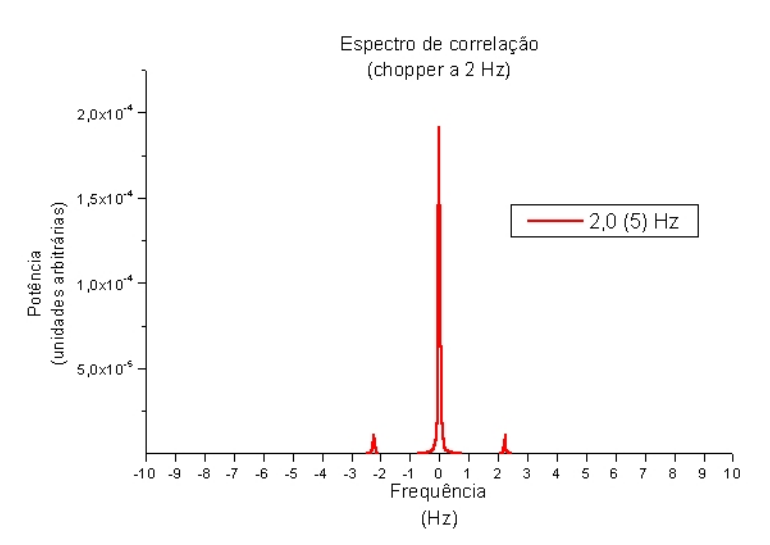

(a) Simétrico $(2 \mathrm{~Hz})$

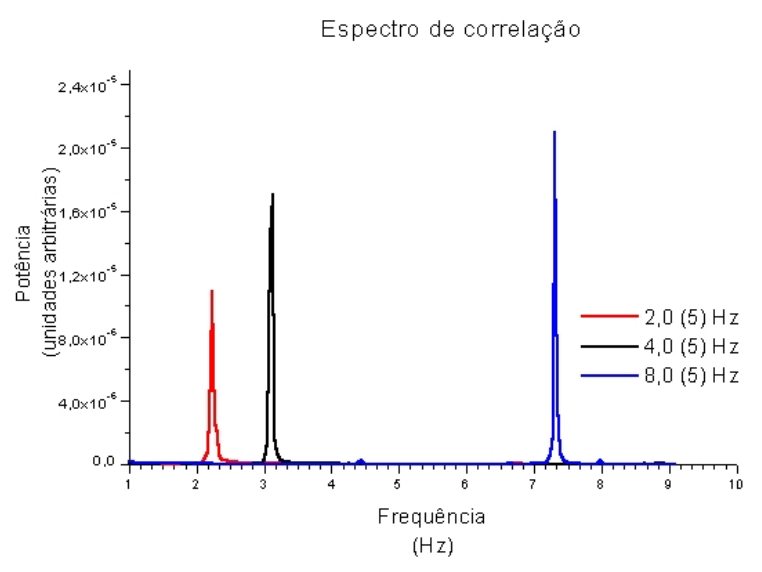

(b) $\operatorname{Picos}(2 \mathrm{~Hz}, 4 \mathrm{~Hz}$ e $8 \mathrm{~Hz})$

Figura 4.15: Espectro de potência para as três modulações.

Os valores de frequência apontados nos espectros de autocorrelações são coerentes, dentro das incertezas experimentais, com aqueles ajustados na modulação do feixe (figura 4.15(b)). Esta simulação bastante simplificada ilustra a aplicação da densidade espectral de potência na obtenção de informações concernentes a modulações contidas em um THSP. Quando se trata de um tecido biológico, os agentes da modulação são, em última instância, os movimentos das partículas no tecido. Naturalmente, nesse caso, a complexidade do espectro de frequências é bem maior, porém ainda assim é possível obter uma frequência média do espectro e, deste modo, estimar uma velocidade média dos espalhadores [36]. 


\subsubsection{Visualização de Relevo Sob Camada de Tinta}

Uma simulação visando o mapeamento de superfícies através do biospeckle foi realizada por meio do monitoramento do processo de secagem de uma camada de tinta aplicada sobre o relevo de uma moeda. A configuração utilizada será discutida mais detalhadamente na seção 5.1 (figura 5.4).

Logo após a aplicação da camada de tinta, não era mais possível a visualização do relevo da superfície. Iniciou-se então o registro de uma sequência de 400 imagens do objeto, com intervalo médio de $80 \mathrm{~ms}$. O tempo total de análise foi de aproximadamente 30 segundos. A figura 4.16 mostra o aspecto final da moeda, sendo bastante difícil distinguir detalhes de seu relevo.

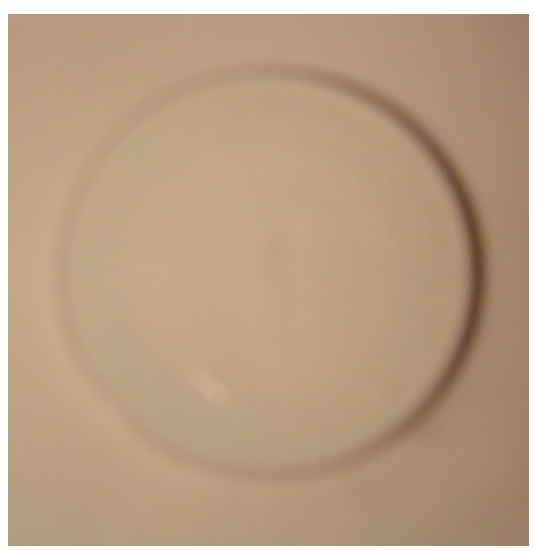

Figura 4.16: Moeda coberta por camada de tinta.

Por meio do método de Fujii, uma imagem foi construída a partir dos registros feitos durante o período de secagem. Embora em cada registro individual não fosse possível a identificação do relevo da moeda, o mapa final permitiu essa identificação. Esse fato ocorre porque a camada de tinta não seca de maneira uniforme ao longo de toda sua topografia. Nas partes mais altas, onde a camada de tinta é mais fina, a secagem ocorre mais rapidamente e estas regiões deixam de ser ativas, enquanto nas partes mais baixas o processo de evaporação do solvente da pintura perdura por mais tempo. No mapa final, essas regiões aparecem avermelhadas, permitindo o contraste. O mapa de Fujii pseudo-colorido é exibido na figura 4.17. 


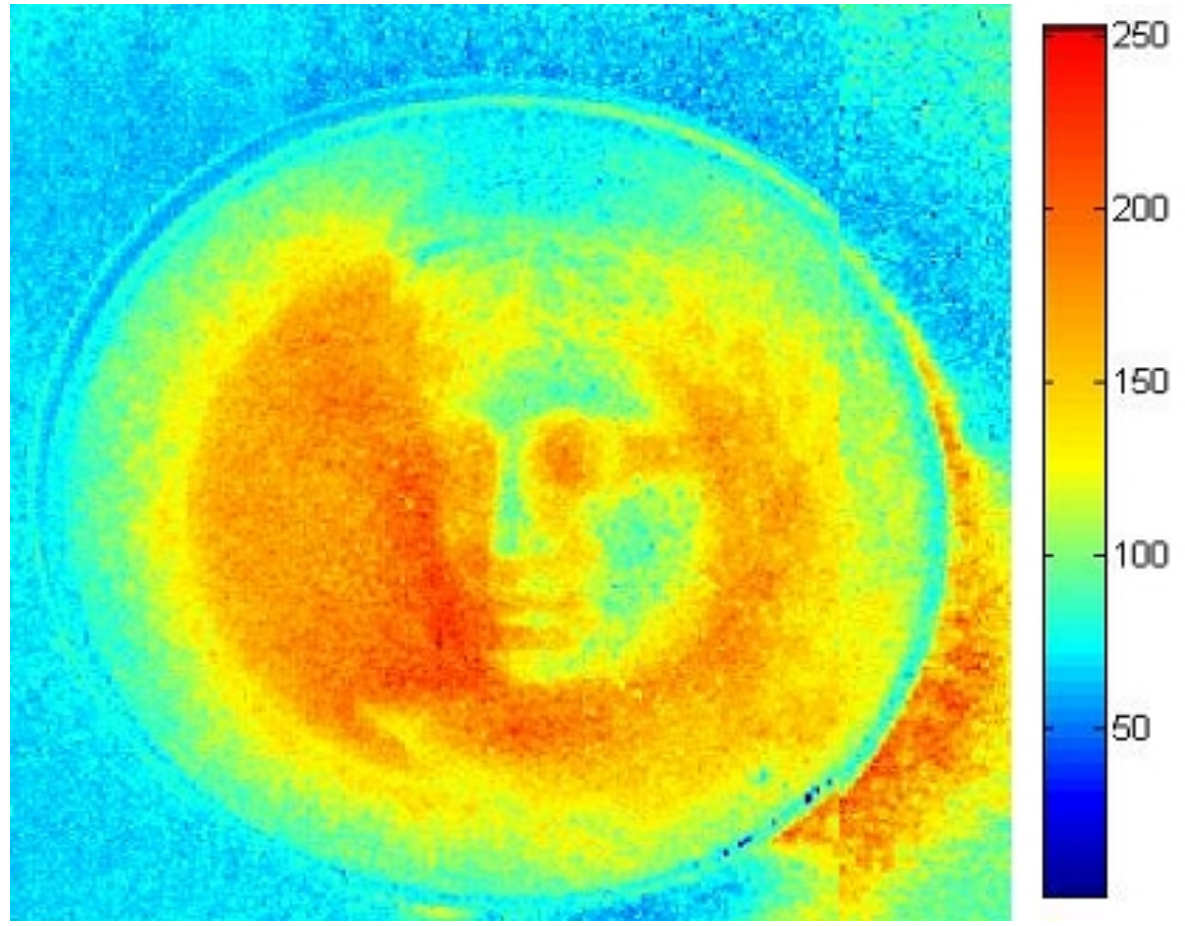

Figura 4.17: Mapa de Fujii mostrando o relevo de uma moeda de $\mathrm{R} \$ 1,00$ encoberta por camada de tinta. 


\section{Capítulo 5}

\section{Ensaios in vivo}

Neste capítulo são apresentados os ensaios realizados em sistemas biológicos, consistindo na parte aplicada desta dissertação. Aqui, são expostos levantamentos de atividade biológica utilizando os métodos estudados no capítulo 3 e são feitas algumas comparações com os resultados das simulações mostradas no capítulo 4.

Os experimentos foram divididos em cinco grandes grupos: folhas, frutos, flores, animais e humanos, sendo este último nosso objetivo final de aplicação do biospeckle. Os estudos feitos em tecidos vegetais foram realizados, em grande parte, no Centro de Investigaciones Opticas, da Universidad Nacional de La Plata, Argentina. Já os testes em animais e seres humanos foram desenvolvidos, respectivamente, nas dependências do laboratório de óptica do IFUSP e do ambulatório do Hospital das Clínicas de São Paulo.

\subsection{Arranjo experimental}

Uma das grandes vantagens do biospeckle sobre técnicas ópticas mais tradicionais reside na relativa simplicidade e baixo custo de sua montagem experimental. Essencialmente, os equipamentos requeridos consistem em um laser (cuja potência, em geral, não necessita ser elevada), um dispositivo CCD de média resolução (nesse trabalho a resolução utilizada foi de 640X480), lentes objetivas e/ou expansoras e, eventualmente, espelhos e polarizadores.

Para os estudos que realizamos, foram utilizadas duas configurações: a geometria de propagação em espaço livre e a geometria no plano imagem (seção 1.2.1). Também foram 
utilizados arranjos para obtenção de biospeckle tanto por transmissão quanto por refle$x \tilde{a} o$. Na grande maioria dos casos, a fonte de luz consistiu em um laser de He-Ne, com potência de saída do feixe de aproximadamente $10 \mathrm{~mW}$. Entretanto, algumas vezes, foi utilizada a raia verde de um laser de Argônio $(\lambda=514 \mathrm{~nm})$, com potências de saída variando entre $30 \mathrm{~mW}$ e $300 \mathrm{~mW}$. Nas análises no plano de Fraunhoffer, também foi utilizado um polarizador diante da câmera CCD para garantir que o speckle registrado fosse do tipo polarizado.

Os formatos utilizados para a gravação das imagens foram $p c x, b m p$ e $A S C I I$ e os programas de captura já haviam sido anteriormente desenvolvidos em nosso grupo de pesquisa, com base nas bibliotecas do Global Lab, da Data Translation. Esses formatos têm a vantagem de não realizarem nenhum tipo de compressão, preservando assim a integridade dos valores de intensidade das imagens. A tabela 5.1 apresenta um resumo dos principais componentes usados na realização dos ensaios experimentais.

As figuras 5.1, 5.2, 5.3 e 5.4 apresentam as configurações básicas utilizadas nos

Tabela 5.1: Principais componentes usados e especificações.

\begin{tabular}{cc}
\hline Componente & Especificações \\
\hline laser He-Ne & $\lambda=632.8 n m$ \\
Potência: $10 \mathrm{~mW}$
\end{tabular}

ensaios descritos a seguir. Ocasionalmente, pequenas alterações foram efetuadas para adequação ao tipo de tecido analisado, todavia, essencialmente, sempre utilizamos essas 
quatro configurações.

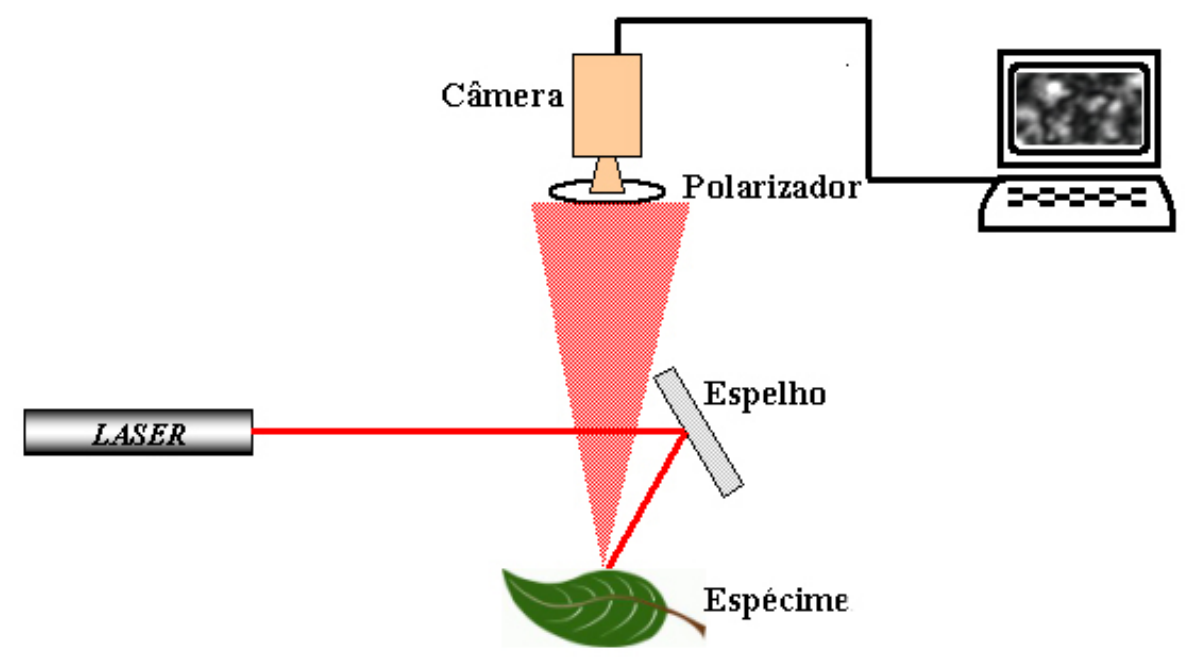

Figura 5.1: Esquema básico da montagem experimental com propagação em espaço livre e speckle obtido por reflexão.

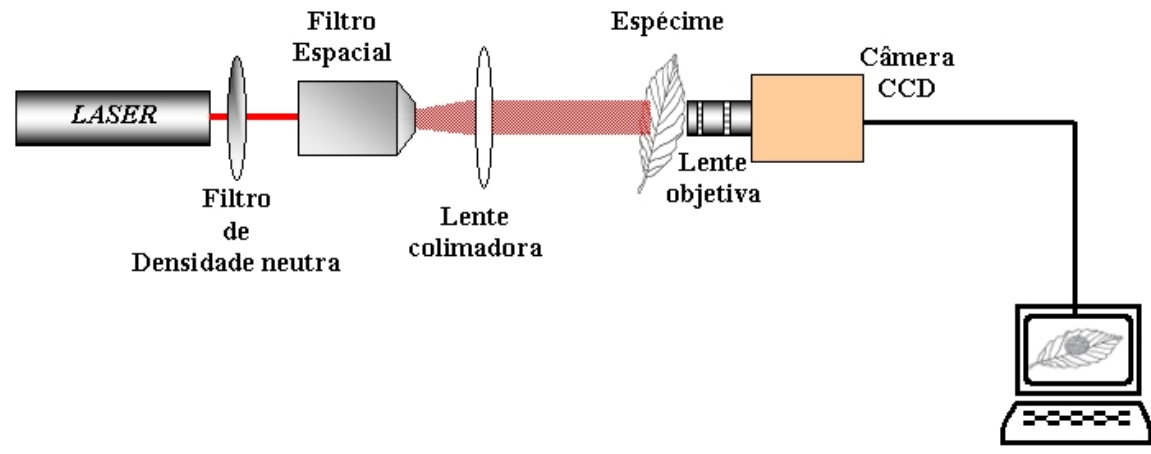

Figura 5.2: Arranjo experimental para observações no plano imagem e speckle obtido por transmissão. 


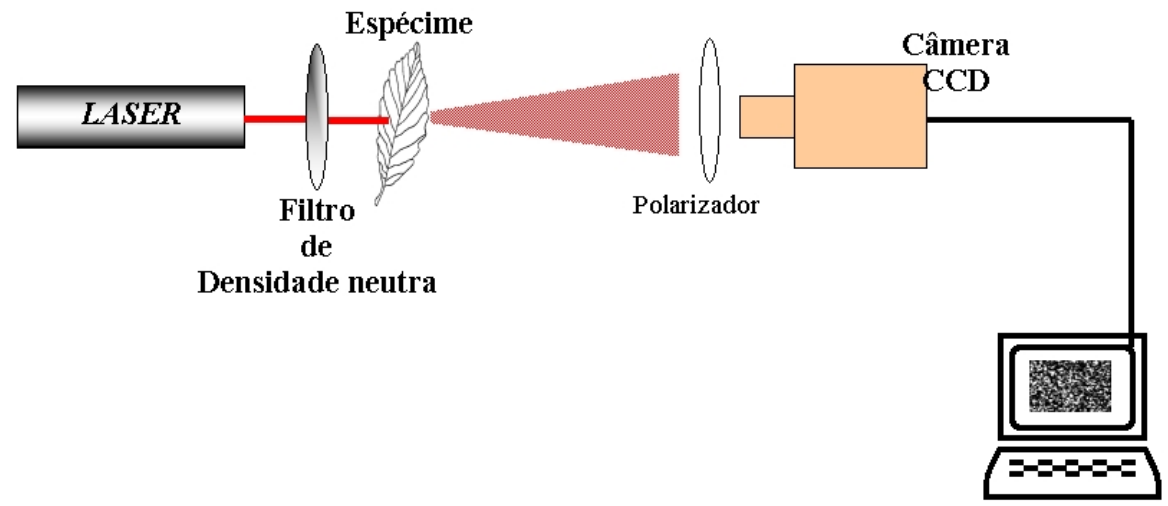

Figura 5.3: Arranjo para observações de biospeckle obtido por transmissão no plano de Fraunhoffer.

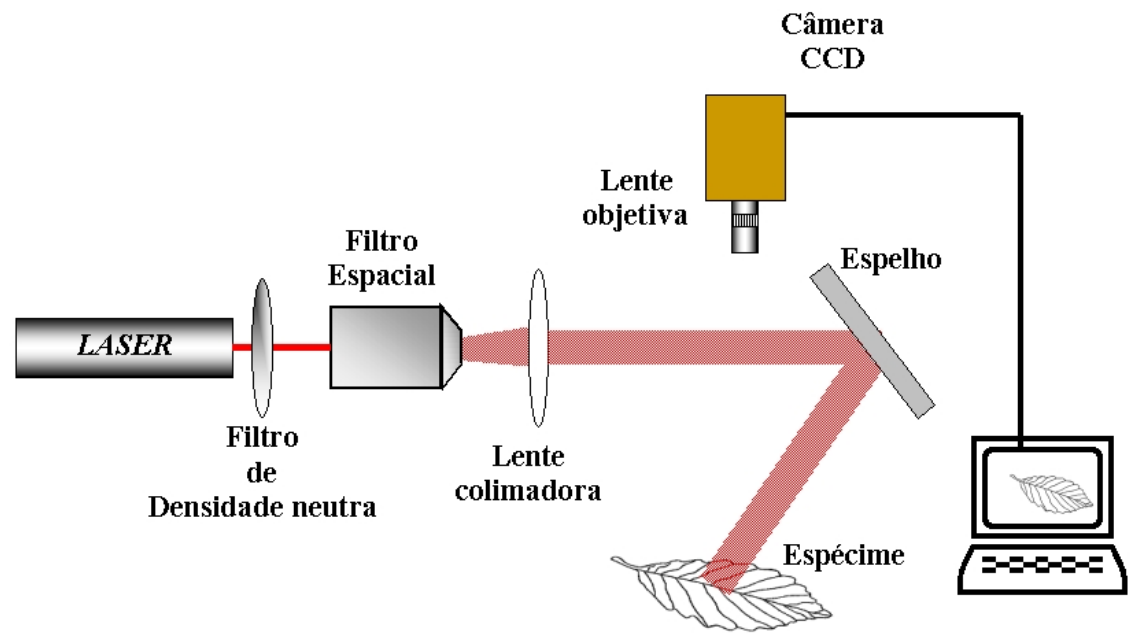

Figura 5.4: Arranjo para observações de biospeckle obtido por reflexão no plano imagem. 


\subsubsection{Programas usados na análise dos dados}

As análises foram realizadas com emprego dos métodos expostos no capítulo 3. Para cada um dos métodos lá discutidos, foi construída uma rotina computacional no ambiente de programação do software Mat Lab \%.0, da Math Works Incorporation. Essas rotinas computacionais estão disponibilizadas no apêndice B.

As representações pictóricas de atividade (matrizes de co-ocorrências, mapas de atividade, etc.) foram obtidas através das ferramentas de tratamento de imagens deste mesmo software. Os gráficos, ajustes de função e tratamentos estatísticos foram realizados a partir do software Origin 5.0, da Microcal Software Incorporation. Quando a quantidade de imagens foi elevada, as rotinas de software criadas em Mat Lab trabalharam com os nomes das entradas sequenciadas em ordem numerada, a fim de facilitar a utilização de loops. Nessas ocasiões, o software livre Irfan View foi utilizado para renomear essas imagens em lotes.

\subsubsection{Dependência do nível de cinza}

Um fator preponderante nas observações do biospeckle é a intensidade de luz utilizada. A essência dos métodos de análise apresentados anteriormente é baseada em estudos das variações do nível de cinza registrado nas imagens fotografadas a partir de um dispositivo CCD. Dessa maneira, quando a intensidade da iluminação da amostra é menor que a sensibilidade do sensor ("sub-iluminação"), há perda de informação que deixa de ser registrada. Por outro lado, quando a iluminação é muito intensa, isto é, quando o sensor do dispositivo de registro fica saturado, também ocorre essa perda, pois as variações deixam de ser captadas. A fim de se determinar níveis ideais de iluminação, empreendemos alguns estudos analisando o comportamento da autocorrelação (seção 3.2) em função do nível de cinza médio em imagens de biospeckle.

O experimento consistiu no monitoramento de uma amostra biológica cuja atividade foi suposta constante durante o tempo de análise. Assim, um espécime de cogumelo (figura 5.5) foi colhido e deixado ao ar livre por um período de aproximadamente 24 horas. A configuração para análise foi aquela apresentada na figura 5.1. O laser usado na iluminação foi do tipo He-Ne e a intensidade de iluminação foi variada com auxílio de um 
filtro de densidade neutra.

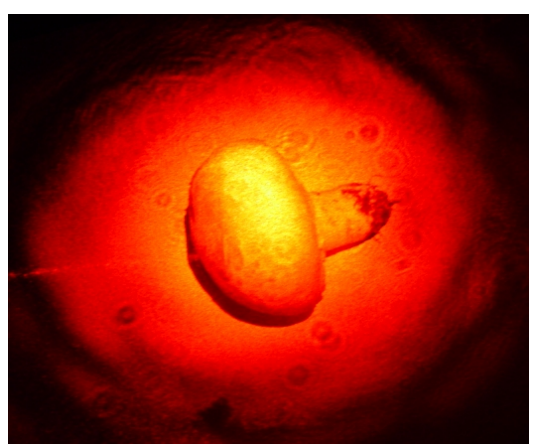

Figura 5.5: Espécime utilizado para estudo da influência do nível de intensidade da iluminação.

A resolução do dispositivo CCD utilizado era de 8 bits e os níveis de cinza médios variaram no intervalo de 25 a 150. Os perfis de correlação apresentaram forte dependência em função do nível de cinza médio. Notamos a perda de informação para níveis inferiores a 60 e superiores a 125. A figura 5.6 mostra as autocorrelações.

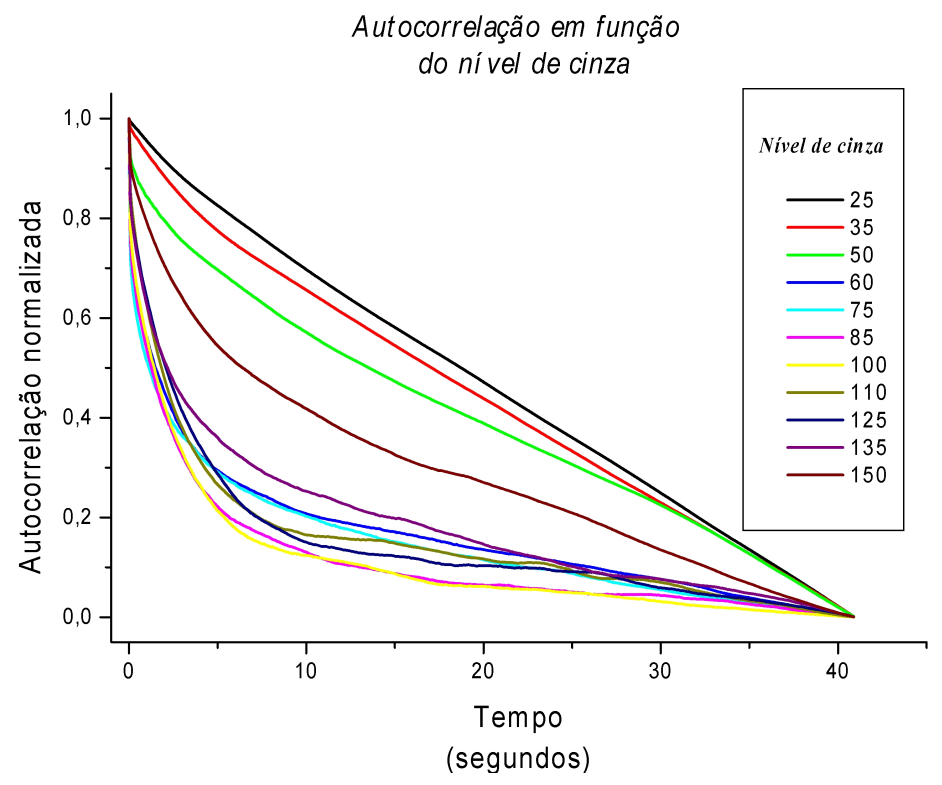

Figura 5.6: Perfis de autocorrelação em função do nível de cinza (atividade mantida constante).

De acordo com esses estudos, o nível de cinza que otimiza a extração de informações situou-se em torno de 100, correspondendo aproximadamente ao centro da nossa escala de cinza $(0-255)$. 


\subsection{Monitoramento de atividade em folhas}

\subsubsection{Senescência}

Vários trabalhos na literatura abordam o uso do biospeckle no monitoramento do processo de senescência ${ }^{1}$ de tecidos vegetais $[57,58]$. Utilizando a geometria de propagação em espaço livre (figura 5.1), monitoramos três folhas de seringueira, em estágios distintos após a colheita. Os THSPs foram construídos por meio do registro do biospeckle ao longo de quatro minutos, ou seja, foi registrada uma linha a cada dois segundos (vide nota na página 38). Os THSPs foram analisados através das matrizes de co-ocorrências e os resultados são exibidos na figura 5.7 .

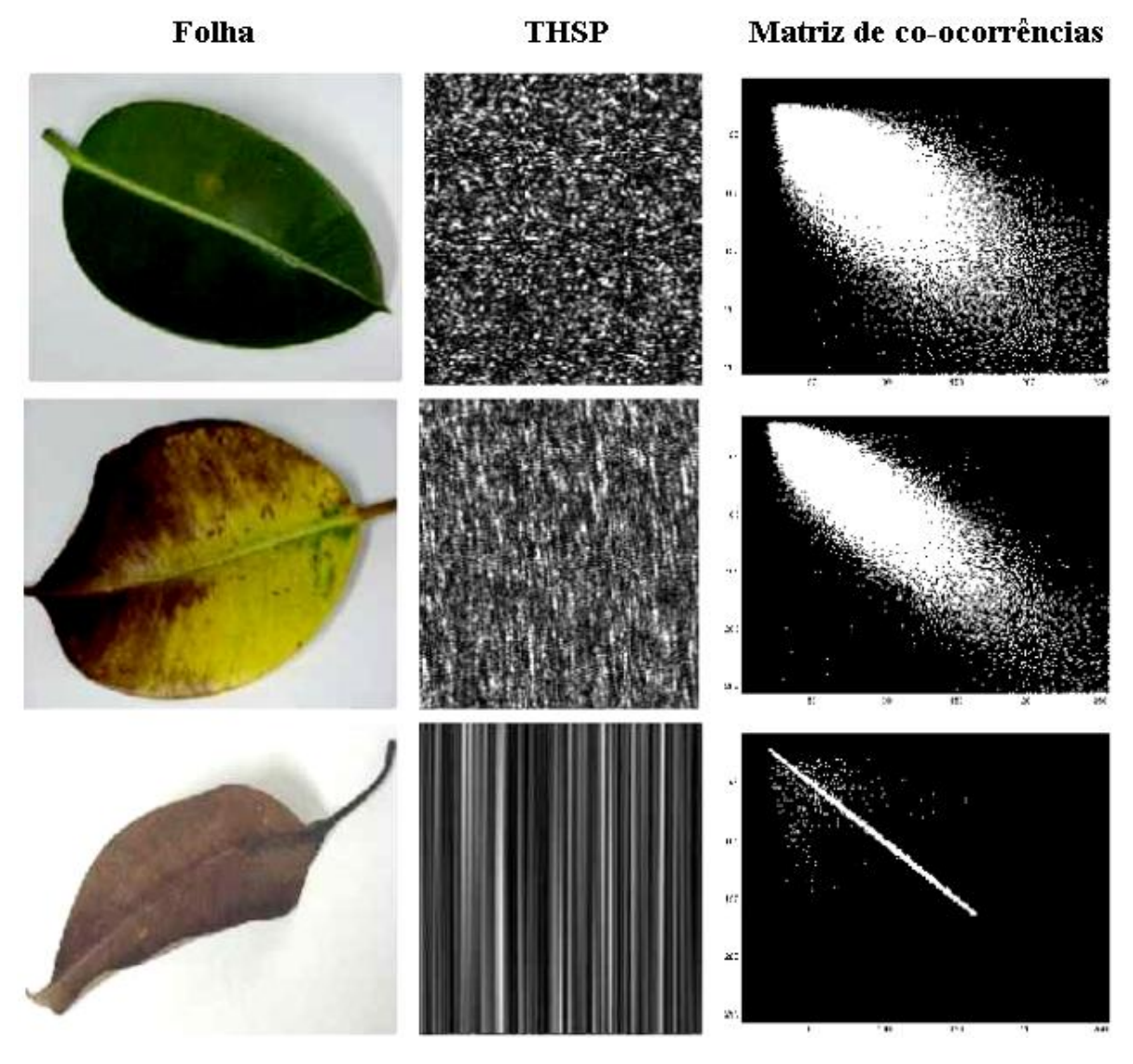

Figura 5.7: THSP e matrizes de co-ocorrência de folhas de seringueira.

A primeira folha (verde), recém colhida, apresentou THSP com elevado nível de ativi-

\footnotetext{
${ }^{1}$ É o processo de envelhecimento natural dos seres vivos e perda da capacidade metabólica de suas células. Um vegetal, assim que colhido, entra nessa processo.
} 
dade e MCO com pontos bastante dispersos em torno da diagonal principal. Na segunda folha (amarelada) essa situação se reduziu, indicando diminuição de atividade, com os pontos se condensando ao redor da diagonal, e finalmente na folha seca o padrão temporal constituiu-se por barras verticais paralelas com elevado nível de concentração dos pontos em torno da diagonal na matriz de co-ocorrência. Os momentos de intensidade, calculados segundo a expressão 3.3, também indicaram a queda progressiva de atividade (tabela 5.2).

Tabela 5.2: Momentos de inércia do biospeckle de folhas em diferentes estágios após a colheita.

\begin{tabular}{cc}
\hline Folha & MI \\
\hline Verde & 380,9 \\
\hline Amarela & 265,6 \\
\hline Seca & 5,3 \\
\hline
\end{tabular}

\subsubsection{Mapeamento de Vascularização}

A observação da rede vascular de folhas vegetais só é possível no plano imagem. A configuração experimental utilizada foi aquela correspondente ao esquema apresentado na figura 5.2. Dentre os métodos apresentados no capítulo 3, os que forneceram melhores resultados foram os métodos de Fujii e LASTCA.

As folhas foram analisadas imediatamente após a colheita. Duas espécies diferentes foram estudadas: uma folha de Bauhinia forficata ${ }^{2}$ e uma folha de amoreira (Morus nigra). Estas folhas foram escolhidas por serem relativamente delgadas, permitindo ensaios por transmissão. Além disso, elas também apresentam uma rede vascular abundante, o que torna a visualização mais fácil.

Na figura 5.8 são apresentas a fotografia de uma folha de Bauhinia forficata iluminada com laser e o respectivo mapa preto e branco construído com a metodologia LASTCA a partir de uma coleção de 50 imagens da folha. Na iluminação desta folha foi usada a raia

\footnotetext{
${ }^{2}$ Esta folha, devido ao seu formato peculiar, é popularmente conhecida como "pata de vaca"
} 
verde $(514 n m)$ de um laser de Argônio. A figura 5.9 apresenta o mapa pseudo-colorido, com a venação destacada pelas regiões avermelhadas.

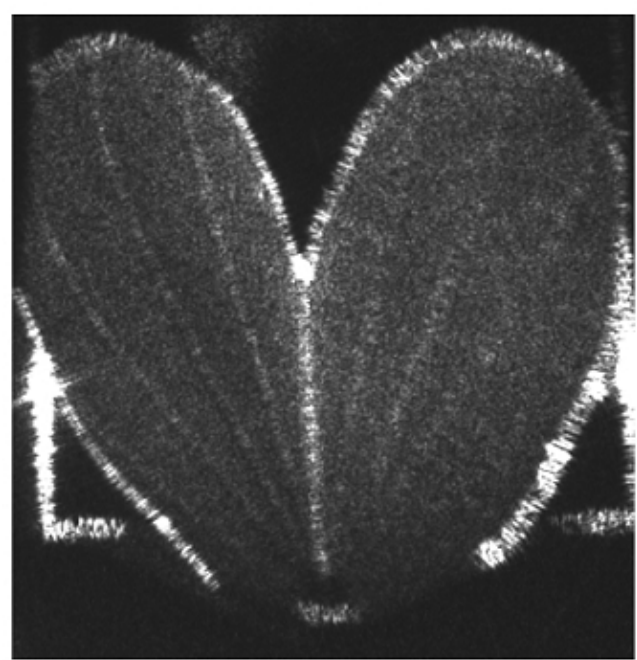

(a) registro simples

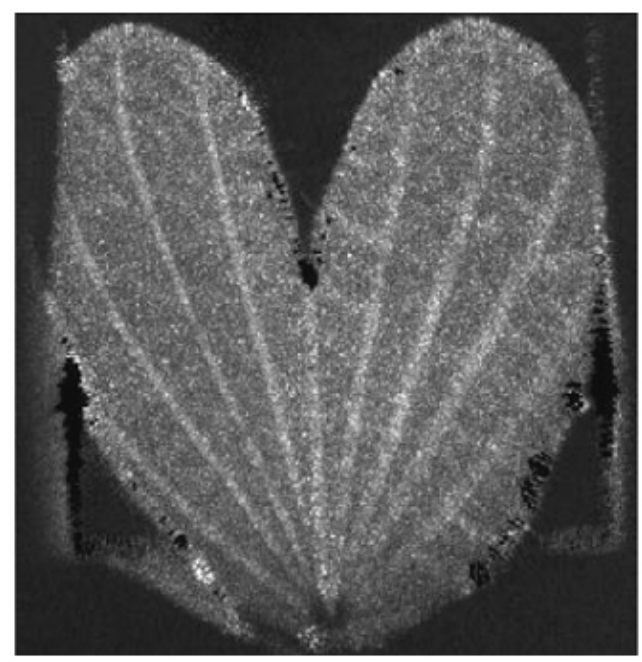

(b) mapa LASTCA

Figura 5.8: Mapeamento de folha de Bauhinia forficata.
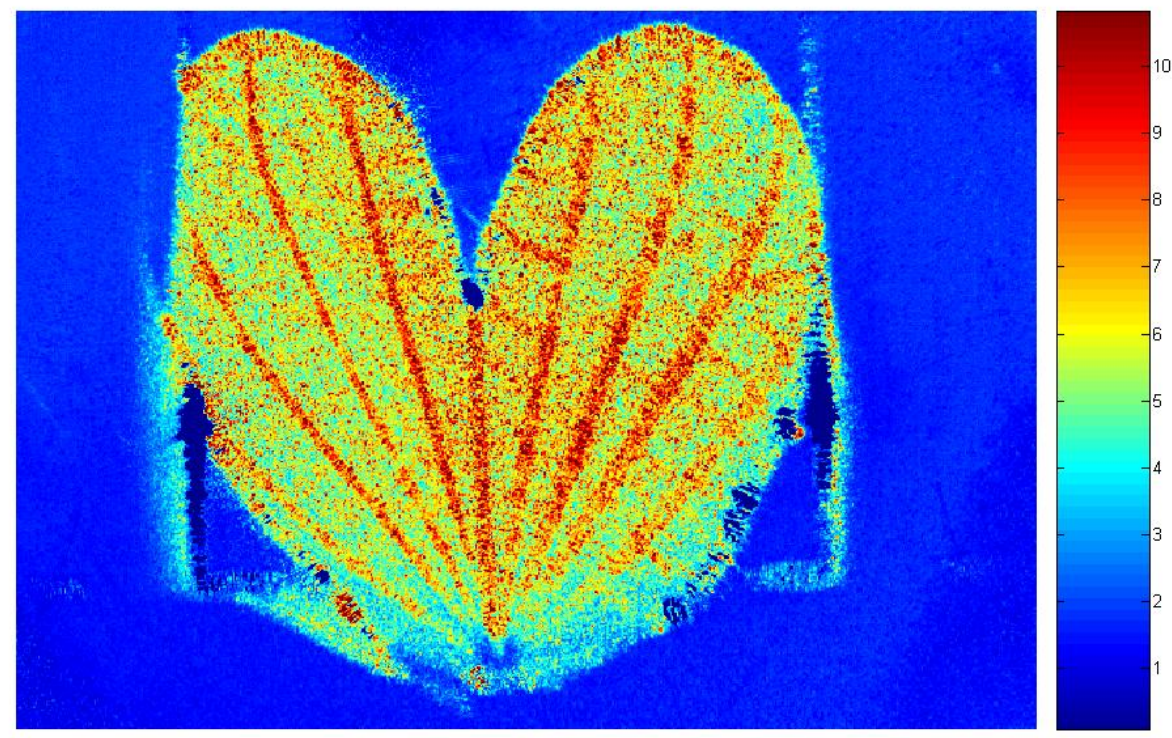

Figura 5.9: Mapa pseudo-colorido construído pelo método LASTCA.

Na figura 5.10 são apresentados uma fotografia direta e o respectivo mapa preto e branco, construído através do método de Fujii. Na sequência (figura 5.11) é mostrado o mapa correspondente pseudo-colorido, onde ficam evidentes as zonas de maior circulação 
através de regiões vermelhas indicando a venação principal e regiões alaranjadas indicando a rede secundária.

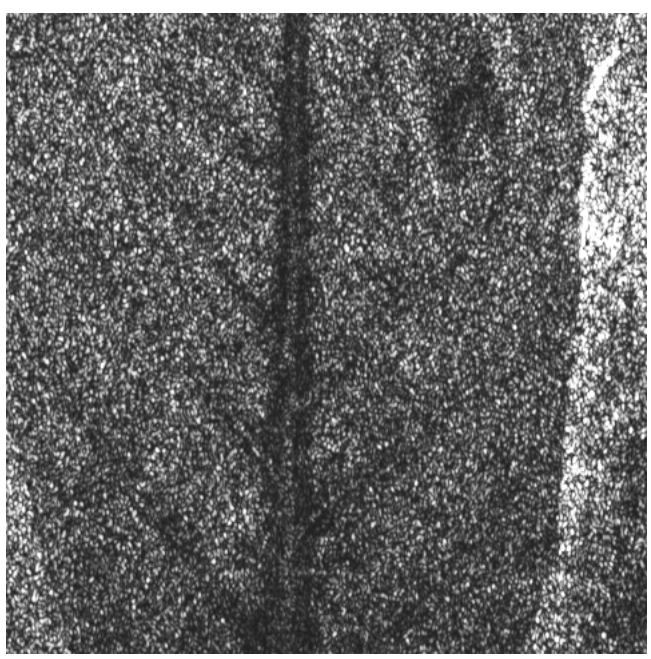

(a)

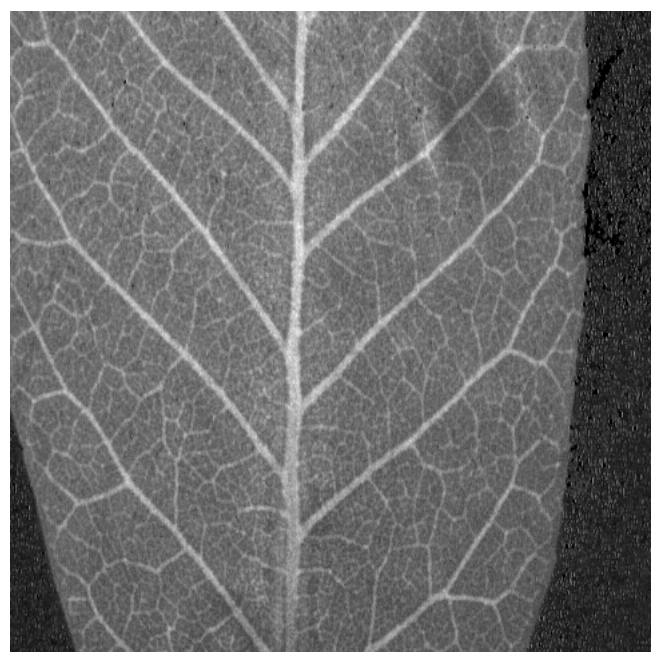

(b)

Figura 5.10: (a) Fotografia simples de folha de amoreira iluminada com laser e (b) o respectivo mapa de Fujii.

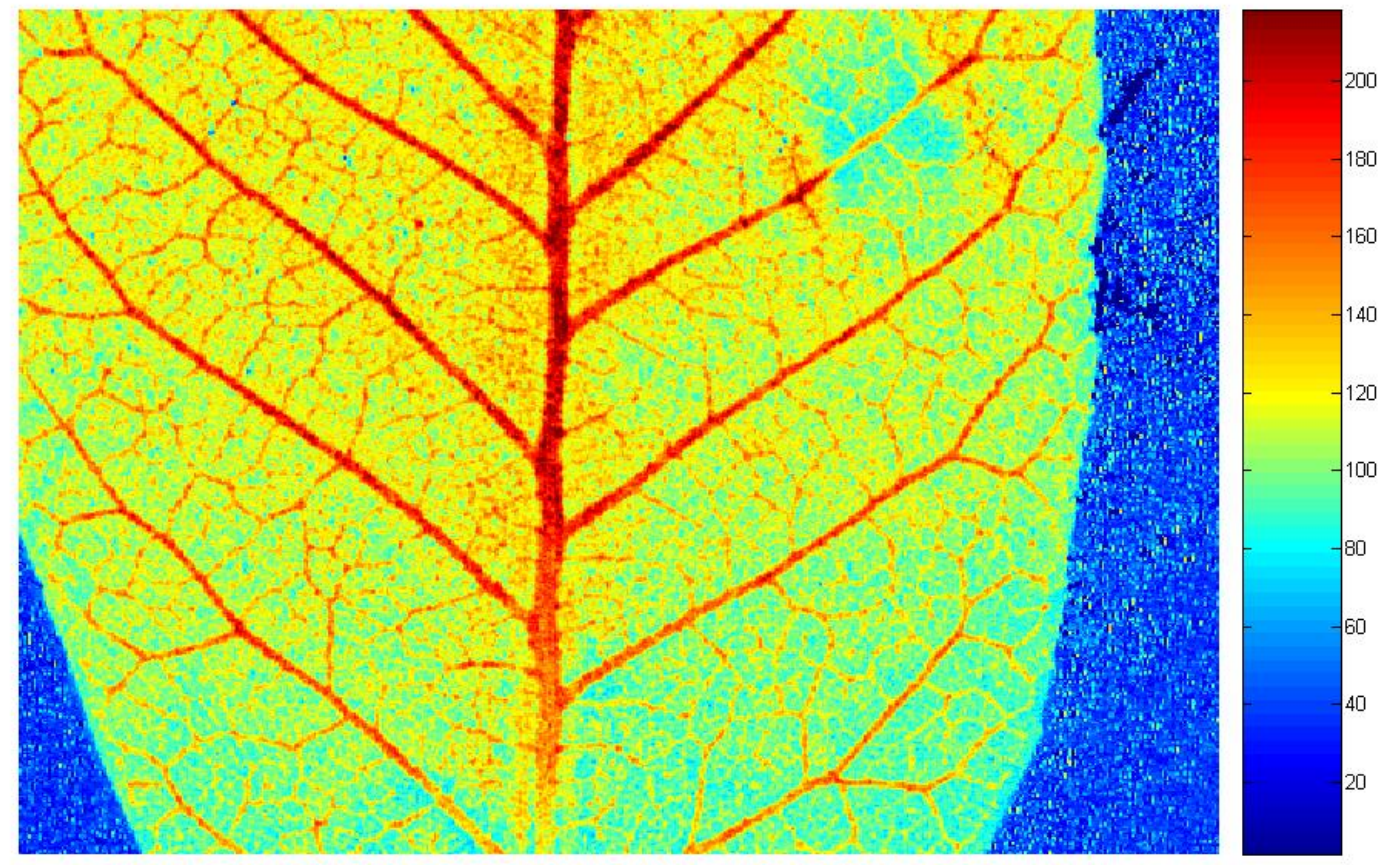

Figura 5.11: Mapa pseudo-colorido construído através do método de Fujii. As zonas avermelhadas indicam a venação principal da folha. 


\subsubsection{Mapeamento de Fitopatologia}

Outra grande potencialidade do biospeckle é seu emprego no monitoramento de lesões fitopatológicas causadas por pequenos organismos (fungos, bactéricas, insetos ...) em vegetais. A fim de ilustrar essa aplicação, empregamos a técnica na observação de uma folha contaminada com pulgão (Macrosiphum avenae). A configuração experimental utilizada foi aquela exibida na figura 5.2.

Empregamos o método de Fujii na construção do mapa de atividade, registrando o total de 400 imagens da folha. A figura 5.12 mostra um registro simples da folha iluminada com laser e o respectivo mapa. O mapa pseudo-colorido é exibido em 5.13.

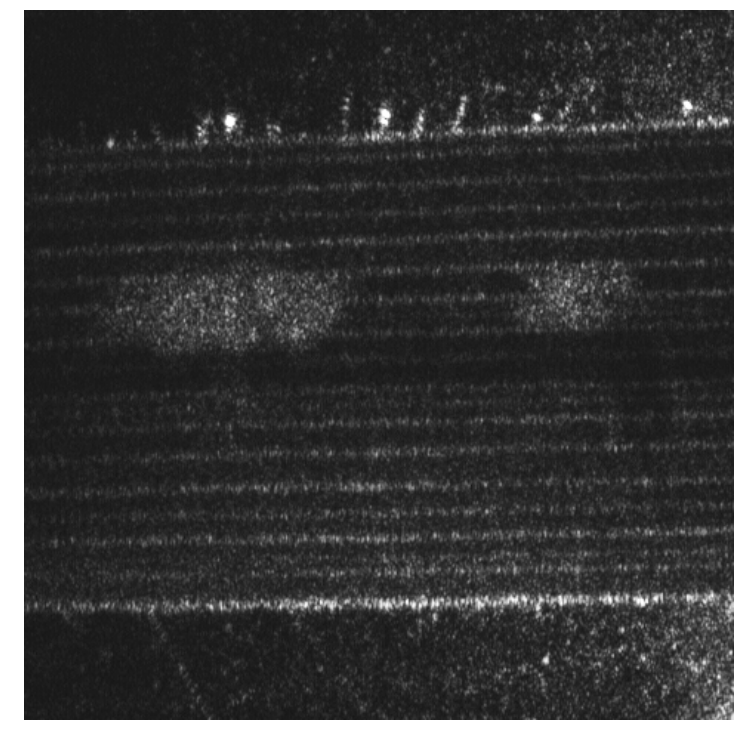

(a) registro simples

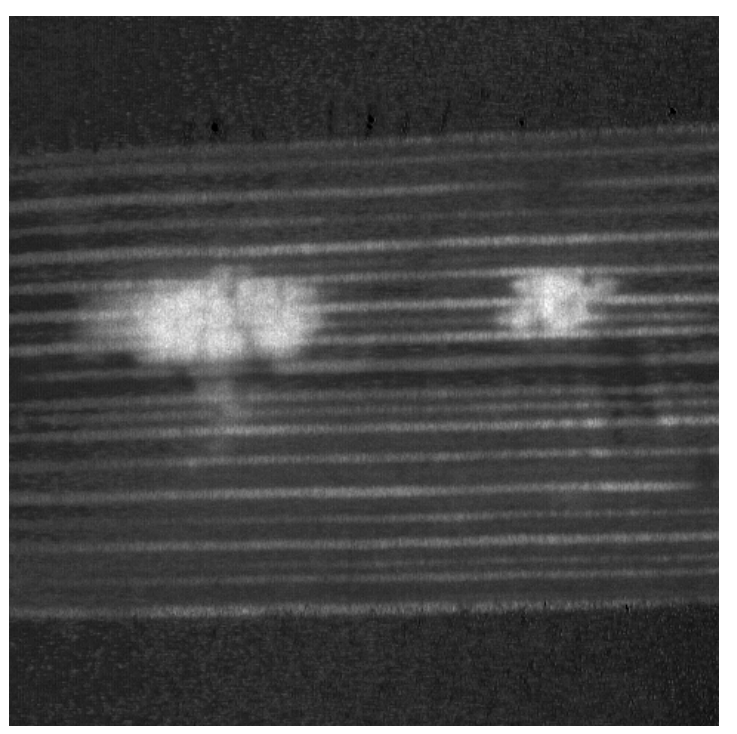

(b) mapa de Fujii

Figura 5.12: Mapeamento de folha contaminada com pulgões. 


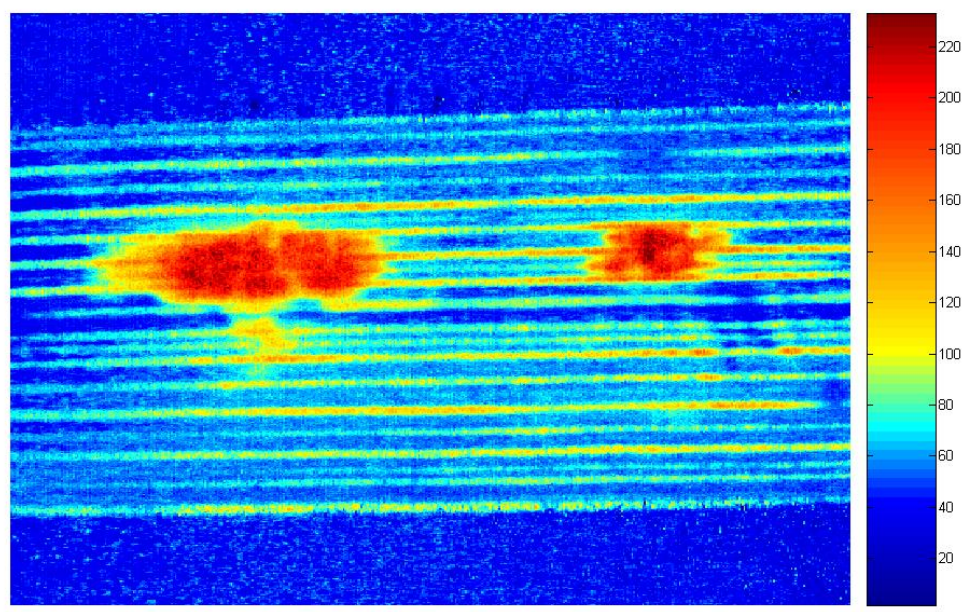

Figura 5.13: Mapa pseudo-colorido construído com o método de Fujii. As zonas avermelhadas indicam ataque de pulgões (Macrosiphum avenae). 


\subsection{Monitoramento de Atividade em Frutos}

A metodologia empregada na observação de frutos foi muito semelhante à utilizada na seção anterior. Todavia, devido à sua grande espessura, a configuração utilizada no arranjo experimental foi aquela mostrada na figura 5.4, ou seja, realizamos a observação do biospeckle no plano imagem por reflexão.

Foram estudadas amostras de morango, laranja e amora. A análise de morangos incluiu ainda uma situação de contaminação por fungos e a observação de amoras foi realizada em dois estágios distintos de maturação. A construção dos mapas foi realizada por meio do método de Fujii.

\subsubsection{Mapeamento em morangos}

A figura 5.4 esquematiza o arranjo utilizado na observação de morangos (Fragaria vesca) e a figura 5.14 apresenta em detalhe a fruta iluminada com luz coerente.

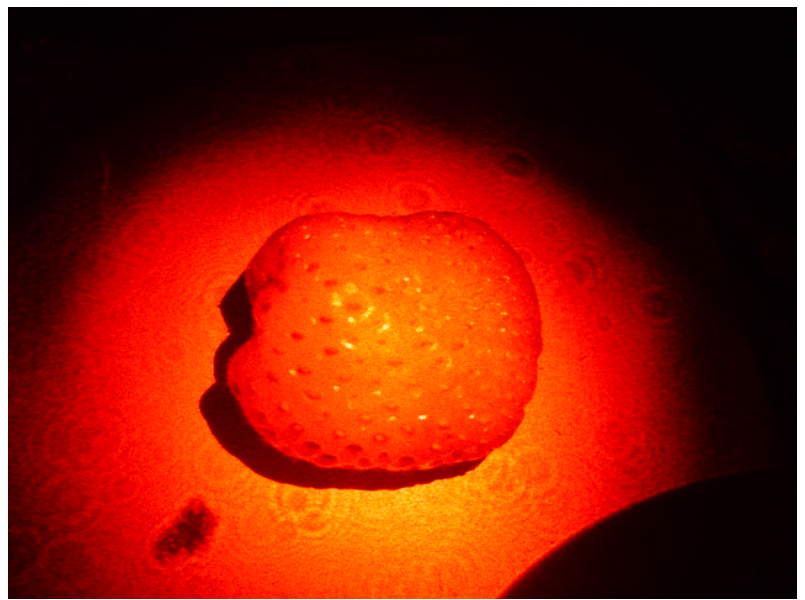

Figura 5.14: Detalhe do morango iluminado com laser.

O mapa pseudo-colorido é apresentado na figura 5.15. As regiões avermelhadas indicam a região onde fica localizada a polpa, enquanto as zonas verde-azuladas apontam os aquênios. Essas estruturas são portadoras de sementes e possuem grau de hidratação consideravelmente menor que a polpa e, por isso, apresentam menor nível de atividade.

O mesmo tipo de ensaio foi realizado com uma fruta contaminada por fungos. O exemplar utilizado na análise é mostrado em detalhe na figura 5.16 e o respectivo mapa já pseudo-colorido é apresentado em 5.17. 


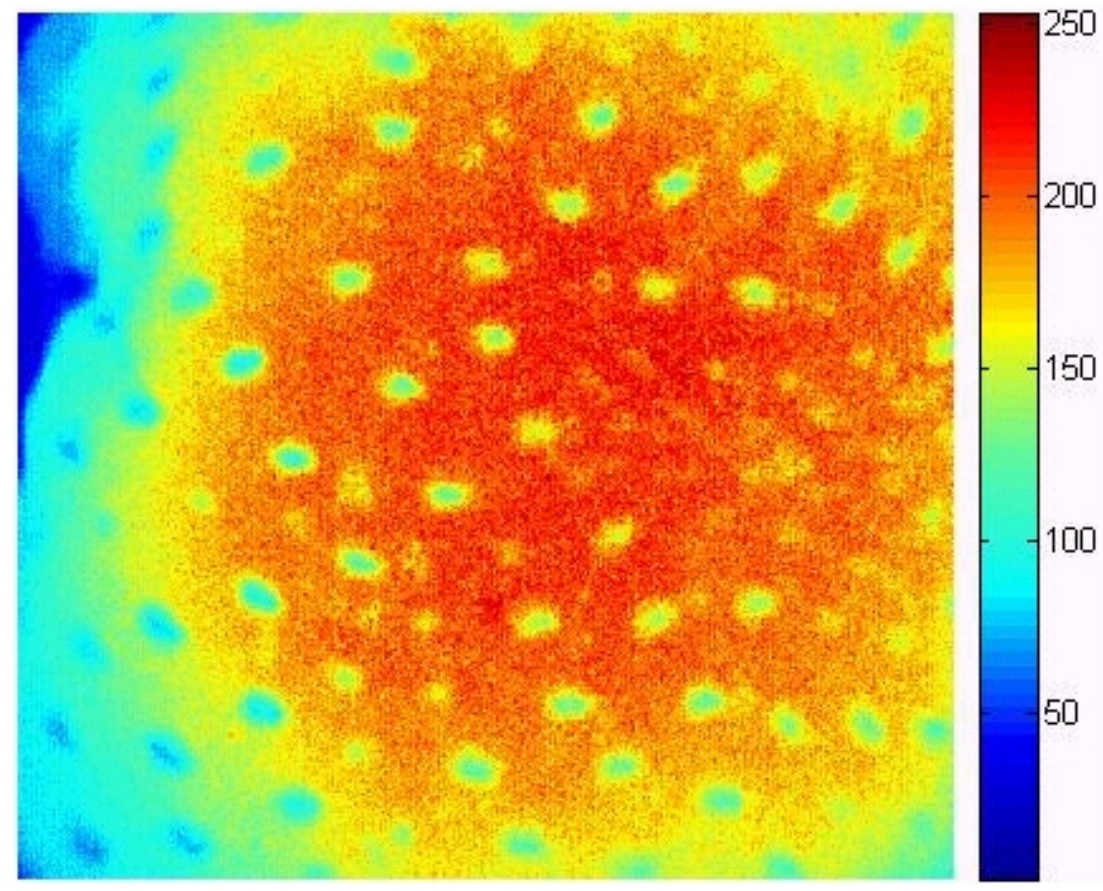

Figura 5.15: Mapa de Fujii de morango saudável.

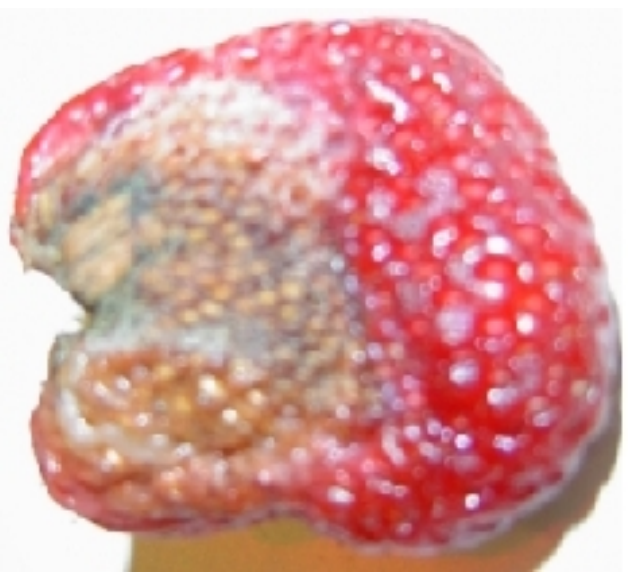

Figura 5.16: Morango contaminado por fungo. 


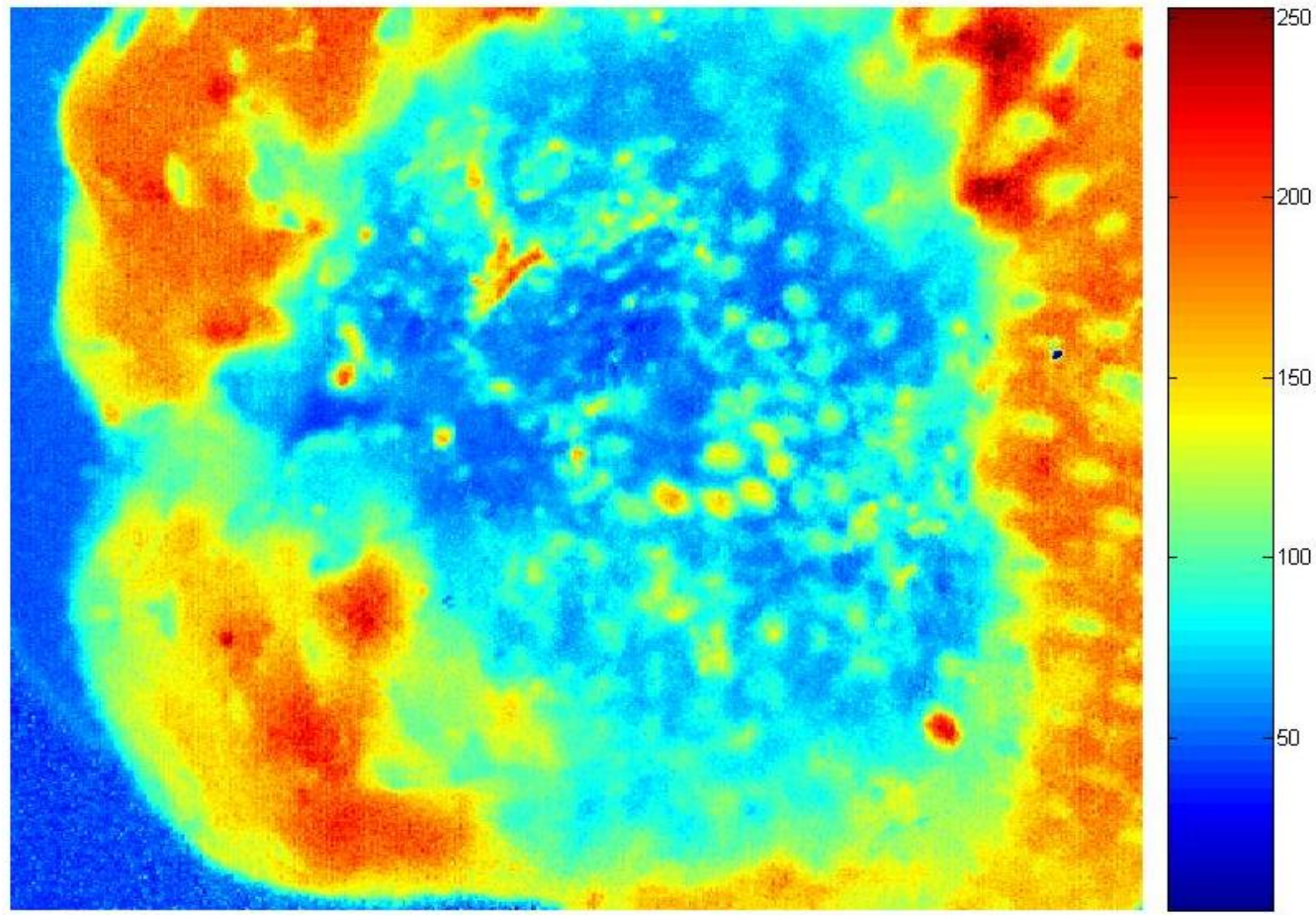

Figura 5.17: Mapa pseudo-colorido apontando o perfil de atividade em morango contaminado com fungo. 


\subsubsection{Mapeamento em Laranjas}

O monitoramento de atividade em laranjas (Citrus $x$ sinensis) através do biospeckle já foi largamente estudado em laboratórios brasileiros e estrangeiros [57]. Aqui nos limitamos apenas à apresentação do mapeamento dessa fruta empregando o método de Fujii.

Na figura 5.18 são apresentados o detalhe da região de inserção do pedúnculo ${ }^{3}$ e seu respectivo mapeamento.

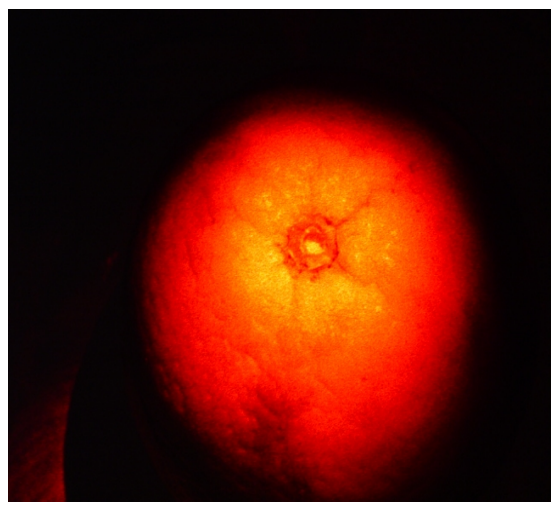

(a) registro simples

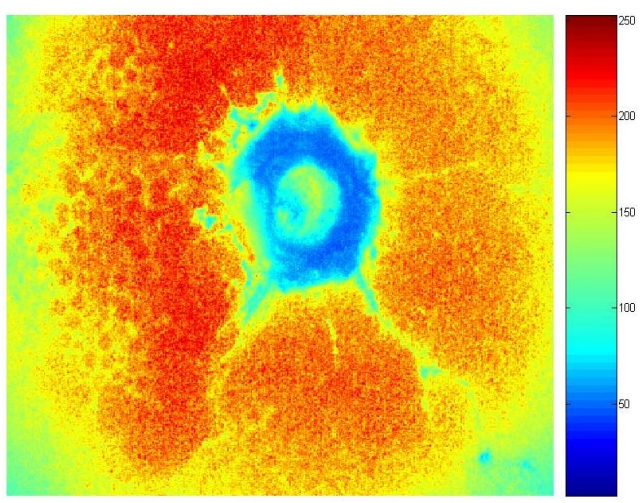

(b) mapa de Fujii

Figura 5.18: Detalhe da região de inserção do pedúnculo e respectivo mapa de atividade em laranja.

Na área peduncular, há uma zona azulada indicando menor atividade. Esse resultado é esperado, uma vez que essa região sofre necrose como forma de proteger a polpa do fruto e evitar o acesso de organismos estranhos ao seu interior.

\subsubsection{Mapeamento em Amoras}

Estudamos dois exemplares de amoras (Morus nigra). Uma delas foi colhida em um estágio mais apropriado ao consumo, enquanto a segunda já havia passado do ponto ideal de maturação. A figura 5.19 mostra a primeira fruta e o respectivo mapa de atividade construído por meio do método de Fujii.

A figura 5.20 mostra o mapa pseudo-colorido de uma fruta em avançado estado de maturação. O perfil de atividade neste segundo caso é completamente diferente daquele apresentado anteriormente.

\footnotetext{
${ }^{3}$ É a estrutura através da qual o fruto se prende ao galho.
} 


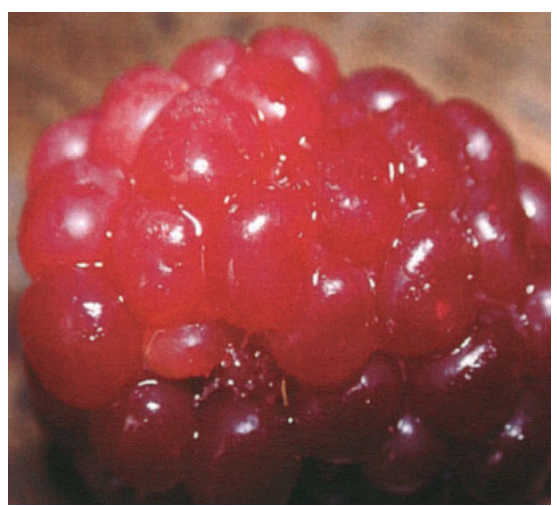

(a)

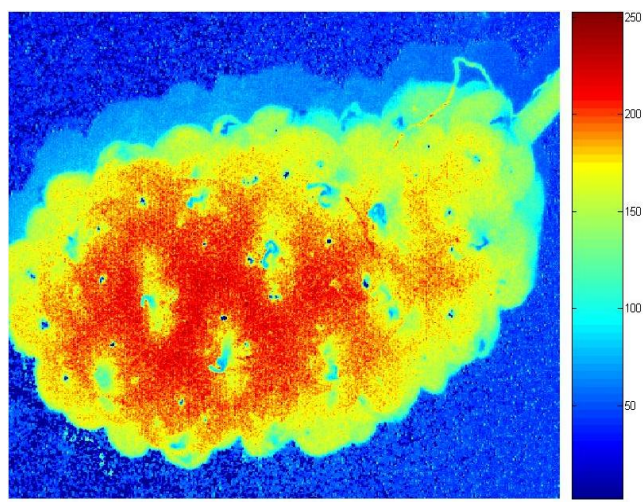

(b)

Figura 5.19: (a) Detalhe da amora observada e (b) respectivo mapa de atividade.

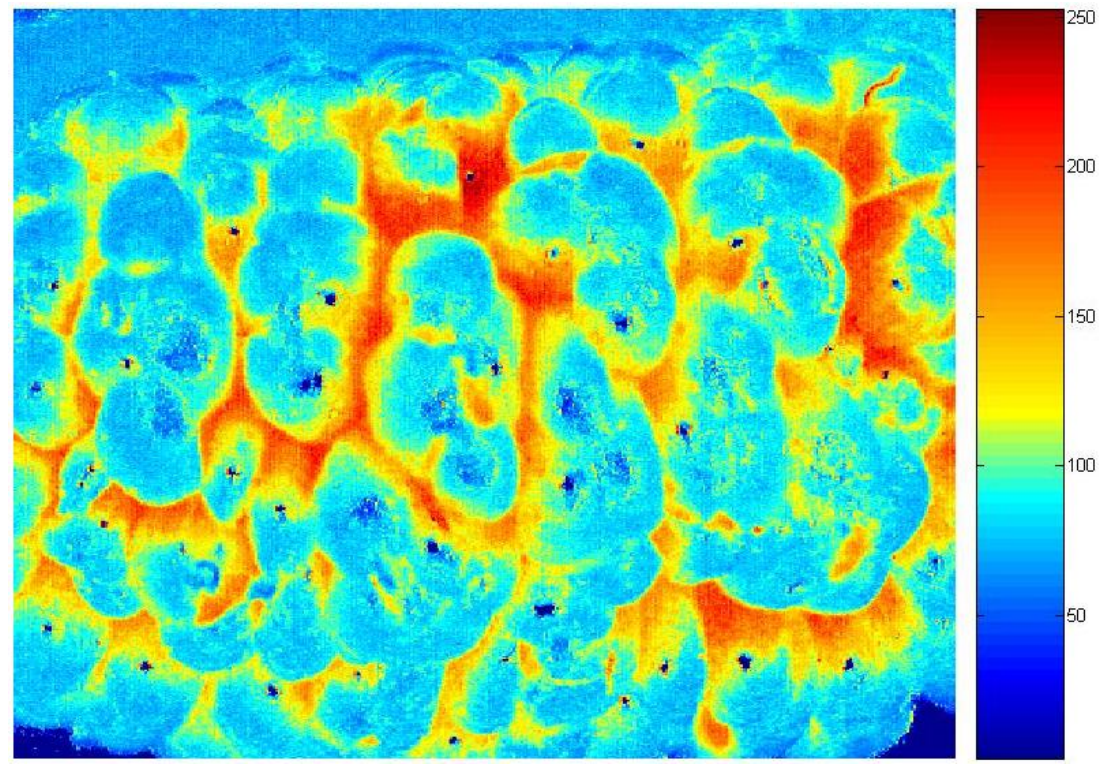

Figura 5.20: Mapa de Fujii de uma amora em avançado estágio de maturação. 


\subsection{Monitoramento de Atividade em Flores}

De maneira semelhante àquela realizada na observação de frutos, os estudos envolvendo flores foram realizados de acordo com o arranjo experimental esquematizado na figura 5.4. Os ensaios foram realizados imediatamente após a colheita, sendo uma margarida (Bellis perennis) o espécime escolhido.

Na figura 5.21 são mostradas as condições de iluminação dos experimentos.

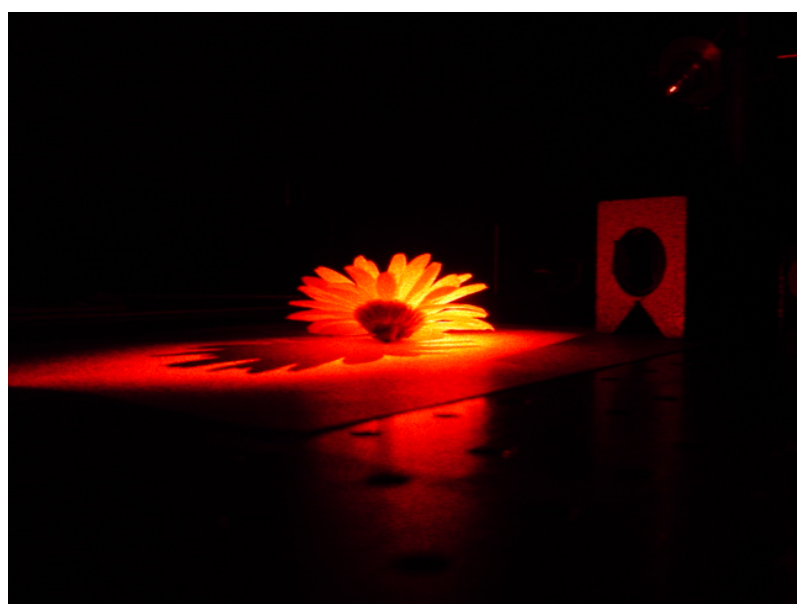

Figura 5.21: Flor preparada para mapeamento.

A técnica de mapeamento adotada foi o método de Fujii e o resultado é apresentado na figura 5.22. Nessa imagem, podemos verificar que a região das pétalas possui maior nível de atividade comparada ao "miolo" da flor. Esse resultado se justifica se compararmos os índices de hidratação dessas duas regiões: na planta recém-colhida a evaporação de água nas pétalas é muito superior àquela apresentada pelo núcleo da flor. 


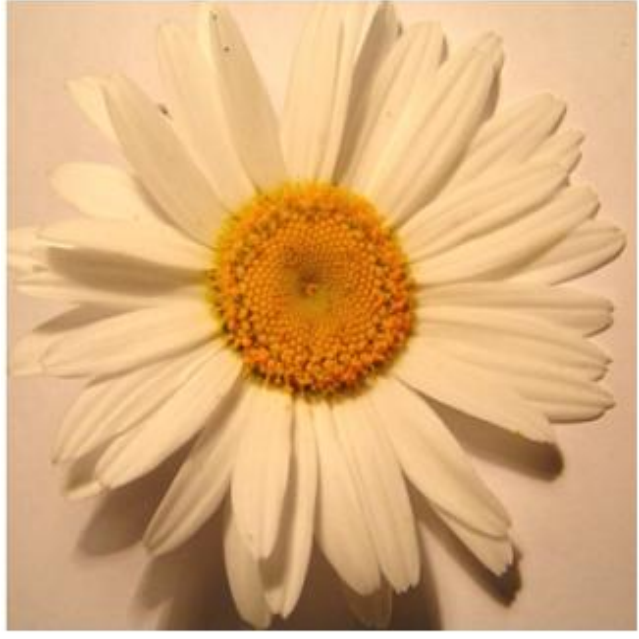

(a)

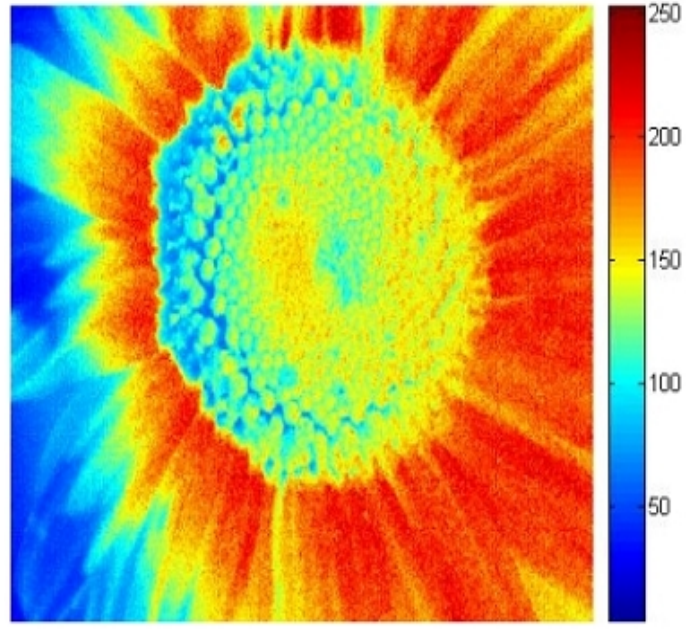

(b)

Figura 5.22: Mapeamento de flores pelo método de Fujii. 


\subsection{Microscopia de biospeckle}

Uma possibilidade bastante interessante para aplicações do biospeckle está relacionada ao seu uso em microscopia [59]. Espécimes com dimensões bastante reduzidas, cobertos com a estrutura granular, podem ser observados através de um microscópio e, no caso em que a amostra é dinâmica, a evolução temporal pode ser monitorada por meio das técnicas já expostas.

O arranjo experimental utilizado foi basicamente o mesmo já apresentado na figura 5.2. Entretanto, no lugar da objetiva da câmera CCD foi utilizado todo o conjunto óptico de um microscópio Leitz (figura 5.24), que fornecia um aumento total de 50x. A única modificação realizada foi a substituição do módulo de iluminação do aparelho por um laser He-Ne de $10 \mathrm{~mW}$. O feixe não precisou sequer ser expandido, pois a própria lente de focalização da fonte de luz já atuava como um expansor.

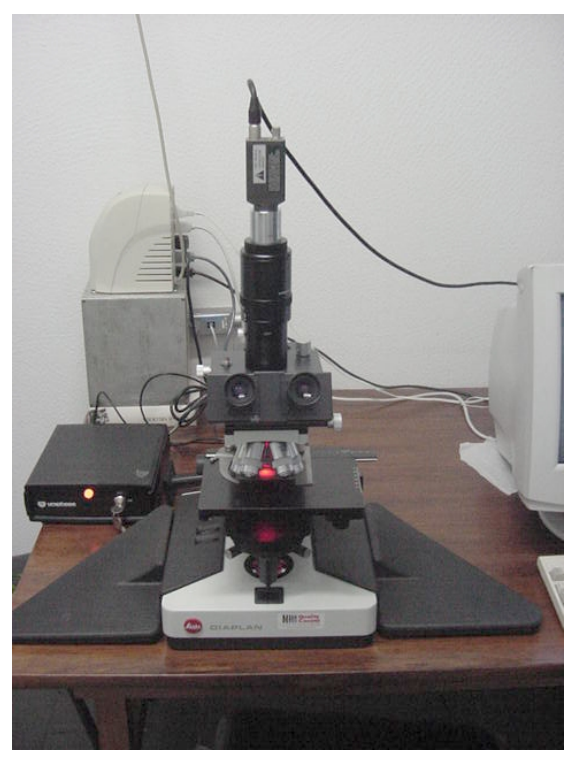

Figura 5.23: Arranjo para microscopia de biospeckle.

O espécime examinado foi uma folha vegetal e os respectivos mapas, contruídos através do método de Fujii, são exibidos na figura 5.24. 


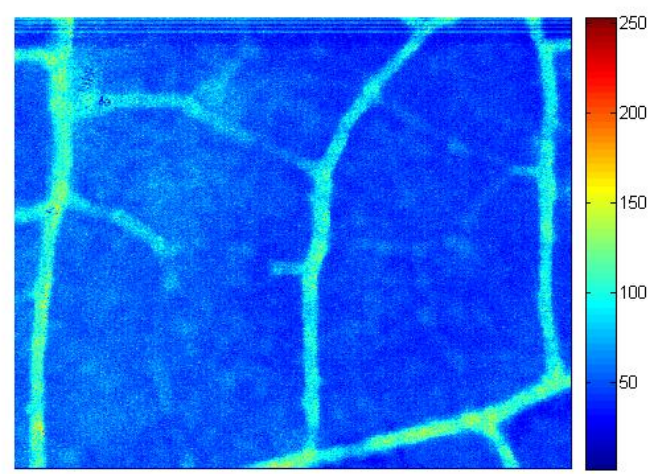

(a)

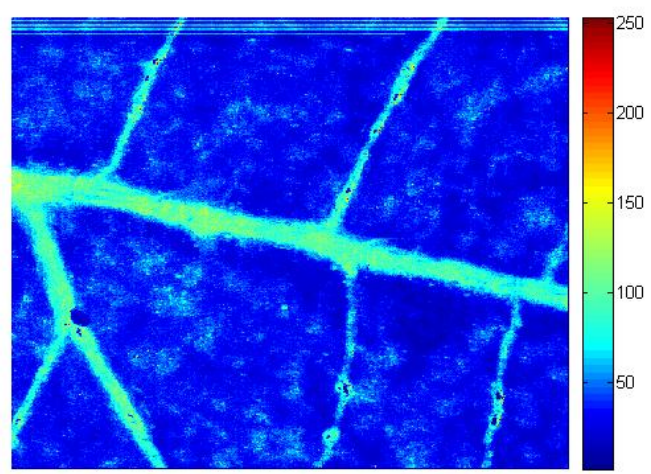

(b)

Figura 5.24: Mapas construídos através da microscopia de biospeckle.

\subsection{Biospeckle em Tecidos Animais}

O uso de técnicas de biospeckle aplicadas ao monitoramento de tecidos animais configurase, talvez, na aplicação mais interessante dos métodos até aqui apresentados. Os ensaios podem ser realizados de maneira não-invasiva e nenhum outro procedimento, exceto o uso de anestesia, precisa ser empreendido para que o monitoramento seja realizado. Essas características indicam grande potencial do biospeckle como ferramenta auxiliar à pesquisa nas áreas da biomedicina, onde questões éticas envolvendo a manipulação de animais em ambiente de laboratório vêm sendo amplamente discutidas nos últimos tempos. Além disso, a pesquisa em seres humanos torna-se facilitada.

Os ensaios apresentados a seguir foram realizados, em nosso laboratório, no contexto de uma tese de doutoramento da Faculdade de Ciências Médicas da UNICAMP [60]. Todos os experimentos tiveram a supervisão da médica Dra. Tâmara Maria Nieri ${ }^{4}$ e os protocolos adotados tiveram anuência do Comitê de Ética em Pesquisa daquela universidade.

\footnotetext{
${ }^{4}$ Registro CREMESP: 53841
} 


\subsubsection{Estudo do processo de cicatrização em ratos}

Quatro ratos adultos, tipo wistar, do sexo masculino, com 12 semanas de vida e pesando aproximadamente $300 \mathrm{~g}$, foram submetidos à cirurgia da parede abdominal para colocação de uma tela de polipropileno, no interior da camada muscular, para contenção de hérnia incisional (figura 5.25(a)).

O grande objetivo do trabalho foi avaliar, através do método óptico, os perfis de atividade na área operada e no tecido não operado da região abdominal. As análises envolvendo biospeckle foram realizadas no vigésimo dia pós-operatório. O biospeckle foi registrado no plano de Fraunhoffer e a configuração experimental correspondeu àquela esquematizada em 5.1. Uma fotografia apresentando o arranjo experimental é exibida em 5.25(b). O tempo total de aquisição foi da ordem de 30 segundos.

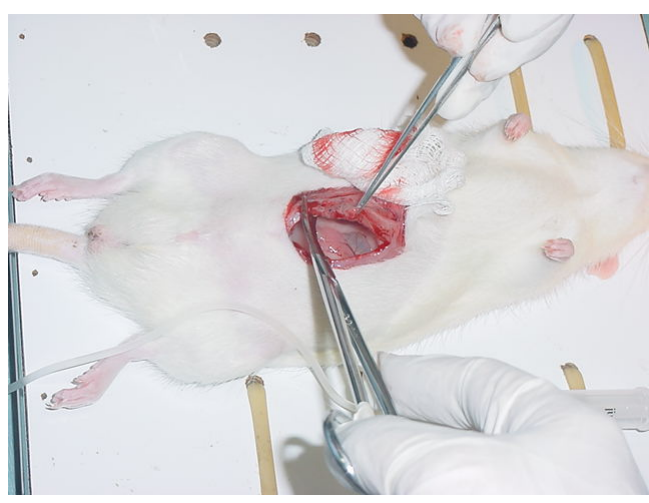

(a)

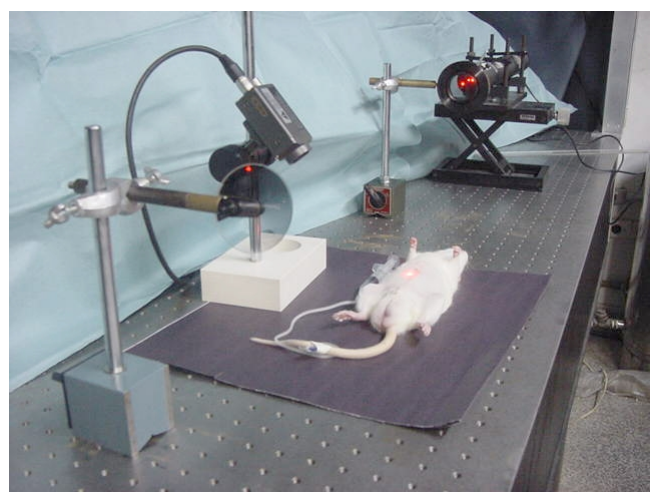

(b)

Figura 5.25: Detalhe da cirurgia e fotografia do arranjo experimental.

\subsubsection{Resultados}

Os THSPs foram analisados através do cálculo do contraste de correlação apresentado na seção 3.8. Nos quatro casos, esse índice revelou maior atividade no biospeckle extraído a partir da região que continha a tela de poliuretano, sugerindo a existência de correlação entre o processo de cicatrização e a atividade apresentada pelo biospeckle. Os resultados são exibidos na tabela 5.3.

A observação dos índices revela ainda que, na cobaia número 4, a atividade apresentada na região não operada foi superior às apresentadas pelas cobaias 1 e 2 na região 
Tabela 5.3: Contrastes de correlação de processo de cicatrização em ratos.

\begin{tabular}{ccc}
\hline Cobaia & $\begin{array}{r}\text { Tecido } \\
\text { com tela }\end{array}$ & $\begin{array}{c}\text { Tecido } \\
\text { não operado }\end{array}$ \\
\hline Rato 1 & 0,0104 & 0,0081 \\
\hline Rato 2 & 0,0109 & 0,0067 \\
\hline Rato 3 & 0,0115 & 0,0093 \\
\hline Rato 4 & 0,0181 & 0,0111 \\
\hline
\end{tabular}

onde realizou-se a cirurgia. Esse dado chama a atenção para o fato do biospeckle fornecer um índice geral de atividade no tecido, a qual tem origem em diversos fatores tais como pulsação, frequência respiratória, estado da rede vascular do animal, movimentos peristálticos, etc. Portanto, a comparação entre índices obtidos a partir de espécimes distintos deve ser realizada com bastante critério. Todavia, a partir desses quatros exemplos obtidos, torna-se consistente a idéia de que é possível avaliar tecidos de mesma natureza, no mesmo espécime, através desse método óptico.

\subsection{O biospeckle como ferramenta de diagnóstico em tecidos humanos}

O desenvolvimento de técnicas ópticas aplicadas tanto à terapia quanto ao diagnóstico em medicina tem sido objeto da atenção de inúmeros grupos de pesquisa ao redor do mundo [61, 62]. Nesse contexto, nos últimos anos, cunhou-se na área médica o termo "teradiagnóstico" [63] para designar modalidades terapêuticas que fornecem diagnóstico acerca da resposta do paciente ao tratamento. Por outro lado, conforme abordado na seção 1.3.6, vem ganhando força o uso da laserterapia de baixa intensidade como técnica substituta ou coadjuvante na recuperação de tecidos lesados [26]. Os resultados obtidos em tecidos vegetais e animais, aliados a uma parceria com a equipe da Central Médica de Laser do Hospital das Clínicas da USP, nos encorajaram a investigar a implementação do biospeckle como ferramenta de diagnóstico em seres humanos, especialmente aquela ligada ao monitoramento de vascularização em áreas lesadas. 


\subsubsection{Protocolo de tratamento}

Monitoramos uma úlcera venosa crônica na região do osso maléolo direito em voluntária de 65 anos. A paciente reportava dores agudas e a lesão estava presente havia três anos. Terapias tradicionais, com uso de medicação oral e tópica, já haviam sido realizadas sem êxito. A ferida possuía formato circular com diâmetro em torno de $3,6 \mathrm{~cm}$ e profundidade da ordem $0,5 \mathrm{~cm}$.

Os testes foram realizados em três ocasiões nas dependências do ambulatório do InCor $^{5}$, sob supervisão da Prof. Dra. Maria Cristina Chavantes ${ }^{6}$. A primeira análise foi realizada no início do tratamento, a segunda, uma semana depois, e a terceira, na vigésima semana. Em cada dia, fotografamos a lesão, utilizando o biospeckle, antes de qualquer procedimento clínico. Em seguida, a lesão era irradiada com laser de baixa potência, com aplicação em pontos no interior da lesão mais varredura na área externa conforme indicado na figura 5.26. Após a aplicação da laserterapia, um novo registro era realizado.

No primeiro dia, foram utilizados dois comprimentos de onda distintos, $685 \mathrm{~nm}$ e 830 $\mathrm{nm}$, com potência de $33 \mathrm{~mW}$. O primeiro comprimento de onda foi irradiado em oito pontos, durante 7 segundos. Essa série foi repetida três vezes. A seguir foi realizada varredura em torno da lesão durante 140 segundos. Luz de comprimento de onda $830 \mathrm{~nm}$ foi irradiada apenas nos 8 pontos interiores à lesão e a série foi repetida apenas uma vez. O mesmo procedimento (incluindo a mesma dosagem) foi aplicado à região contra-lateral a fim de obtermos uma comparação entre as atividades apresentadas pelo biospeckle antes e depois da aplicação da laserterapia. Os resultados são mostrados na seção 5.7.3.

Na semana seguinte, o procedimento adotado foi parecido. Contudo, em virtude dos resultados insatisfatórios na semana anterior, a equipe médica optou por mudar a dose de LBI (laser de baixa intensidade). Novamente, um registro prévio da lesão (coberta com biospeckle) foi realizado e, em seguida, os mesmos comprimentos de onda foram irradiados. O comprimento de $685 \mathrm{~nm}$ foi utilizado em apenas dois pontos no interior da

\footnotetext{
${ }^{5}$ INSTITUTO DO CORAÇÃO, vinculado ao Hospital das Clínicas da Faculdade de Medicina da USP.
}

${ }^{6}$ Registro CREMESP: 61772 


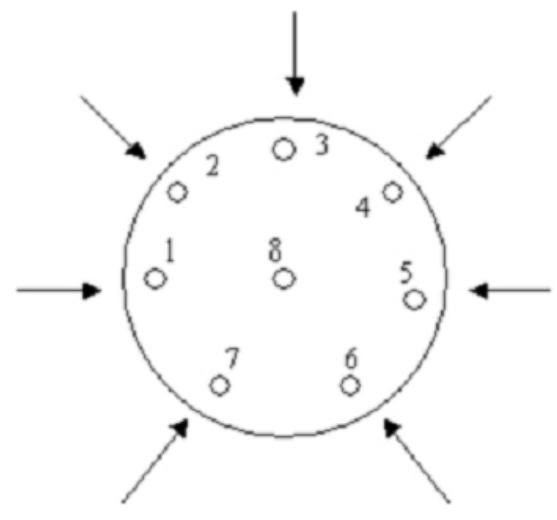

(a)

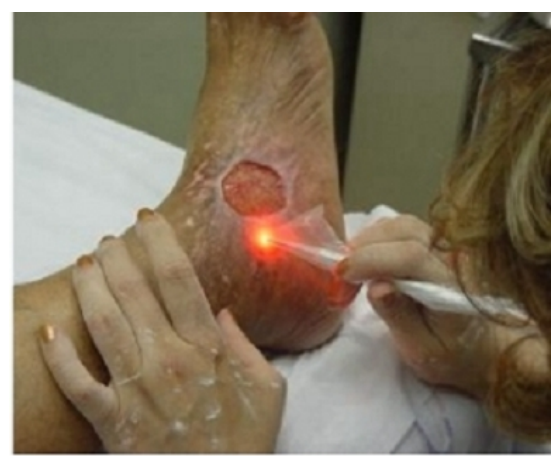

(b)

Figura 5.26: Mapas construídos através da microscopia de biospeckle.

ferida e o lado externo teve luz irradiada por apenas 49 segundos. Essa série foi repetida 3 vezes. Luz de comprimento de $830 \mathrm{~nm}$ foi irradiada em quantidade bem maior em relação à semana anterior (22 pontos) e também a região posterior da perna recebeu tratamento.

Esses procedimentos com irradiação de LBI continuaram nas semanas que se seguiram, com posterior administração de antibióticos. Durante esse tempo, houve progressiva melhora da paciente, especialmente com significativa diminuição da dor reportada. Na vigésima semana (após 5 meses de tratamento) realizamos novamente o monitoramento por meio do biospeckle. Porém, dada a evolução do tratamento, apenas o comprimento de onda de $830 \mathrm{~nm}$ foi utilizado. A aplicação foi realizada em 9 pontos no interior da lesão, durante 9 segundos cada, com potência de $25 \mathrm{~mW}$. Na área externa, foi realizada varredura durante 207 segundos, nas mesmas condições de potência. A tabela 5.4 resume as principais características de aplicação do LBI nos ensaios realizados.

A figura 5.27 mostra o aspecto da área lesada nas semanas em que os ensaios foram realizados. Na vigésima semana, a lesão apresentava menor profundidade e já era notória a presença de tecido de reparação (figura 5.27(c)).

\subsubsection{Metodologia de registro e análise de imagens}

O arranjo para o registro fotográfico utilizou o speckle por reflexão, observado no plano imagem. A configuração esquemática básica é aquela exibida na figura 5.4. Um filtro espacial foi posicionado a uma distância de aproximadamente $60 \mathrm{~cm}$ da lesão, com objetivo de expandir o feixe de tal forma que seu diâmetro ocupasse toda a região da ferida. 
Tabela 5.4: Resumo das aplicações de laser de baixa intensidade.

\begin{tabular}{|c|c|c|c|c|c|c|c|}
\hline Semana & $\begin{array}{c}\lambda \\
(\mathrm{nm})\end{array}$ & $\begin{array}{l}\text { Potência } \\
\text { (mW) }\end{array}$ & $\begin{array}{c}\text { Tempo } \\
\text { (s) }\end{array}$ & $\begin{array}{l}\text { Número } \\
\text { de pontos }\end{array}$ & Repetições & $\begin{array}{c}\text { Energia } \\
\qquad(\mathrm{J})\end{array}$ & Local \\
\hline Primeira & 685 & 33 & 7 & 8 & 3 & 5,5 & Interior da lesão \\
\hline Primeira & 685 & 33 & 7 & 20 & 1 & 4,6 & Varredura externa \\
\hline Primeira & 830 & 33 & 7 & 8 & 1 & 1,8 & Interior da lesão \\
\hline Primeira & 830 & 33 & 7 & 20 & 1 & 4,6 & Varredura externa \\
\hline Segunda & 685 & 33 & 7 & 2 & 3 & 1,4 & Interior da lesão \\
\hline Segunda & 685 & 33 & 7 & 7 & 3 & 4,8 & Varredura externa \\
\hline Segunda & 830 & 33 & 7 & 22 & 2 & 10,2 & Interior da lesão \\
\hline Segunda & 830 & 33 & 7 & 1 & 3 & 0,7 & $\begin{array}{c}\text { Região superior } \\
\text { da perna }\end{array}$ \\
\hline Terceira & 830 & 25 & 9 & 9 & 1 & 2,0 & Interior da lesão \\
\hline Terceira & 830 & 25 & 9 & 23 & 1 & 5,2 & Varredura externa \\
\hline
\end{tabular}

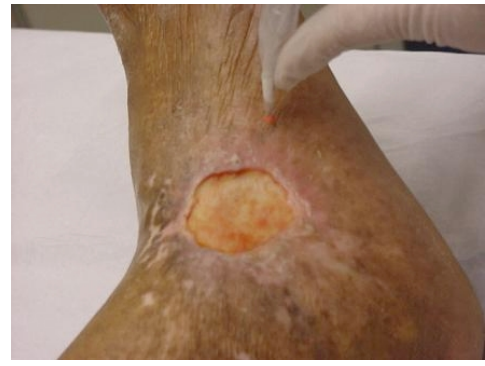

(a) primeira semana

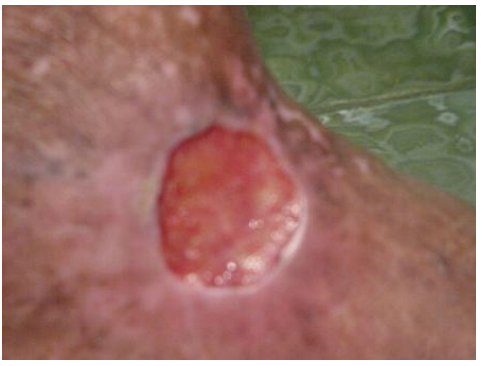

(b) segunda semana

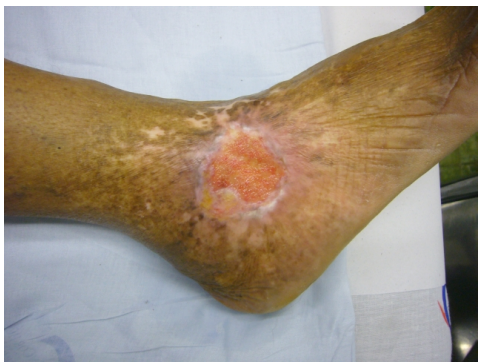

(c) vigésima semana

Figura 5.27: Evolução da lesão ao longo das semanas de tratamento.

Por razões de conforto para o paciente, e maior facilidade de posicionamento, a montagem foi realizada no chão, de maneira que a perna era mantida na vertical. Uma fotografia do arranjo é mostrada na figura 5.28, onde a seta indica a direção da luz incidente e a posição do sistema de registro é ilustrada (o laser e o filtro espacial não são exibidos).

A fonte de luz usada foi um laser de He-Ne, com potência de $10 \mathrm{~mW}$. A câmera e a lente objetiva utilizadas, assim como o sistema computacional adotado, têm suas características descritas na tabela 5.1. Devido à mobilidade do paciente, para análise das imagens, foi escolhido foi o método LASCA, descrito na seção 3.6. Ensaios preliminares apontaram que, dentre os tempos de integração disponíveis, o que fornecia melhores resultados (ou seja, maior contraste entre zonas de diferentes atividades) era de $17 \mathrm{~ms}$. 


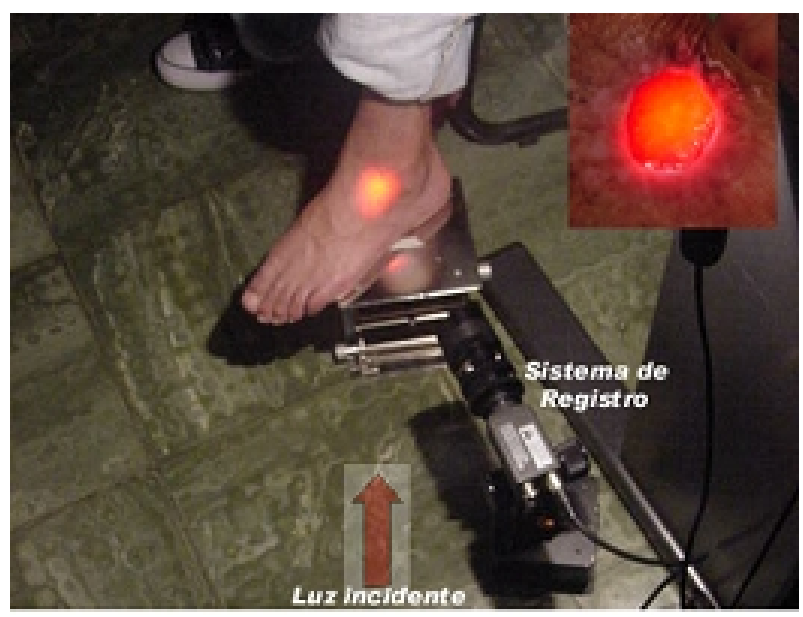

Figura 5.28: Arranjo para registro fotográfico do biospeckle em paciente, com a iluminação da lesão exibida em detalhe.

\subsubsection{Resultados}

Como se trata de mapeamento de uma região extensa e dadas as dificuldades de mobilidade inerentes a organismos vivos, a técnica de análise adotada foi o método LASCA (seção 3.6). Os resultados obtidos na primeira semana são apresentados na figura 5.29.

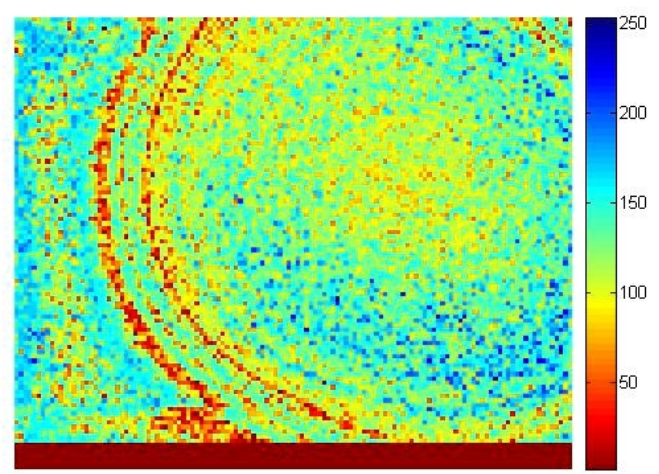

(a) Antes da laserterapia

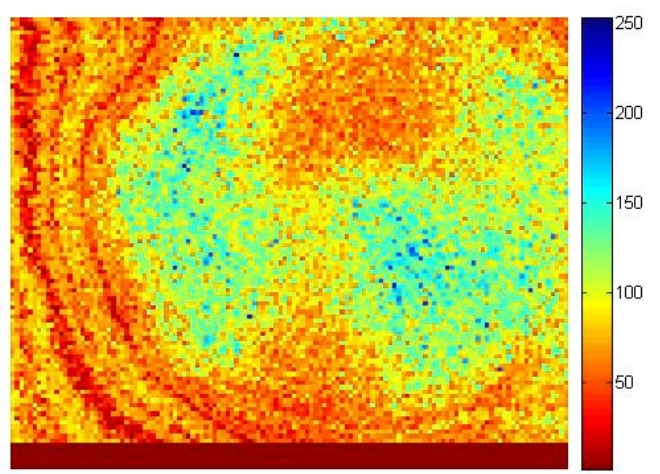

(b) Depois da laserterapia

Figura 5.29: Mapas de atividade da lesão na primeira semana.

É importante ressaltar que na metodologia LASCA a visualização dos mapas requer uma interpretação ligeiramente distinta daquela empregada no mapas gerados a partir dos métodos de Fujii e afins. É preciso ter em mente que estamos trabalhando com um mapa de contrastes, ou seja, a imagem final obtida corresponde às variações espaciais de intensidades na zona mapeada. Dessa maneira, uma zona mais ativa apresenta contraste mais 
baixo e, portanto, aparece com menor valor na imagem final. Nos mapas apresentados a seguir, a escala de cores colocada ao lado indica que os valores de contraste (normalizados) vão de 0 (vermelho, mais ativo) a 255 (azul, estático). Com objetivo de ser coerente com a idéia intuitiva de que cores quentes correspondem a pontos mais ativos, foi realizada a inversão da escala de cor para facilitar a interpretação do leitor. Assim uma tonalidade mais azulada indica menor atividade em relação a uma região com tons avermelhados.

Nota-se que na primeira semana houve um aumento significativo de atividade (ampliação da zona avermelhada) após a irradiação com laser de baixa potência.

A figura 5.30 exibe os mapas obtidos para a região contra lateral (saudável). Eles indicam que não houve acréscimo significativo de atividade (comparado com o mapa anterior) com a irradiação do laser. Esse resultado é bastante interessante, pois concorda com a idéia de que a ferida exposta permite maior penetração da luz e consequente iluminação das camadas vascularizadas do tecido cutâneo.

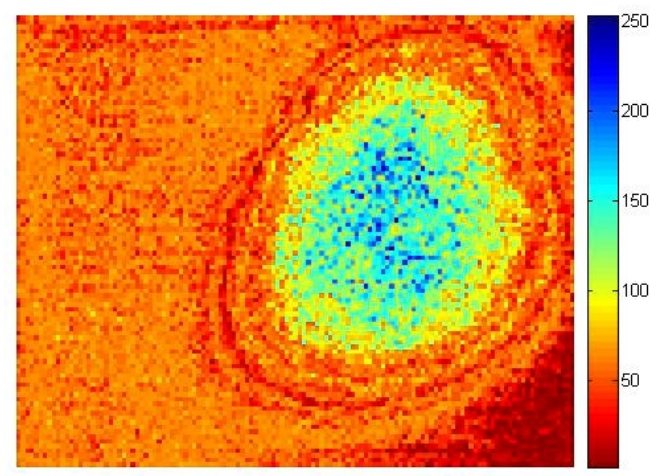

(a) Antes da aplicação

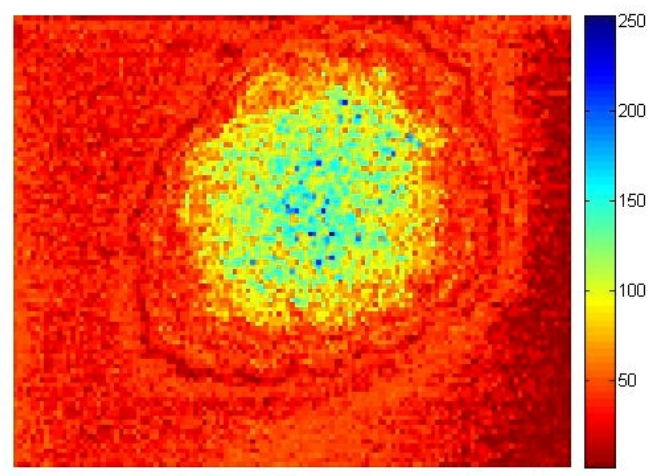

(b) Depois da aplicação

Figura 5.30: Mapas de atividade na região do maléolo saudável.

Os ensaios realizados na segunda semana têm seus resultados exibidos na figura 5.31. Assim como na primeira semana, houve aumento de atividade após a aplicação. No entanto, houve diferenças na distribuição desse aumento. Na segunda semana, o incremento das regiões ativas foi mais homogêneo, possivelmente devido às alterações de dose implementadas pela equipe médica. 


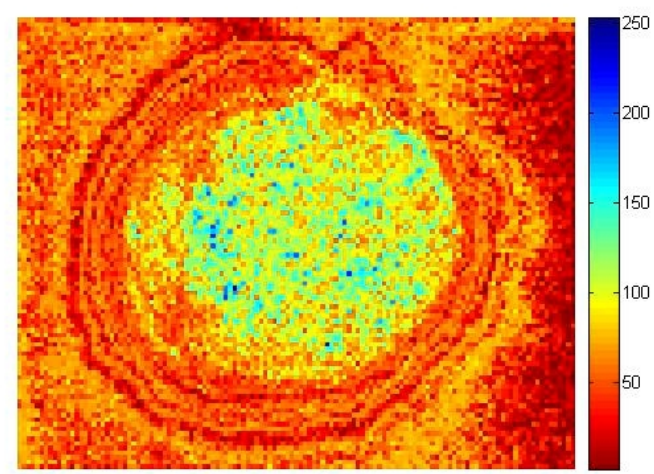

(a) Antes da laserterapia

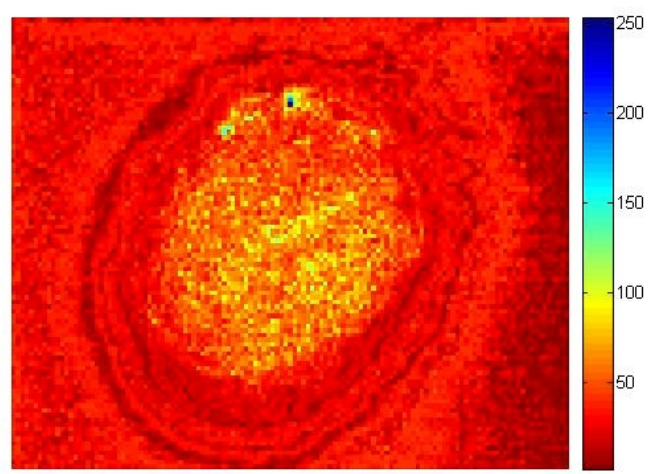

(b) Depois da laserterapia

Figura 5.31: Mapas de atividade na lesão na segunda semana.

Finalmente, na figura 5.32 são exibidos os mapas realizados na vigésima semana. Nessa ocasião, conforme já levantado, a lesão estava em estágio mais adiantado de cicatrização e apresentava resposta clínica ao tratamento à base de antibióticos que foi realizado de forma concomitante com a laserterapia. Assim como nas semanas anteriores, após a aplicação de luz, houve aumento significativo de atividade. Além disso, esse aumento ocorreu de maneira uniforme.

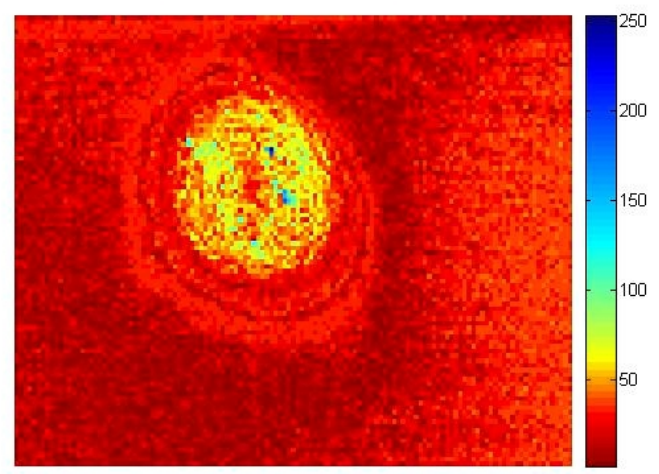

(a) Antes da laserterapia

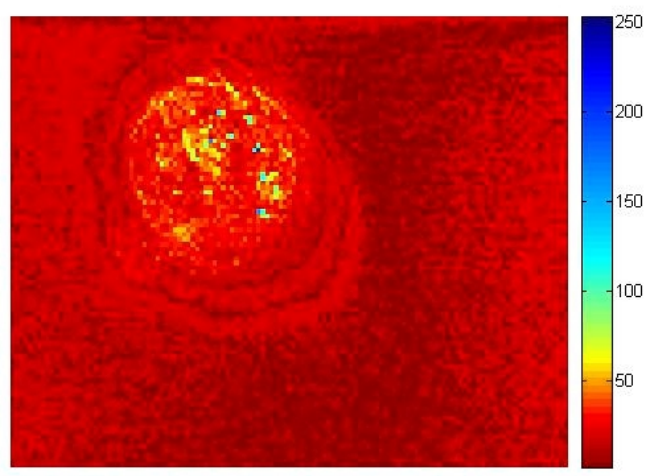

(b) Depois da laserterapia

Figura 5.32: Mapas de atividade na lesão na vigésima semana.

Tais resultados sugerem que há potencial de aplicação do biospeckle e dos métodos expostos nessa dissertação como ferramenta coadjuvante no diagnóstico de lesões. Eventualmente, a própria iluminação utilizada durante as aplicações poderia ser utilizada para 
o monitoramento da resposta da área lesada, indo ao encontro ao conceito de "teradiagnóstico" apresentado no início desta seção. 


\section{Conclusões e Perspectivas}

Ao longo desta dissertação, foram apresentadas as principais propriedades estatísticas de padrões speckle e os mais importantes métodos de análise utilizados na extração de informações a partir do granulado óptico. O fenômeno do biospeckle teve particular atenção, especialmente na sua aplicação ao monitoramento de atividade em tecidos. Simulações numéricas foram implementadas com duplo objetivo: testar os métodos de análise e fornecer subsídios para as interpretações in vivo. Esses trabalhos computacionais tiveram, ainda, a intenção de introduzir o uso de modelos numéricos no contexto de nosso grupo de pesquisa. Nos estudos experimentais foi usada uma variedade relativamente ampla de organismos biológicos, de folhas vegetais a seres humanos, sendo esta última nossa grande meta de aplicação.

As primeiras conclusões que podem ser tiradas são aquelas inerentes às técnicas de speckle em geral e não ao biospeckle em particular. O fato de ser um método não invasivo e de não necessitar de contato mecânico são grandes vantagens no estudo de sistemas biológicos e na sua aplicação em áreas da saúde.

Outro aspecto interessante é a relativa simplicidade do arranjo experimental. O uso de poucos componentes, aliado ao seu baixo custo, tornam as técnicas aqui apresentadas bastante simples e acessíveis. No que se refere ao biospeckle propriamente dito, sua implementação na vasta gama de tecidos aqui apresentada mostra a grande versatilidade do fenômeno e sua aplicabilidade aos mais diversos campos das ciências biológicas, da agronomia à biomedicina. A adequação das condições experimentais ao tipo de informação desejada é indispensável. Assim, se o objetivo é a determinação de um índice que expresse uma medida global da atividade, a observação no plano de Fraunhoffer é mais adequada. No entanto, quando se deseja construir um mapa, indicando os perfis de atividade em 
zonas distintas de uma região extensa, a configuração no plano imagem é a recomendada. A variedade dos métodos de análise apontados ilustra as muitas opções para se determinar a bioatividade usando o granulado. Entretanto, essa amplitude de aplicações e possibilidades implicam na necessidade de cuidados especiais na interpretação dos resultados obtidos, merecendo aqui uma discussão em maior profundidade.

Por exemplo, um sistema bastante ativo apresenta pequeno comprimento de correlação, porém o respectivo momento de intensidades é elevado. Nos mapas gerados a partir do método de Fujii, uma região mais clara (ou mais avermelhada, nos mapas coloridos) tem interpretação ligeiramente distinta dos mapas produzidos usando a técnica de LASCA. Nas análises de contraste espacial, jamais pode ser esquecido o fato de que, essencialmente, é calculado um desvio-padrão relativo das intensidades em uma região. A observação desse detalhe chama a atenção para necessidade de se considerar a relação sinal-ruído na interpretação desses mapas. Assim, no conjunto das figuras de 5.29 a 5.32, a região que está fora da área da lesão também aparece ativa. Isto é devido ao ruído eletrônico intrínseco ao sistema de aquisição e, sendo menor a intensidade média fora da região iluminada, a relação sinal-ruído é menor, indicando maior contraste. Uma análise desatenta pode levar, então, à interpretação errônea de atividade nesses locais. Em contrapartida, observando os mapas de Fujii, vê-se que a região fora da área do espécime aparece, corretamente, com baixa atividade. Isso se deve ao fato desse tipo de mapa ser construído a partir de um acúmulo de visibilidades. Entretanto, embora possua uma interpretação mais simples e intuitiva, os mapas de Fujii têm o inconveniente de necessitarem de uma grande quantidade de imagens. Os melhores mapas obtidos, monitorando folhas vegetais, necessitaram de cerca de 400 imagens (figura 5.11, por exemplo). Essa grande quantidade de registros inviabiliza a utilização desse método na análise de organismos animais in vivo, devido à mobilidade. Por isso, a técnica LASCA, que necessita apenas de um registro praticamente instantâneo, foi a escolhida para o monitoramento em seres humanos.

Outra conclusão tirada ao longo do trabalho foi a respeito da análise do contraste temporal (LASTCA). Notou-se que esse método necessita de uma quantidade muito menor de imagens para a composição do mapa final quando comparado à técnica de Fujii. De 
acordo com os experimentos empreendidos com folhas, cerca de 50 registros sequenciais foram suficientes para obtenção de bons mapas de contraste temporal (figura 5.9).

Nas simulações, os momentos de inércia e os contrastes de correlação apresentaram praticamente o mesmo comportamento (vide as figuras 4.9 e 4.10). Entretanto, algumas diferenças importantes podem ser destacadas entre estes dois índices. Os momentos de intensidades têm como aspecto positivo a representação gráfica das matrizes de coocorrências, fornecendo, assim, uma interpretação qualitativa imediata. Já os contrastes de correlação mostram maior regularidade com aumento de velocidade, sendo possível um ajuste de parábola praticamente perfeito.

A função de autocorrelação apresenta a vantagem de ser complementada pela densidade espectral de potência, o que permite a extração de informações no domínio de frequências. Além disso, dos índices estudados com o modelo numérico mostrado no capítulo 4, o comprimento de correlação eficaz foi aquele que apresentou menor dependência da distribuição de velocidades dos centros espalhadores. Essa característica pode ser bastante útil na análise de sistemas biológicos, uma vez que, possivelmente, indivíduos diferentes de uma mesma espécie apresentam distribuições distintas para as velocidades dos fluxos e movimentos em nível histológico. Em relação ao contraste de Briers, nossos estudos sugeriram sua validade no contexto do modelo numérico apresentado, porém, sua aplicação ao estudo de espécimes biológicos precisa ser melhor avaliada para ser efetivamente posta em prática. Além disso, ele não apresentou nenhuma vantagem significativa sobre o conjunto dos demais métodos apresentados.

As conclusões expostas acima podem ser sumarizadas da seguinte forma:

1. Nas análises no plano de Fraunhoffer, o método que apresentou maior regularidade foi o contraste de correlações. Esse mesmo comportamento foi confirmado pelos ensaios realizados em tecidos animais;

2. Tanto os momentos de inércia quanto os contrastes de correlação apresentaram forte dependência em relação à distribuição de velocidades dos centros espalhadores, sugerindo que tais índices possam ser investigados na determinação dessas distribuições em tecidos; 
3. A função de autocorrelação, aparentemente, não é tão suceptível às diferentes distribuições quanto os dois métodos do item anterior. O comportamento da correlação eficaz não variou com a distribuição das velocidades dos espalhadores, dependendo apenas do valor máximo de velocidade (figura 4.13);

4. Os melhores mapeamentos foram obtidos por meio do método de Fujii. No entanto, esse método é ideal apenas para vegetais ou organismos onde não há grande mobilidade, pois a quantidade de imagens necessárias é grande;

5. A análise de contraste espacial possui o inconveniente da perda de resolução, porém o fato de precisar de um registro instantâneo torna a técnica a mais adequada ao mapeamento de atividade em animais vivos e seres humanos. Nesse caso, é fundamental tomar cuidados na interpretação dos mapas, considerando a discussão acerca da relação sinal-ruído feita acima;

6. O método de análise do contraste temporal possui a vantagem de precisar de menos imagens que o método de Fujii. Talvez a explicação para isso esteja relacionada ao limite da mínima variância [24]. Todavia, possivelmente a quantidade de registros necessários varie de acordo com o espécime biológico estudado;

7. No estudo de úlcera venosa em seres humanos, o biospeckle revelou seu grande potencial, de forma que seja essa, talvez, a maior contribuição desse trabalho. Os monitoramentos realizados apontaram que é possível fazer comparações entre a atividade antes e depois da aplicação da medida terapêutica. Esses fatos abrem inúmeras perspectivas para o uso do método em ambiente clínico, pois o custo é baixo, o arranjo é simples e sua concepção vai de encontro às tendências atuais de uso de técnicas não-invasivas e "teradiagnóstico".

No campo das perspectivas e trabalhos futuros, as técnicas aqui apresentadas fatalmente devem passar pelo uso de maiores velocidades de aquisição e melhores taxas de resolução. Nas aplicações em seres humanos, os métodos de análise de contraste (tanto espacial quanto temporal) são os mais promissores. O aumento de resolução permitiria de imediato o uso de células de contraste maiores, melhorando a estatística dos cálculos. 
O uso de equipamentos mais velozes (algo da ordem de 100 frames por segundo) abriria possibilidades para o uso da "redução ativa de ruído", que recentemente vem sendo desenvolvida por grupos de pesquisa europeus $[48,64]$. Outra linha de trabalhos que também pode ser largamente estudada são as simulações numéricas, com o uso de modelos mais complexos, prevendo espalhamentos múltiplos, espalhadores com distribuições diferentes de velocidades, espalhamentos quasi-elásticos, etc. Ainda há necessidade de se explorar modelos que trabalham com o biospeckle no plano imagem. Por fim, outra possibilidade vislumbrada ao longo da dissertação foi o desenvolvimento de trabalhos que combinem técnicas de microscopia com aquelas apresentadas aqui, abrindo novas possibilidades ao mapeamento de atividade em níveis celulares e de microorganismos [59].

Com base no conteúdo exposto ao longo desta dissertação, acredito que o potencial desse fenômeno, até certo ponto corriqueiro na óptica coerente, foi aqui demonstrado. Em suma, corroborando as já citadas palavras de Dennins Garbor, ficou evidente que " $n a$ verdade não é ruído, é informação (...)". 


\section{Apêndice A}

\section{Tópicos em estatística}

\section{A.1 Teorema do Limite Central}

O teorema do limite central (ou teorema central do limite) possui importância capital em vários ramos da teoria estatística. A abordagem feita aqui não é exatamente rigorosa, sendo, em grande parte, extraída da referência [65].

Sejam as quantidades $y_{1}, y_{2}, \ldots, y_{N}$ admitidas como $\mathrm{N}$ variáveis aleatórias independentes, com mesma distribuição de probabilidades, com valor médio verdadeiro $\mu$ e variância $\sigma^{2}$.

A quantidade $S_{N}^{*}$ é definida por:

$$
S_{N}^{*}=\frac{S_{N}-N \mu}{\sigma \sqrt{N}}
$$

onde

$$
S_{N}=y_{1}, y_{2}, \ldots, y_{N}
$$

Uma vez que a variância correspondente à soma $S_{N}$ é $\sigma_{S}^{2}=\sigma^{2} N$, a quantidade $S_{N}^{*}$ é o número de desvios-padrão $\sigma \sqrt{N}$ que a soma $S_{N}$ difere do valor médio verdadeiro correspondente $(N \mu)$.

Seja a probabilidade de $S_{N}^{*}$ ser menor ou igual a um número finito qualquer $a$, localizado no intervalo $[-\infty \leq a \leq \infty]$. O teorema do limite central estabelece que:

$$
\lim _{N \rightarrow \infty} P\left(S_{N}^{*} \leq a\right)=\int_{-\infty}^{a} \frac{e^{\frac{-1}{2} z^{2}}}{\sqrt{2 \pi}} d z
$$


Em palavras, o teorema estabelece que a probabilidade de que a grandeza $S_{N}^{*}$ seja menor ou igual a um valor $a$ é igual ao valor que teria esta probabilidade se a distribuição de probabilidades para $S_{N}^{*}$ fosse uma distribuição normal, com valor médio $\mu=0$ e desvio-padrão $\sigma=1$.

\section{A.2 F.D.P. Marginal}

Para uma dada f.d.p., dependente de duas variáveis, chama-se de marginal à f.d.p. obtida quando se desconsidera o valor assumido por uma das variáveis [24]. Assim, seja $p\left(x_{1}, x_{2}\right)$ a f.d.p. conjunta das variáveis $x_{1}$ e $x_{2}$. A f.d.p. marginal de $x_{1}$ é dada por:

$$
h\left(x_{1}\right)=\int_{-\infty}^{\infty} p\left(x_{1}, x_{2}\right) d x_{2}
$$

Ou seja, $h\left(x_{1}\right)$ é a f.d.p. da variável $x_{1}$, independentemente do valor assumido pela variável $x_{2}$. Note-se, ainda, que $h\left(x_{1}\right)$ corresponde à projeção de $p\left(x_{1}, x_{2}\right)$ sobre o eixo $x_{1}$.

\section{A.3 Função Característica}

Chama-se função característica da f.d.p. $f(x)$ à transformada de Fourier $\phi(t)[24]$ :

$$
\phi(t)=\int_{-\infty}^{\infty} \exp (i x t) f(x) d x
$$

A f.d.p. pode ser recuperada pelo cálculo da respectiva anti-transformada de Fourier.

\section{A.4 O teorema de Wiener-Khintchine}

O teorema de Wiener-Khintchine estabelece que a densidade espectral de potência de um sinal aleatório, digamos $A(t)$, é dada pela transformada de Fourier da função de autocorrelação correspondente. Assim:

$$
\mathcal{P}(\omega)=\int_{-\infty}^{\infty} \gamma(\tau) \exp \{-i \omega \tau\} d \tau
$$

onde $\gamma(\tau)$ é a função de autocorrelação definida em 2.39. 


\section{Apêndice B}

\section{Códigos-fonte dos softwares}

\section{desenvolvidos}

Os códigos-fonte de minha autoria, desenvolvidos ao longo dessa dissertação, são listados aqui. Todos eles utilizaram o ambiente Mat Lab \%.0. O uso é livre, desde que para fins científicos, com a fonte devidamente citada.

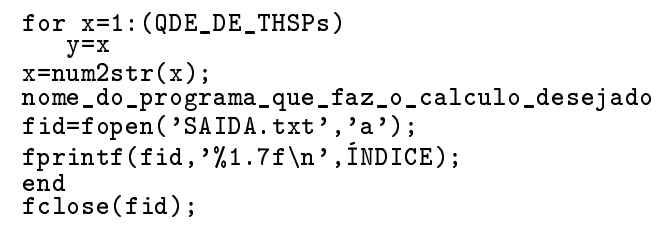

Código B.0.1: Código-fonte de rotina que "chama" os programas que calculam índices em THSPs, permitindo cálculo de vários THSPs de uma só vez. 


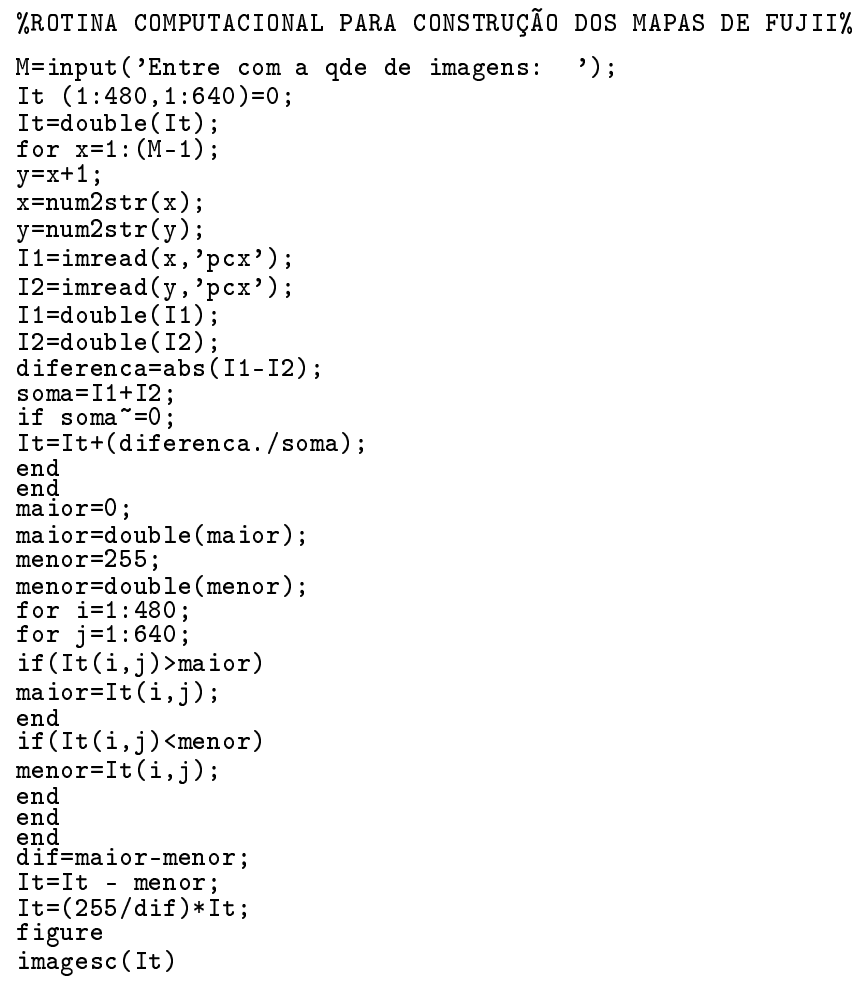

Código B.0.2: Código-fonte usado para a construção dos mapas de Fujii. 


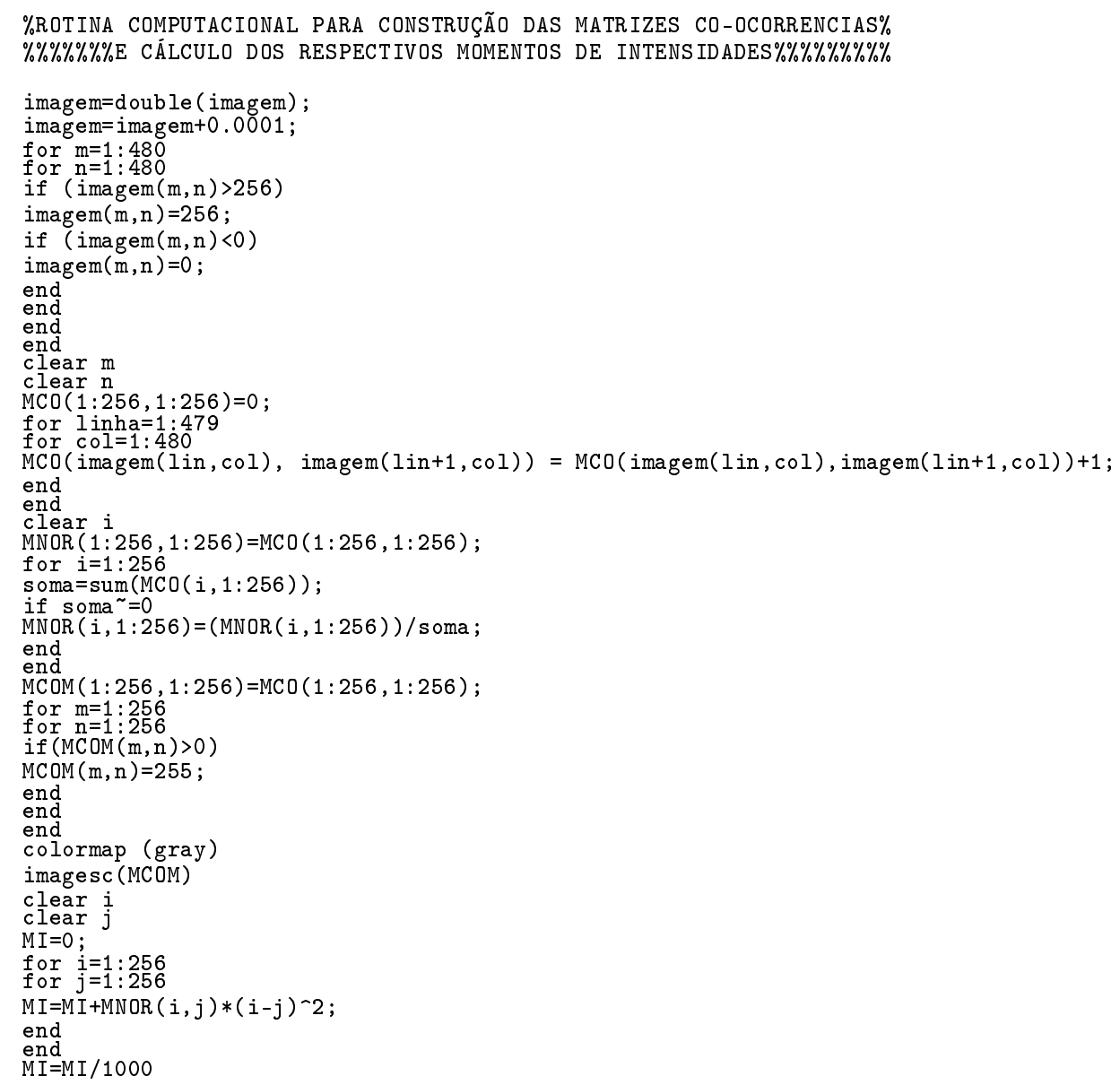

Código B.0.3: Código-fonte usado na construção das matrizes de co-ocorrência e cálculo do momento de inércia. 


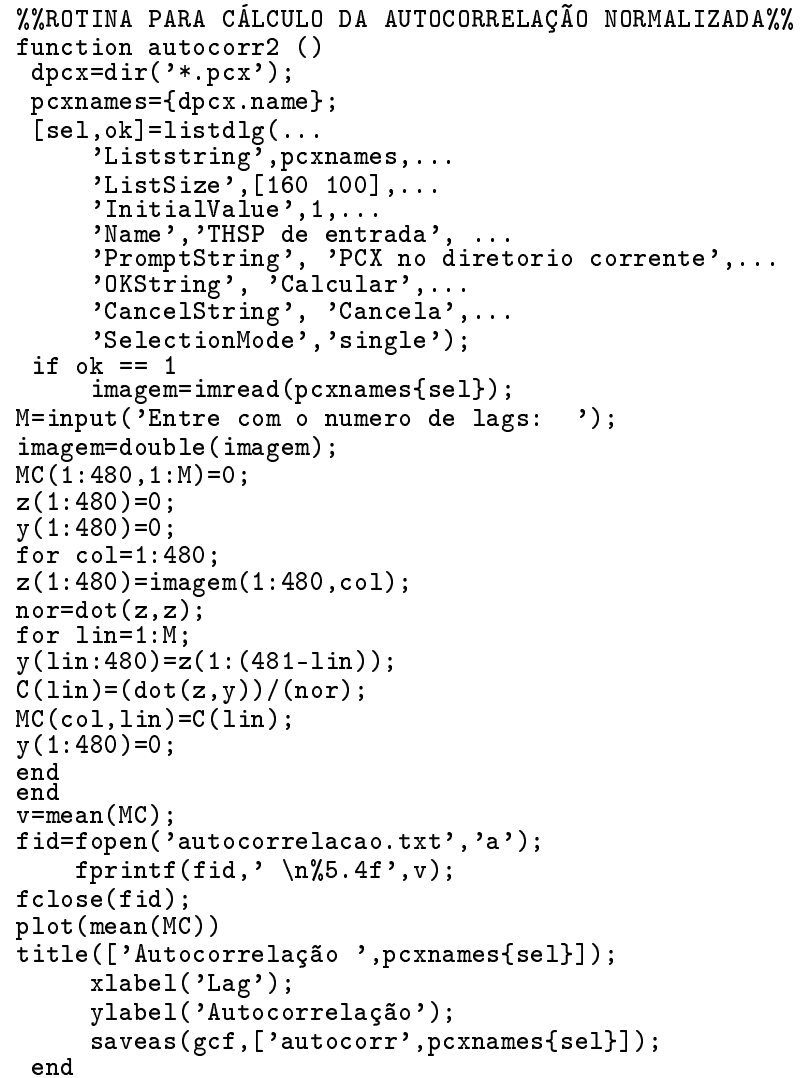

Código B.0.4: Código-fonte no cálculo da função de autocorrelação.

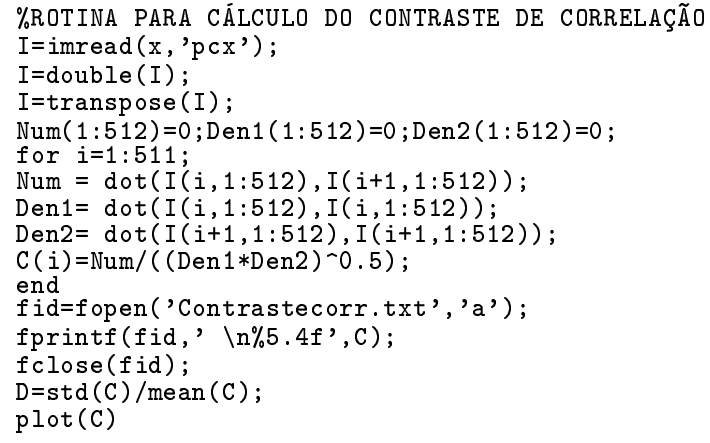

Código B.0.5: Código-fonte no cálculo do contraste de correlação.

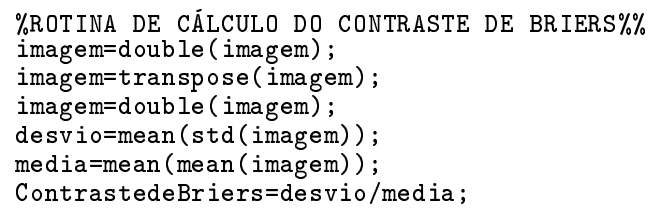

Código B.0.6: Código-fonte usado no cálculo do contraste de Briers. 


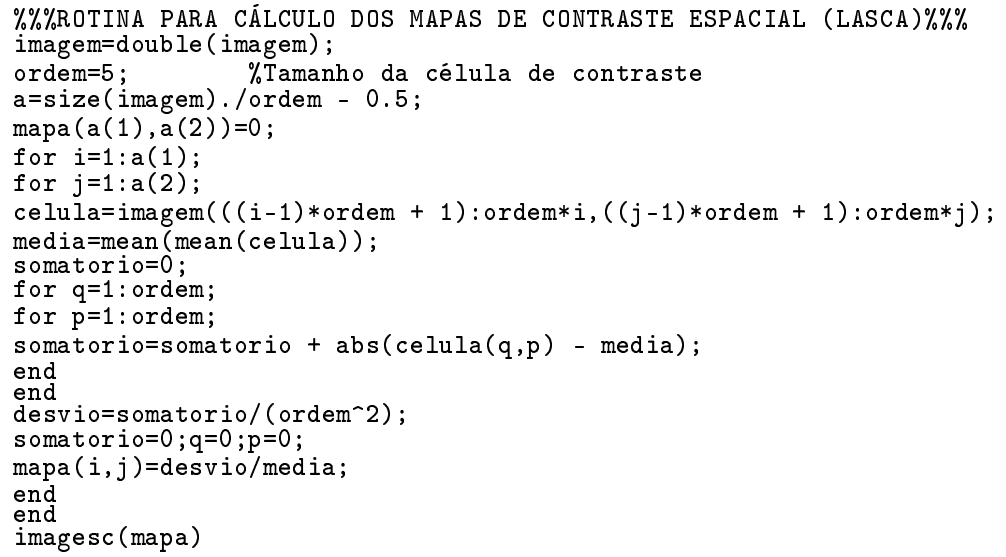

Código B.0.7: Código-fonte usado para a construção dos mapas de contraste espacial (LASCA).

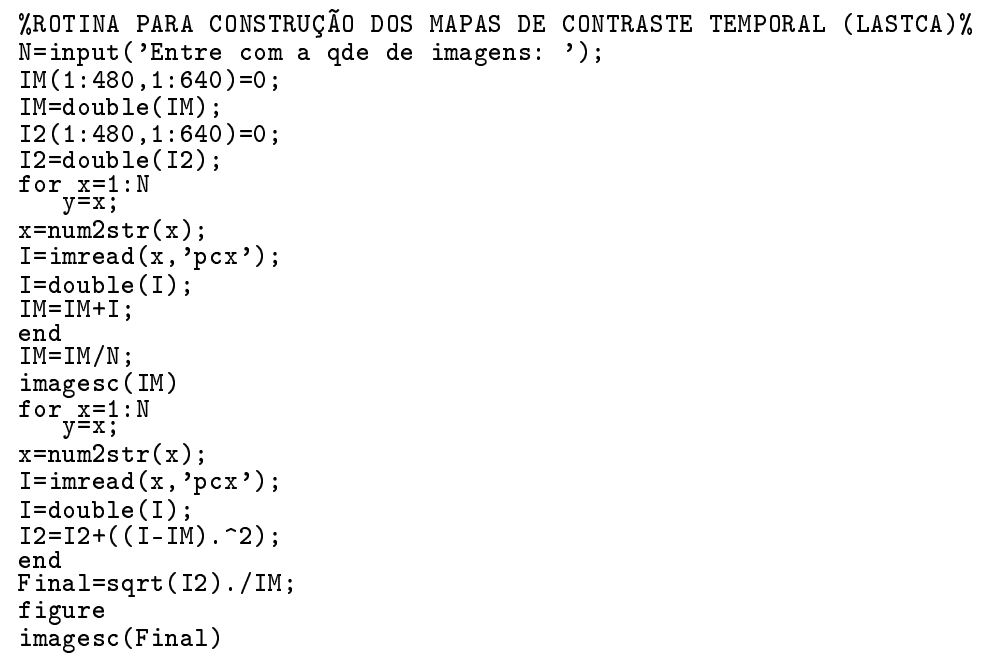

Código B.0.8: Código-fonte usado para a construção dos mapas de análise de contraste temporal (LASTCA). 


\section{Referências Bibliográficas}

[1] Newton, I. Óptica. 1 ed. São Paulo: Edusp, 1991. p.83.

[2] Exner, K. Sitzungsbericht Kaiserl. Acad. Wiss. (Wien) 76, 522 (1877).

[3] Gabor, D. Holography: 1948-1971. Nobel Lecture, 1971. p.38.

[4] Burch, J.M.; Tokarski, J.M.J. Production of multiple beam fringes from photographic scatterers. Opt. Acta 15. 1968. p. 101-11.

[5] $\star$ Goodman, J.W. Statistical Properties of Laser Speckle Patterns. In: Dainty, J.C. (ed). Laser speckle and related phenomena. Berlin: Springer-Verlag, 1984. p. 9-75.

[6] Dainty, J.C. Recent Developments. In: Dainty, J.C. (ed.). Laser speckle and related phenomena. Berlin: Springer-Verlag, 1984. p.321-335.

[7] Briers, J.D. Wavelength dependence of intensity fluctuations in laser speckle patterns from biological specimens. Opt. Comm. 13. 1974. p.324-326.

[8] Anisimov, V.V.; Kozel, S.M.; Lokshin G.R. Space-time statistical properties of coherent radiation scattered by a moving diffuse reflector. Opt. Spectrosc. 27. 1969. p.258.

[9] Nussenzveig, H.M. Curso de Física Básica 4: Ótica, Relatividade e Física Quântica. 1 ed. São Paulo: Edgard Blücher, 1998. Pass.

[10] « Hecht, E. Óptica. 1 ed. Lisboa: Calouste Gunbenkian, 1991. Pass.

[11] Malacara, D. Óptica Básica. 1 ed. Ciudad del Mexico: Secretaría de Educación Pública, 1989. Pass.

[12] Bergkvist, A. Biospeckle-based Study of the Line Profile of Light Scattered in Strawberries. Master Thesis. Centro de Investigaciones Opticas (CIOP), Universidad Nacional de La Plata,La Plata, Argentina, 1997. Pass. 
[13] Born, M.; Wolf E. Principles of Optics: Electromagnetic Theory of Propagation Interference and Diffraction of Light. 6 ed. Cambridge: Cambridge University Press, United Kingdom, 1980. Pass.

[14] Nussenzveig, H.M. Curso de Física Básica 2: Fluidos, Oscilações e Ondas e Calor. 1 ed. São Paulo: Edgard Blücher, 1983. Pass.

[15] Mobley, J.; Vo-Dinh, T. In: Vo-Dinh, T. Biomedical Photonics Handbook, seccions 2.1 and 2.6. Washington D.C.: CRC Press, 2002.

[16] Santos, A.O.; Adão, F.M.R.B.; Hernandez, J. L.; Orlando, T.G.S. Determinação do fluxo de seiva em videira através da técnica do pulso de calor. Rev. Bras. Agromet. 13. 2005. p.262-272.

[17] Suzaki, T.; Arikawa, M.; Saito, A.; Omura, G.; Khan, S.M.M.K.; Sakaguchi, M. et al. Organelle movement in Actinophrys sol and its inhibition by cytochalasin B. Acta Protozool. 42. 2003. p.7-10.

[18] Bohrmann, J.; Biber, K. Cytoskeleton-dependent transport of cytoplasmatic particles in previtellogenic to mid-vitellogenic ovarian follicles of Drosophila: time-lapse analysis using video-enhanced contrast microscopy. J. Cell Sci. 107. 1994. p.849-858.

[19] $\star$ Briers, J.D. A note on the statistics of laser speckle patterns added to coherent and incoherent uniform background fields and a possible application for the case of incoherent addition. Opt. Quant. 7. 1975. p.422-424.

$[20] \star$ Briers, J.D. The statistics of fluctuating speckle patterns produced by a mixture of moving and stationary scatterers Opt. Quant. Electron. 10. 1978. p.364-366.

[21] * Goldfischer, L.I. Autocorrelation function and power spectral density of laserproduced speckle patterns. J. Opt. Soc. Am. 55. 1965. p.247-254.

[22] ^ Cummins, H.Z.; Swinney, H.L. Light beating spectroscopy. In: Wolf, E. (ed.). Progress in Optics, v.8. Amsterdan: Elsevier, 1970. p.133-200.

[23] Forrester, A.T. Photoelectric mixing as a spectroscopic tool. J. Opt. Soc. Am. 51. 1961. p.253-259. 
[24] Vanin, V.R.; Gouffon P.; Helene, O.A.M. Tópicos Avançados em Tratamento Estatístico de Dados em Física Experimental. Notas de aula. 2ed. São Paulo: Instituto de Física da Universidade de São Paulo, 1998. Pass.

[25] Goodman, J.W. Some effects of target-induced scintillation on optical radar performance. Proc. IEEE 53. 1965. p.1688-1700.

[26] Plavnik, L.M.; Crosa, M.E.; Malberti, A.I. Effect of low power radiation (He-Ne) upon submandibulary glands. J. Clin. Laser Med. and Surg. 21. 2004. p.219-225.

[27] « Karu, T. Photobiological fundamentals of low-power laser therapy. J. Quant. Electr. 23. 1987. p. $1703-1717$.

[28] Karu, T.; Pyatibrat, L.; Kalendo, G. Irradiation with He-Ne laser increases ATP level in cells cultivated in vitro. J. Photochem. Photobiol. B: Biol. 27. 1995. p.219-223.

[29] Karu, T.; Pyatibrat L.V.; Kolyakov, S.L.; Afanayesva, N.I. Absorption measurements of a cell monolayer relevant to phototherapy: Reduction of cytochrome $c$ oxidase under near IR radiation. J. Photochem. Photobiol. B: Biol. 81. 2005. p.98-106.

[30] Almeida-Lopes, L.; Rigau, J.; Zângaro, R.A.; Guidugli-Neto, J.; Jaeger, M.M.M. Comparison of the low level laser therapy effects on cultured human gingival fibroblasts proliferation using different irradiance and same fluence, Lasers Surg. Med. 29. 2001. p.179-184.

[31] Wilder-Smith, C.H.; Wilder-Smith, P.; Grosjean, P.; van den Bergh, H.; Woodli, A.; Monnier, P. et al. Photoeradication of Helicobacter pylori using 5-Aminolevulinic acid: preliminary human studies. Lasers Surg. Med. 31. 2002. p.18-22.

[32] Aimbire, F.; Lopes-Matins R.A.B.; Castro-Faria-Neto, H.C.; Albertini, R.; Chavantes, M.C.; Pacheco, M.T.T. et al. Low-level laser therapy can reduce lipopolysaccharide-induced contractile force dysfunction and $\mathrm{TNF}-\alpha$ levels in rat diaphragm muscle, Laser Med. Sci. 21. 2006. p.238-244. 
[33] ^ Oulamara, A.; Tribillon, G.; Duvernoy, J. Biological activity measurement on botanical specimen surfaces using a temporal decorrelation effect of laser speckle. J. Mod. Opt. 36. 1989. p. 164-179.

[34] « Silva, F.C. Aplicação do speckle dinâmico para o estudo do processo de secagem de pinturas. Disssertação de Mestrado. Instituto de Física, Universidade de São Paulo, São Paulo, 2000. Pass.

[35] Malvino, A.P. Eletrônica 1. 1ed. São Paulo: Mc Graw Hill, 1986. Pass.

[36] $\star \mathrm{Xu}, \mathrm{Z}$; Joenathan, C.; Khorana, B.M. Temporal and spatial properties of the varying speckles of botanical specimens. Opt. Engineer. 34. 1995. p. 1487-1501.

[37] ^ Arizaga, R.; Trivi, M.; Rabal, H.J. Speckle time evolution characterization by the co-occurrence matrix analysis. Opt. Lasers Techn. 31. 1999. p.163-169.

[38] Haralick, R.M.; Shanmugan, K.; Dinstein, I. Textural features for image classification. IEEE Transac. Syst. Man Cybern., SMC-3(6). 1973. p.610-621.

[39] Fujii, H.; Nohira, K.; Yamamoto, Y.; Ikawa, H.; Ohura T. Evaluation of blood flow by laser speckle image sensing (part 1). Appl. Opt. 26. 1987. p.5321-5325.

[40] Braga Junior, R.A.; Rabelo, G.F.; Granato, L.R.; Santos, E.F.; Machado, J.C.; Arizaga, R.; Rabal, H.J.; Trivi, M. Detection of fungi in beans by the laser biospeckle technique. Biosyst. Engineer. 91. 2005. p.465-469.

[41] « Briers, J.D.; Webster, S. Laser speckle contrast analysis (LASCA): a nonscanning, full-field technique for monitoring capillary blood flow. J. Biom. Opt. 1. 1996. p.174179.

[42] Dunn, A.K.; Bolay, H.; Moskowitz, M.; Boas, D.A. Dynamic imaging of cerebral blood flow using laser speckle. J. Cereb. Blood Flow and Metab. 21. 2001. p.195-201.

[43] Yu, P.; Peng, I.; Mustata, M.; Turek, J.J.; Melloch, M.R.; Nolte, D.D. Time-dependet speckle in holographic optical coherence imaging and the health of tumor tissue. Opt. Lett. 29. 2004. p.68-70. 
[44] Dunn, A.K.; Devor, A.; Bolay, H.; Andermann, M.L.; Moskowitz, M.A.; Dale A.M.; Boas, D.A. Simultaneous imaging of total cerebral hemoglobin concentration, oxygenation, and blood flow during functional activation. Opt. Lett. 28. 2003. p.28-30.

[45] Tearney, G.J.; Bouma, B.E. Atherosclerotic plaque characterization by spatial and temporal speckle pattern analysis. Opt. Lett. 27. 2002. p. 533-535.

[46] Briers, J.D. Time-varying laser speckle for measuring motion and flow. In: Workshop Coherent Optics. Saratov Fall Meeting 2000: International School for Young Scientists and Students on Optics, Laser Physics and Biophisics, 2000. Saratov, Russia.

[47] Li, P.; Ni, S.; Zhang, L.; Zeng, S.; Luo, Q. Imaging cerebral blood flow through the intact rat skull with temporal laser speckle imaging. Opt. Lett. 31. 2006. p. 1824-1826.

[48] Weber, B.; Burger, C.; Wyss, M.T.; von Schulthess, G.K.; Scheffold F.; Buck, A. Optical imaging of the spatiotemporal dynamics of cerebral blood flow and oxidative metabolism in the rat barrel cortex. Europ. J. Neurosc. 2004. p. 1-7.

[49] Muramatsu, M. Técnicas ópticas para análise de superfície. Tese de Livre-docência. Instituto de Física, Universidade de São Paulo, São Paulo: 2001. Pass.

[50] ^ Rabal, H.J.; Arizaga, R.; Cap, N.L.; Grumel, E.; Trivi, M. Numerical model for dynamic speckle: an approach using the movement of the scatterers. J. Opt. A: Pure Appl. Opt. 5. 2003. p. S381-S385.

[51] Upadhyaya, A.; Rieu, J.P.; Glazier, J.A.; Sawada, Y. Anomalous difusion and nonGaussian velocity distribution of Hydra cells in cellular aggregates. Physica A 293. 2001. p. 549-558.

[52] Czirók, A.; Schlett, K.; Madarász, E.; Vicsek, T. Exponential distribution of locomotion activity in cell cultures. Phys. Rev. Lett. 81. 1998. p.3038-3041.

[53] Federico, A.; Kaufmann, G.H.; Galizzi, G.E.; Rabal, H.J.; Trivi, M.; Arizaga, R. Simulation of dynamic speckle sequences and its application to the analysis of transient processes. Opt. Comm. 260. 2005. p.493-499. 
[54] Sendra, G.H.; Arizaga, R.; Rabal, H.J.; Trivi, M. Decomposition of biospeckle images in temporary spectral bands. Opt. Lett. 30. 2005. p.1641-1643.

[55] Okamoto, T.; Asakura, T. Velocity dependence of image speckles produced by moving diffuser under dynamic speckle illumination. Opt. Comm. 77. 1990. p.113-120.

[56] Ma, S.N.; Lin, Q. Laser speckle velocimetry: using modulated dynamic speckle to measure the velocity of moving diffusers. Appl. Opt. v.25. 1986. p.22-25.

[57] Rabelo, G.F. Avaliação da aplicação do speckle dinâmico no monitoramento da qualidade da laranja. Tese de Doutorado. Faculdade de Engenharia Agrícola, UNICAMP, Campinas, 2000. Pass.

[58] Silva, E.R.; Muramatsu, M. Monitoramento da evolução temporal de tecidos através do biospeckle. In: Encontro Nacional de Física da Matéria Condensada, XXIX, 2006, São Lourenço, Minas Gerais. Anais. Sociedade Brasileira de Física. Márcia Barbosa (org.): 1 CD. p. 131-1 [resumo].

[59] ^ Cheng, H.; Luo, Q.; Liu, Q.; Qiang, L.; Gong, H.; Zeng, S. Laser speckle imaging of blood flow in microcirculation. Phys. Med. Biol. 49. 2004. p.1347-1357.

[60] Nieri, T.M. Criação de um Modelo Experimental para o Estudo do Comportamento Óptico da Parede Abdominal por Biospeckle e sua Interação com um Material Protético: Trabalho Experimental em Ratos. Tese de Doutorado. Faculdade de Ciências Médicas, UNICAMP, Campinas, 2005. Pass.

[61] Yang, V.X.D.; Mao, Y.X.; Munce, N.; Standish, B.; Kucharczyk, W.; Marcon, N.E.; Wilson B.C.; Vitkin, I.A. Interstitial Doppler optical coherence tomograph. Opt. Lett. 30. 2005. p.1791-1793.

[62] Yang, V.X.D.; Gordon, M.L.; Seng-Yue, E.; Lo, S.; Qi, B.; Pekar, J.; Mok, A.; Wilson B.C.; Vitkin, I.A. High speed, wide velocity dynamic range Doppler optical coherence tomography (Part II): Imaging in vivo cardiac dynamics of Xenopus laevis. Opt. Express 11. 2003. p.1650-1658. 
[63] Yang, V.X.D.; Pekar, J.; Lo, S.; Gordon, M.L.; Wilson, B.C.; Vitkin, I.A. Optical coherence and Doppler tomography for monitoring tissue changes induced by laser thermal therapy: An in vivo feasibility study. Rev. Sci. Instrum. 74. 2003. p. 437-440.

[64] Völker, A.C.; Zkharov, P.; Weber, B.; Buck, F.; Scheffold, F. Laser speckle imaging with an active noise reduction scheme. Opt. Express 13. 2005. p. 9782-9787.

[65] Vuolo, J.H. Fundamentos da Teoria de Erros. 2 ed. São Paulo: Edgard Blücher, 2000. Pass.

[66] « Sirohi R.S. (ed.). Selected papers on Speckle Metrology. SPIE Milestone Series, v.MS 35. Washinghton D.C.: SPIE Optical Engineering Press, 1991. Pass. 


\section{Índice Remissivo}

Arizaga, 41

ATP, 23

batimento de frequências, 12

Bauhinia forficata, 76

biomodulação, 22

célula

melanissomos, 17

ciclo de Krebs, 23

comprimento de correlação, 40

contra lateral, 96

contraste

da soma incoerente, 29

speckle desenvolvido, 28

contraste de correlação, 52

Dennis Gabor, 2

difração de Fresnel, 56

difusão, 13

dimensões

cloroplastos, 17

complexo de Golgi, 17

fibras colágeno, 17

hemácias, 17

lisossomos, 17

mitocôndrias, 17 núcleo, 17

distribuições

de velocidades, 58

Dopler, 7

efeito Doppler, 12

espalhamento

difuso, 6

elástico, 7

geométrico, 8

ineslástico, 6

Mie, 8

quasi-elástico, 7

Rayleigh, 7

espectro de Wiener, 34

espectroscopia de batimento de luz, 32

estatística

de primeira ordem, 24

Exner, 1

FDP

da amplitude do campo, 27

da fase, 27

da intensidade, 27

da soma de dois padrões, 29

exponencial negativa, 28

floema, 19 
folha de amoreira, 77

frequência média, 40

Fujii, 46

função característica, 28

função estrutura, 42

geometria

de espaço livre, 11

imagem, 11

hérnia incisional, 90

Haralick, 41

laserterapia, 22, 91

Macrosiphum avenae, 79

matrizes de co-ocorrências, 41

modelo

de Goodman, 24

de Rabal et al, 54

premissas de Goodman, 25

Morus nigra, 76

movimento de corpo rígido, 57

NAD, 22

Newton, 1

oogênese, 18

osso maléolo, 92

Oulamara, 38

passeio aleatório, 10

pata de vaca, 76

pele

células, 20 camadas, 20

espessuras, 21

perfil

Lorentziano, 14

plano

de Fraunhofer, 11

imagem, 11

pulgão, 79

soma

com fundo uniforme, 30

de dois padrões, 28

speckle

completamente desenvolvido, 24

objetivo, 11

polarizado, 25

por reflexão, 70

por transmissão, 70

subjetivo, 11

teorema central do limite, 26

teorema de Wiener-Khintchine, 34

teradiagnóstico, 91

THSP

construção, 38

turbulência, 12

velocidade

do sangue, 18

floema, 18

oogênese, 19

vacúolo digestivo, 18 
venação, 19

visibilidade, 46

wistar, ratos, 90

xilema, 19 